\title{
PHOTOGRAPHY AS EXHIBITED IN THE GREAT EXHIBITION OF THE WORKS OF INDUSTRY OF ALL NATIONS, 1851
}

\author{
by \\ Robin O'Dell \\ Associate of Science, Montreat College, 1981 \\ Bachelor of Arts, University Of South Florida, 1986 \\ A thesis presented to Ryerson University \\ in partial fulfillment of \\ the requirement for the degree of \\ Master of Arts \\ in the program of \\ Photographic Preservation and Collections Management
}

Toronto, Ontario, Canada, 2013

(CRobin O'Dell 2013 


\section{AUTHOR'S DECLARATION FOR ELECTRONIC SUBMISSION OF A THESIS}

I hereby declare that I am the sole author of this thesis. This is a true copy of the thesis, including any required final revisions, as accepted by my examiners.

I authorize Ryerson University to lend this thesis to other institutions or individuals for the purpose of scholarly research.

I further authorize Ryerson University to reproduce this thesis by photocopying or by other means, in total or in part, at the request of other institutions or individuals for the purpose of scholarly research.

I understand that my thesis may be made electronically available to the public. 


\title{
PHOTOGRAPHY AS EXHIBITED IN THE GREAT EXHIBITION OF THE WORKS OF INDUSTRY OF ALL NATIONS, 1851
}

Master of Arts, 2013

Robin O'Dell

Photographic Preservation and Collections Management

Ryerson University and George Eastman House International Museum of Photography and Film

\begin{abstract}
The 1851 Great Exhibition of the Works of All Nations was the first world's fair and the first time that photographs from around the world were exhibited together. To accompany the exhibition, the Royal Commissioners created a set of volumes that included an Official Catalogue and Reports by the Juries. These contain information explaining how the Exhibition was organized, descriptions of content, and annotations offered by experts in various fields.
\end{abstract}

This thesis addresses the photographic information contained in the presentation set of these volumes held at George Eastman House's Richard and Ronay Menschel Library. It includes a summary of the information pertaining to photography contained within these books, formatted into a concise and easily accessible reference source. In addition, it offers an analysis of some of this information. The topics include the formation of content, language and classification, photographic processes, and the controversy regarding the awarding of prize medals. 


\section{ACKNOWLEDGEMENTS}

I am grateful for the support of the George Eastman House staff and the Department of Photographs in particular. Alison Nordström, Senior Curator of Photographs, acted as my first reader, my professor, and the provider of irreplaceable encouragement and advice. Librarian and Curator of Rare Books, Rachel Stuhlman, was my second reader, and under her guidance and patience the Richard and Ronay Menschel Library became a second home.

I would also like to acknowledge my professors and the staff in the School of Image Arts at Ryerson University for their continued support and the sharing of their abounding knowledge with me.

My studies would not have been possible without the love of my family and the encouragement of my friends. Their support, both spiritual and material, buoyed me throughout the journey. Special thanks to those who helped edit innumerable papers: especially my sister Dawn Abeita, and my friends Tim Clemmons and Louise Reeves.

I would also like to add a special thank you to Jennifer Hardin, Chief Curator at the Museum of Fine Arts, St. Petersburg, Florida who has acted as mentor, friend, and cheerleader. 


\section{TABLE OF CONTENTS}

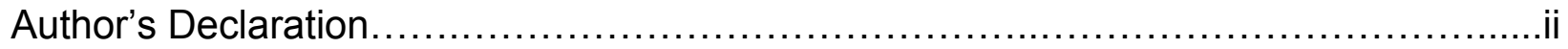

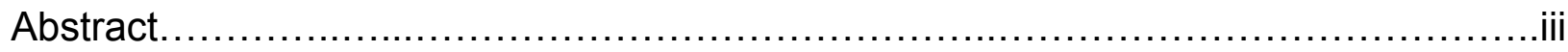

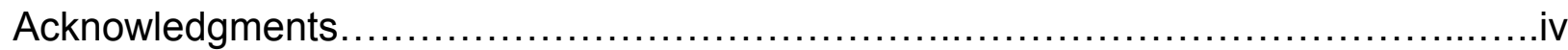

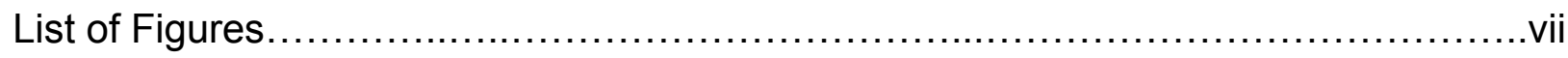

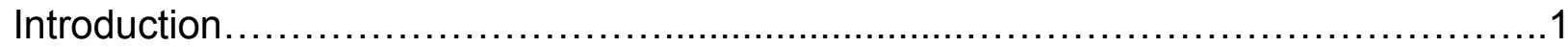

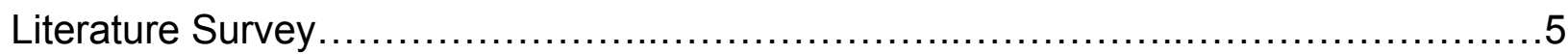

Part One: Description and Analysis ................................................. 10

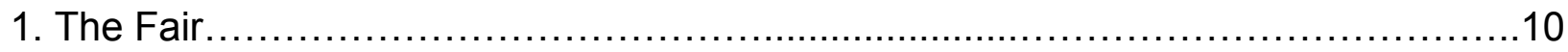

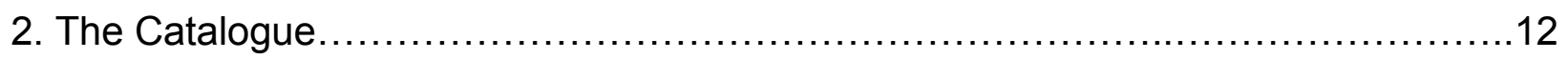

Compilation of the Catalogue................................................ 14

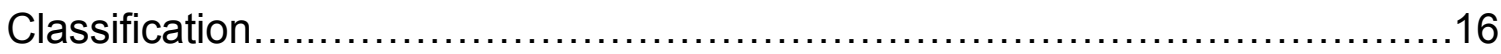

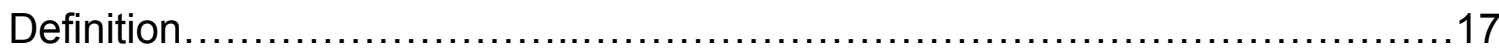

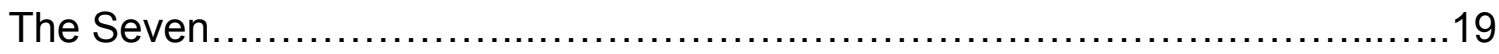

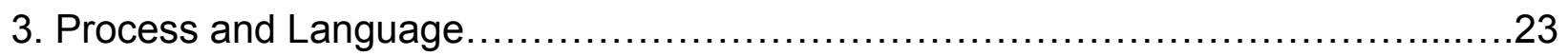

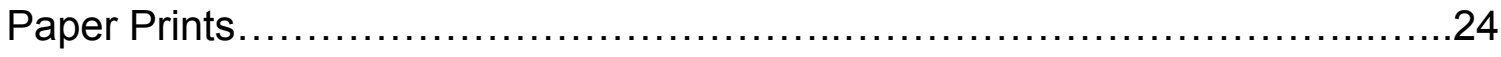

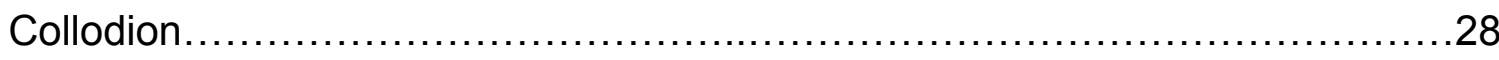

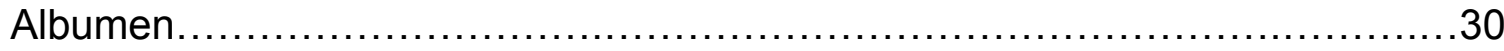

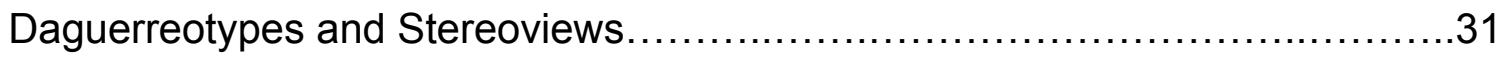

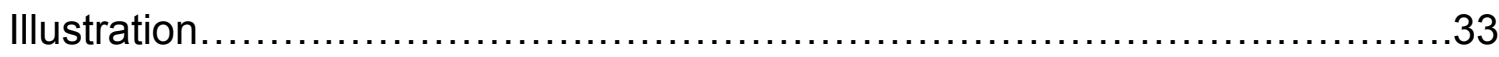

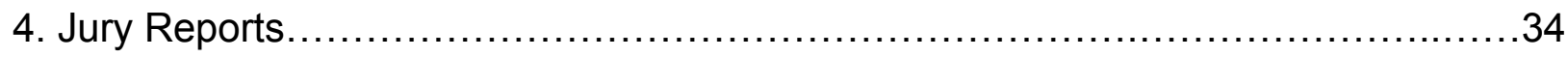

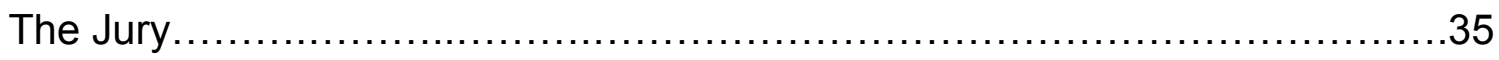

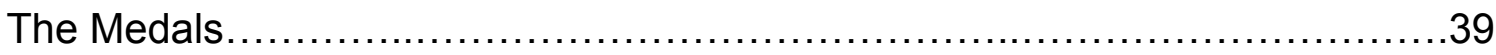




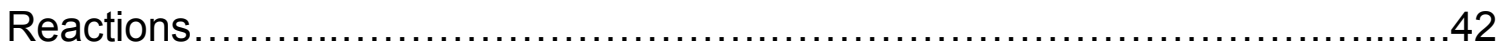

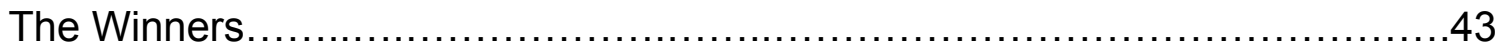

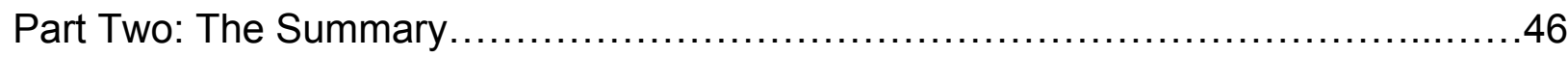

1. Alphabetical Listing of Exhibitors.........................................................

2. Additional Text from the Catalogue.....................................................91

3. Additional Text from the Jury Reports..................................................95

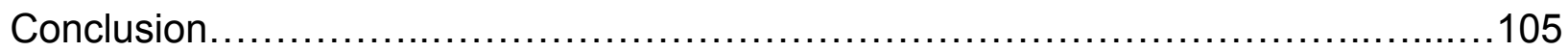

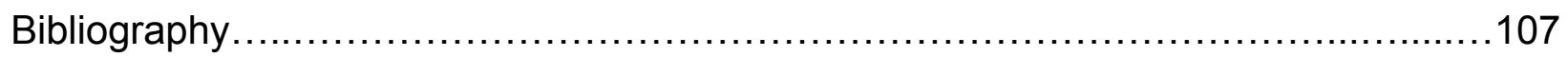




\section{LIST OF FIGURES}

Figure 1, page 16 - Arthur Kett Barclay Presentation Set of Official Catalogues, Jury Reports, and Reports to the Crown, Collection of the Richard and Ronay Menschel Library, Courtesy of George Eastman House International Museum of Photography and Film.

Figure 2, page 25 - Official Descriptive and Illustrated Catalogue of the Great Exhibition of the Works of Industry of All Nations, London: Spicer Brothers and W. Clowes and Sons, 1851, p. 434, Courtesy of George Eastman House International Museum of Photography and Film.

Figure 3, page 46 - Reports by the Juries on the Subjects in the Thirty Classes Into Which the Exhibition was Divided, Volume 2, frontispiece. Photograph by Hugh Owen, General View from Transept, Looking East, 1851, 25 x $35 \mathrm{~cm}$. Courtesy of George Eastman House International Museum of Photography and Film.

Figure 4, page 52 - Arthur Kett Barclay Presentation Set of Medals, Collection of the Richard and Ronay Menschel Library, Courtesy of George Eastman House International Museum of Photography and Film. 


\section{INTRODUCTION}

This thesis considers the way photographs and photography are described in the Official Descriptive and Illustrated Catalogue of the Great Exhibition of the Works of Industry of all Nations, $1851^{1}$ and the Reports by the Juries on the Subjects in the Thirty Classes into which the Exhibition was Divided, $1852 .^{2}$ It is divided into two sections. The first section, after giving a brief explanation of the Great Exhibition itself, explains how the volumes were organized, while addressing some of the more confusing or controversial issues associated with the Exhibition. The second section is a summary of all the information associated with photography contained in both sets of volumes, combined into an easily accessible resource. The goal is to make the photographic information in these dense volumes readily available to anyone interested in this formative period. Some of the most hallowed names in early photographic history participated in the Great Exhibition, and a concise gathering of this information will make access to it much more simple and straightforward. There is no definitive list of the photographs that were displayed at the Exhibition, but by combining all the information written about each exhibitor from both sets of volumes, a more complete understanding of photography's role can be achieved.

The method of organization utilized in the creation of the Official Illustrated Catalogue and the Reports by the Juries makes independently accessing their photographic

\footnotetext{
${ }^{1}$ Royal Commissioners, Official Descriptive and Illustrated Catalogue of the Great Exhibition of the Works of Industry of all Nations (London: Spicer Brothers and W. Clowes and Sons, 1851).

${ }^{2}$ Royal Commissioners, Reports by the Juries on the Subjects in the Thirty Classes into which the Exhibition was Divided (London: Spicer Brothers and W. Clowes and Sons, 1852).
} 
information difficult. Like the Exhibition, the Catalogue is organized by nation, with Great Britain further divided into thirty classes. The exhibitors are listed within the Catalogue by nation, and then by order of their placement within their respective galleries.

Exhibitors were each assigned a number according to where they were displayed, and as the photographic exhibitors were rarely exhibited beside each other, their listings are spread throughout the Catalogue, even within a particular country. The Catalogue provides more than one index, but the Index of Exhibitors and Others Whose Names Appear in the Catalogue ${ }^{3}$ provides only the exhibitor's assigned number and country without any page reference, thereby making it difficult to find a particular exhibitor within the three large volumes of entries. As will be discussed later in more detail, antiquated process names and language also make it difficult to find photography in the index titled Alphabetical and Classified List of Articles described in the Catalogue. ${ }^{4}$ Looking up "photographs" would provide only the direction to "See also Daguerreotype Apparatus, Daguerreotype (or Photographic) Pictures.." Even searching under "daguerreotype" or "calotype" gives inadequate results. By gathering all the photographic information contained in these volumes into one concise document, the summary in this thesis provides not only a time saving tool for researchers, but also offers the assurance that all the photographic information is included.

The Jury Reports provide further descriptions of what specific exhibitors displayed, what the jury thought of these entries, and descriptions of the processes employed. The

\footnotetext{
${ }^{3}$ Cat., cxviii-cxcii.

${ }^{4}$ Cat., xxxiii-cxvii.

${ }^{5}$ Cat., xxxvi.
} 
majority of British photographic entries were classified for display as "Machinery, Class $10(x)$ - Philosophical, Musical, Horological, and Surgical Instruments," with a few being designated as "Fine Arts, Class 30 (xxx) - Sculpture, Models and Plastic Art, Mosaics, Enamels, etc." However, all photography, both British and foreign, was judged under Class 10, making the pertinent information easier to locate within the Reports by the Juries. They are spread between a lengthy introductory essay (pp. 519-525) and individual listings that come later (pp. 594 -608). In order to make this information more convenient, this thesis attaches excerpts from the Jury Reports pertaining to a specific exhibitor to the alphabetical listing of that name in the summary. Additional information not pertaining to a specific exhibitor is then listed separately.

The summary includes every exhibitor who displayed any item related to photography. This includes some who exhibited only cameras, lenses, or other apparatus. There are few of these, as most exhibitors showing technological items also included examples of what they could produce. By including all exhibitors of photographic material, this summary provides a broader understanding of how photography was viewed and understood in 1851 than would be possible by listing only those who exhibited photographs. 


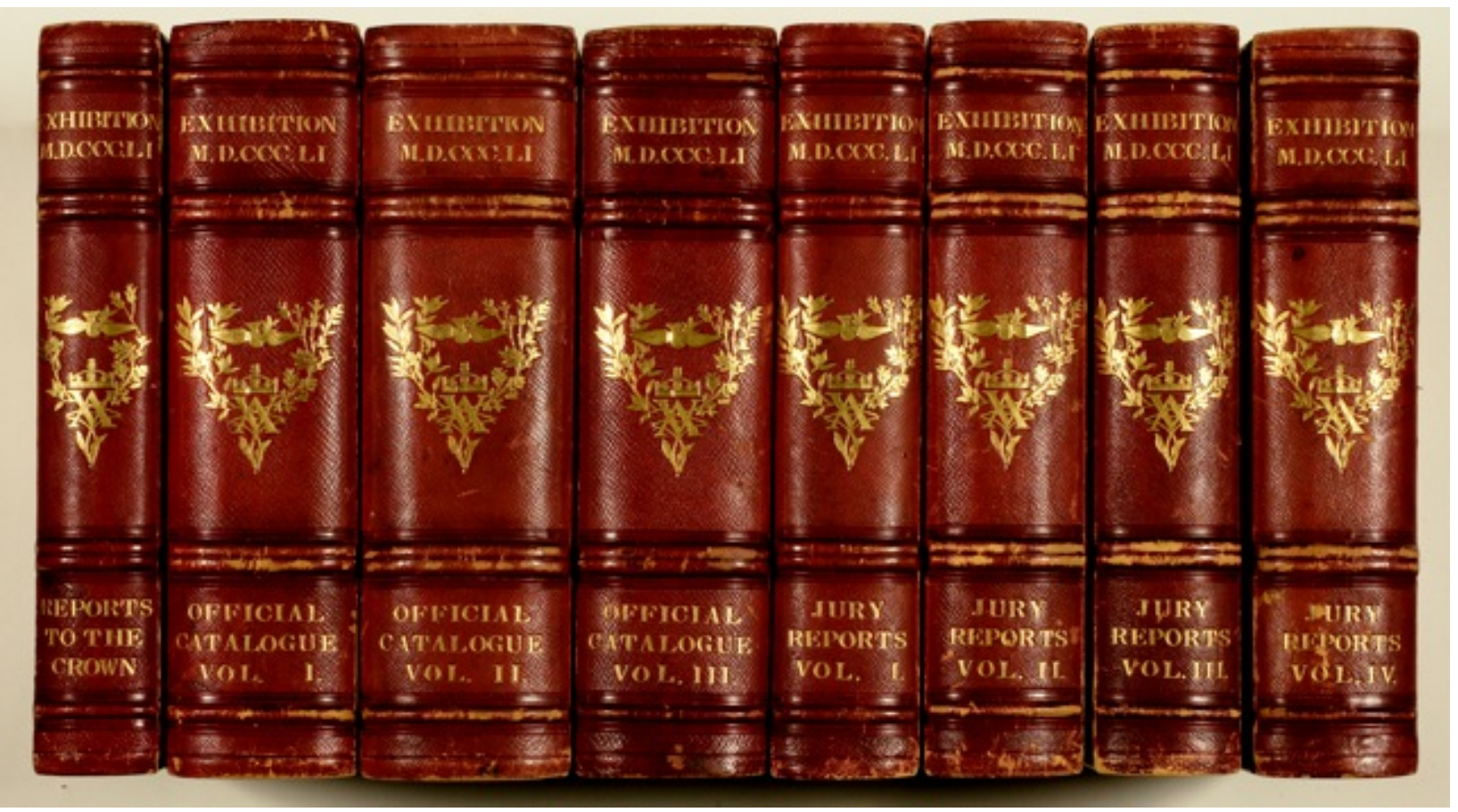

(Figure 1) Arthur Kett Barclay Presentation Set of Official Catalogues, Jury Reports, and Reports to the Crown, Collection of the Richard and Ronay Menschel Library, Courtesy of George Eastman House International Museum of Photography and Film. 


\section{LITERATURE SURVEY}

The 1851 Great Exhibition of the Works of Industry of All Nations has been the subject of hundreds of books and articles. The majority of these focus on the building itself, known as the "Crystal Palace," or on the historical importance of the first international fair, but very few address photography in particular. The major surveys include Hermione Hobhouse's The Crystal Palace and the Great Exhibition: Art, Science, and Productive Industry, ${ }^{6}$ John E. Findling and Kimberly D. Pelle's Encyclopedia of World's Fairs and Expositions, ${ }^{7}$ and Anna Jackson's Expo: International Expositions 1851$2010 .{ }^{8}$ Additional surveys address topics associated with the Exhibition such as religion or industry, but also do not offer information specific to the study of photography. These books include Geoffrey Cantor's Religion and the Great Exhibition of $1851,{ }^{9}$ and Paul Young's Globalization and the Great Exhibition. ${ }^{10}$

The Official Catalogue and Jury Reports used for this thesis are part of a nine-volume set that also includes a case containing copies of the medals awarded and the Report of the Commissioners for the exhibition of $1851 .{ }^{11}$ The Commissioner's Report compiles

\footnotetext{
${ }^{6}$ Hobhouse, Hermione, The Crystal Palace and the Great Exhibition: Art, Science, and Productive Industry: A History of the Royal Commission for the Exhibition of 1851 (London, New York: Athlone Press, 2002).

${ }^{7}$ Findling, John E. and Kimberly D. Pelle, eds., Encyclopedia of World's Fairs and Expositions (Jefferson, NC: McFarland \& Co., 2008).

8 Jackson, Anna, Expo: International Expositions 1851-2010 (London: V \& A Publishing, 2008).

${ }^{9}$ Cantor, Geoffrey, Religion and the Great Exhibition of 1851 (Oxford; New York: Oxford University Press, 2011).

${ }^{10}$ Young, Paul, Globalization and the Great Exhibition: The Victorian New World Order (New York: Palgrave Macmillan, 2009).

${ }^{11}$ Report of the Commissioners for the Exhibition of 1851 (London: Spicer Brothers and W. Clowes and Sons, 1852).
} 
information about how the exhibition was organized and provides statistics for the daily business of the exhibition, but does not address photography specifically. Ryerson Photographic Preservation and Collections Management graduate Jill Offenbeck wrote her 2011 Master's Thesis, The Reports by the Juries: a Finding Aid for a Publication from the Great Exhibition of 1851 in the Collection of The Art Gallery of Ontario, on the Jury Reports, but her work deals only with the 154 salted paper prints by Claude-Marie Ferrier (1811-1889) and Hugh Owen (1808-1901) that are published in the volumes themselves. ${ }^{12}$ These do not include any images of, or information about, the photographs exhibited or photographic exhibitors in the Fair.

While no definitive summary of all of the photographic material contained in the Official Catalogue and Jury Reports has been published prior to this thesis, recent publications have offered some information on this topic. Roger Taylor's Photographs Exhibited in Britain: $1839-1865^{13}$ provides a comprehensive listing of all photographic exhibitions in Britain in that time. Taylor's entries for the 1851 Great Exhibition are taken verbatim from the same Official Catalogue listings that this summary contains, but they lack the additional information provided by the commentary of the Catalogue annotators and the Jury Reports. Since the listings provide mostly vague descriptions of what was exhibited, the extra information contained in this summary provides a greater understanding of what was exhibited and how it was understood and received. This

12 Offenbeck, Jill, The Reports by the Juries: a Finding Aid for a Publication from the Great Exhibition of 1851 in the Collection of The Art Gallery of Ontario. M.A. Thesis (Ryerson University, Toronto, Ontario, 2011).

13 Taylor, Roger, Photographs Exhibited in Britain: 1839-1865 (Ottawa, Canada: National Gallery of Canada, 2002). 
thesis also offers additional photographic exhibitors to those offered by Taylor. Taylor's Impressed by Light: British Photographs from Paper Negatives, $1840-1860^{14}$ offers a biographical dictionary of British calotypists including some of the more obscure photographers, as well as a chapter on the 1851 Exhibition. It does not, however, include information or listings for the photographers who exhibited daguerreotypes or who were not British.

What Roger Taylor achieves for British photographic paper processes, André Jammes and Eugenia Parry Janis's definitive book The Art of French Calotype does for the French. ${ }^{15}$ An extensive history, photographic examples, and a dictionary that includes many of the French photographers' biographies are included, but the book contains information only on calotypes. James Borcoman's $19^{\text {th }}$-Century French Photographs ${ }^{16}$ provides information about the French photographers working with daguerreotypes, although he incorrectly states that Frédéric Martens showed only daguerreotypes in the Great Exhibition. Martens actually exhibited paper photographs from glass negatives to great acclaim. This confusion stems from the Catalogue listing for Martens that mentions only daguerreotypes, but the Reports by the Juries clearly state that additional works on paper were included. This is just one example of why a concise gathering of all of the photographic information from the Exhibition is needed.

\footnotetext{
14 Taylor, Roger and Larry J. Schaaf, Impressed by Light: British Photographs from Paper Negatives, 1840-1860 (New York: Metropolitan Museum of Art, 2007). 15 Jammes, André, and Eugenia Parry Janis, The Art of French Calotype (Princeton, NJ: Princeton University Press, 1983).

${ }^{16}$ Borcoman, James, $19^{\text {th }}$ Century French Photographs (Ottawa: National Gallery of Ottawa, 2010).
} 
All but one of the exhibitors representing the United States displayed daguerreotypes. While not the most current book about American daguerreotypists, Beaumont Newhall's The Daguerreotype in America ${ }^{17}$ provides very concise and useful information. Newhall does not address the Great Exhibition specifically, but he does give pertinent information on most of the American photographers who participated, including W. F. Langenheim, whose photographic lantern slides were the only non-daguerreotype American entry. John Wood's America and the Daguerreotype ${ }^{18}$ offers information directly related to the Great Exhibition, including an explanation of why the American daguerreotypes were so well regarded by the jurists.

Mark Haworth-Booth is a noted scholar on British photography in the nineteenth century. His and Anne McCauley's book The Museum and the Photograph: Collecting Photography at the Victoria \& Albert Museum, 1853-1900 offers the history of how Exhibition organizer Henry Cole (1808-1882) went on to become the first director of the South Kensington Museum, which later became the Victoria \& Albert Museum (V \& A). Haworth-Booth chronicles how the Museum was founded from profits of the Great Exhibition, and how the collection was consequently formed. The Museum purchased some "contemporary art exhibits" from the Exhibition to help form its permanent collection, but Cole did not begin purchasing photographs until 1853, two years after the

\footnotetext{
${ }^{17}$ Newhall, Beaumont, The Daguerreotype in America (New York: Duell, Sloan, and Pierce, 1961).

${ }^{18}$ Wood, John, America and the Daguerreotype (lowa City: University of lowa Press, 1991).
} 
close of the Fair. ${ }^{19}$ In the beginning these consisted only of prints documenting works of art, but the Museum broadened its parameters in $1856 .{ }^{20}$ While it did not acquire photographs from the Great Exhibition directly, the National Art Library at the V \& A has original letters, journals, circulars, and pamphlets pertaining to the Exhibition that could add to the scholarly knowledge of photography at the Fair. However, these were not considered for this thesis as its focus is solely on the core information presented in the official record.

Robert Rydell is a well-known scholar on World Fairs, but his publications primarily deal with exhibitions after 1851. The Book of the Fairs: Materials about the World's Fairs, 1834-1916 is an exception. ${ }^{21}$ This publication is primarily a bibliography of exhibitionrelated materials in the Smithsonian Institute Libraries, which, while helpful for scholarly research, does not directly inform this thesis. More helpful has been the information provided by Imagining Paradise. ${ }^{22}$ This survey of the books held in the Richard and Ronay Menschel Library at George Eastman International Museum of Photography and Film includes pertinent information about the specific volumes that were used for this thesis and was instrumental in the writer's pursuit of this topic.

${ }_{19}$ Haworth-Booth, Mark, and Anne McCauley, The Museum and The Photograph: Collecting Photography at the Victoria \& Albert Museum, 1853-1900 (Williamstown, MA: Sterling and Francine Clark Institute, 1998) 26.

${ }^{20}$ Haworth-Booth, The Museum, 31, 36, 37.

${ }^{21}$ Rydell, Robert W., The Book of the Fairs: Materials about the World's Fairs, 18341916, in the Smithsonian Institute Libraries (Chicago: American Library Association, 1992).

${ }^{22}$ Asser, Saskia, "Reports on the Exhibition of the Works of Industry of All Nations," in Imagining Paradise: The Richard and Ronay Menschel Library at the George Eastman House, Rochester, Sheila Foster, Manfred Heiting, and Rachel Stuhlman, editors, (Göttingen: Steidl; London: Thomas \& Hudson, 2007) 55-57. 


\section{PART ONE: DESCRIPTION AND ANALYSIS}

\section{The Fair}

The Great Exhibition of the Works of Industry of All Nations opened in Hyde Park, London on May 1, 1851. Over the course of the next six months, more than six million visitors viewed the nearly one million items housed in Joseph Paxton's (1803-1865) Crystal Palace constructed of cast iron and glass. Examples of goods on display ranged from raw materials, such as an eighteen-foot specimen of coal, to F \& C. Osler's ornate crystal fountain. Organized by the Society of Arts, led by Sir Henry Cole (1808-1882) and His Royal Highness Prince Albert (1819-1861), the Great Exhibition was the first world's fair and the first time that photographs from throughout the world were exhibited together. ${ }^{23}$

Ascertaining how many nations participated in the Exhibition is difficult due to confusion over whether colonies should be counted as separate nations; accounts range from twenty-four ${ }^{24}$ to thirty-four. ${ }^{25} \mathrm{~A}$ chart showing the exhibition space given to each foreign nation in the Official Catalogue lists 34 foreign states, with an additional 41 colonies of the United Kingdom noted. ${ }^{26}$ Regardless of the number of participants, only a few submitted photographic items to be displayed: the United States, France, Austria, the United Kingdom, and what was then the confederation of Zollverein (38 states and four

${ }^{23}$ Haworth-Booth, The Museum, 10.

24 Arnoux, J.J., "The World's Fair" in The Photographic Art Journal, vol. 2, reprinted from La Lumiere, translated by J. Russell Snelling, M.D. (New York: W.B. Smith, 1851) 153. ${ }^{25}$ Greenhalgh, Paul, Ephemeral Vistas: The Expositions Universelles, Great Exhibitions and World's Fairs, 1851-1939 (Manchester, UK: Manchester University Press, 1988) 12.

${ }^{26}$ Cat., 16, 17. 
free cities that were later united as Germany). ${ }^{27}$ The records that remain (including the Official Catalogue) do not consistently list individual photographs, but it is estimated that around 772 photographs were displayed. ${ }^{28}$ While this may sound like a significant number, the 76 individual photographic exhibitors were only a small percentage of the 17,000 exhibitors overall, ${ }^{29}$ and were spread throughout the sprawling building that extended "not less than 1848 feet."30

${ }^{27}$ Hannavy, J., Encyclopedia of Nineteenth-Century Photography (London: Routledge, 2008) 508.

${ }^{28}$ Arnoux, The World's Fair, 155.

${ }^{29}$ Reports, ii.

${ }^{30}$ Wyatt, M. Digby, "Construction of the Building," in Cat., 51. 


\section{The Catalogue}

The Official Descriptive and Illustrated Catalogue of the Great Exhibition of the Works of Industry of All Nations, 1851 is a massive three volume, 1471 page set of books created to accompany the Great Exhibition. The set referenced for this thesis is part of a nine volume deluxe edition that was presented to Arthur Kett Barclay, one of the five treasurers for the Exhibition. The volumes were a gift to George Eastman House from the Eastman Kodak Company in 1972. The set includes the Catalogue, the Reports by the Juries, Report of the Commissioners, and a matching case that houses copies of each of the medals presented (Figure 1). Bound by hand by Robert Rivière, the books feature red morocco covers, gold lettering, and blue moiré silk endpapers. ${ }^{31} 137$ presentation sets were created for distribution to dignities responsible for organizing the event, selected foreign governments, and a few schools and libraries. ${ }^{32}$

The Official Catalogue includes a list of illustrations; indexes; an introduction by organizer and executive committee member of the Royal Commissioners, Henry Cole; chapters on the construction of the Crystal Palace and the preparation of the Catalogue; and a descriptive listing of all entries with annotations. The Catalogue is illustrated with engravings, primarily supplied by the exhibitors (Figure 2). ${ }^{33}$ Less ornate catalogues were offered for sale at the Exhibition and at a city catalogue office; one offered a full notice of all information, while the other was a condensed version that offered only the names of exhibitors with a brief summary of what they displayed. French and German

\footnotetext{
${ }^{31}$ Asser, Imagining Paradise, 55.

32 Offenbeck, The Reports by the Juries, 26.

${ }^{33}$ Ellis, Robert, "Scientific Revision," in Cat., 84.
} 
editions were also sold, although they were not available until later in the summer of 1851 ${ }^{34} \mathrm{~A}$ joint collaboration between the printers W. Clowes and Sons and the paper company Spicer Brothers produced the Exhibition publications. The information that follows in the Catalogue section of this thesis was taken from the Official Catalogue, unless otherwise noted.

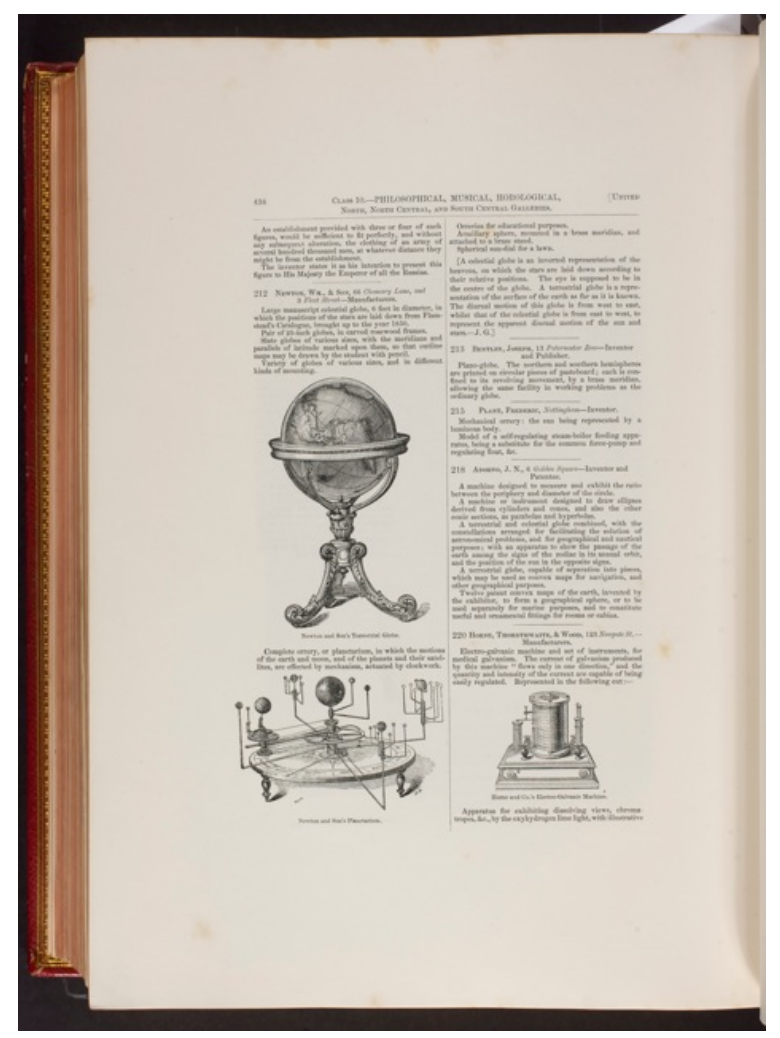

(Figure 2) Official Descriptive and Illustrated Catalogue of the Great Exhibition of the Works of Industry of All Nations, London: Spicer Brothers and W. Clowes and Sons, 1851, Courtesy of George Eastman House International Museum of Photography and Film, p. 434.

${ }^{34}$ Reports, 132, 137. 


\section{Compilation of the Catalogue}

To better understand the entries in the Catalogue, an explanation of how it was compiled is helpful. On pages 82 to 84 of the Catalogue, Robert Ellis, one of the official annotators, describes the process of collecting the information. In the introductory Scientific Revision: Preparation of the Catalogue he suggests that the Catalogue has, in essence, thousands of authors, because other than corrections of typographical, technical, or scientific errors, the information provided by the exhibitor was transcribed directly into the text. Each exhibitor, whether domestic or foreign, was required to fill out a prescribed form in duplicate. The forms were color coded for the four major categories of organization: black for Raw Materials, blue for Machinery, red for Manufactures, and yellow for Fine Arts. The form asked for:

“I. Exhibitor's surname Exhibitor's Christian name

II. Country Address, stating nearest Post Town.

III. Capacity in which the Exhibitor appears, whether as Producer, Importer, Manufacturer, Designer, Inventor, or Proprietor.

IV. The name and description of every Article of importance or class of Articles exhibited, each Article or Class beginning a separate paragraph."35

Specific guidelines were given for the class that was being submitted:

"In Section 2. Machinery, the description should specify-

a. The uses

${ }^{35}$ Ellis, Cat., 82, 83. 
b. The novelty, if any, in the invention.

c. Superiority of execution.

d. Increased efficiency or economy.

e. The importance of the Article in a social or other point of view.

f. The place where produced.

g. Whether the article is patented or not.

h. Where price is an element for consideration, the price at which the producer can sell the Article.

i. Any particular feature which the Exhibitor desires to be noticed by the Jury." ${ }^{36}$

When individual entries are regarded in the Catalogue, it becomes apparent that some exhibitors adhered more closely to the guidelines than others. Some supply very little information, while others give a plentitude. This, then, provides an explanation of why the information for particular photographs and entries differs so greatly. One exhibitor may have given descriptions of each photograph he exhibited, while another may have merely listed "daguerreotypes." Since the Catalogue was assembled in a matter of months and before all the items had been assembled in the great hall, ${ }^{37}$ it was necessary to rely on the information that had been provided by the exhibitors.

In addition to the exhibitor's listings, there are annotations offered under selected entries. These were added as "elucidatory notes." 38 They range from explanations of the

\footnotetext{
${ }^{36}$ Ellis, Cat., 82, 83.

${ }^{37}$ Ellis, Cat., 83, 87.

${ }^{38}$ Ellis, Cat., 85.
} 
processes used to make a photograph to a short history of the medium. There are twenty-six annotators listed in the Official Catalogue, three of whom wrote about entries dealing with photography: Robert Hunt (R.H.), Robert Ellis (R.E.) and James Glaisher (J.G.) ${ }^{39}$ It should be noted that Glaisher was also the Reporter for the Jury Reports, Class 10 , and as such, was responsible for compiling all of the reports for the class under which photography was judged. Further information about the Jury Reports will be addressed in a separate section of this thesis.

\section{Classification}

The exhibitors are divided in the Catalogue by nation, with the United Kingdom further divided into the 30 classes used by the juries. The majority of British photographyrelated exhibitors were placed in Section II: Machinery, Class X (10): Philosophical Instruments, and Processes Depending Upon Their Use, Musical, Horological, and Surgical Instruments. However, seven British photographic exhibitors were classified as Section IV: Fine Arts, Class XXX (30): Sculpture, Models and Plastic Art, Mosaics, Enamels, \&c., and displayed separately in the hall of fine-arts: ${ }^{40}$ Samuel Buckle (No. 301, p. 840), Thomas Craddock (No. 227, p. 834), H.R. Harmer (No. 298, p. 839), David Octavius Hill (No. 300, p. 839), Martin Laroche (No. 252, p. 837), Ross \& Thomson (No. 299, p. 839), and Voigtlander, Evans \& Co. (No. 254, p. 837). It is not stated who made the decision to place photographs in the Fine Arts section. As explained earlier, individual exhibitors submitted color-coded forms according to the category for their

${ }^{39}$ Cat., 88.

${ }^{40}$ Cat., 819-846. 
products, but the Commissioners would have been ultimately responsible for accepting and distributing the products.

There was little precedent for how photographs should be classified. Prior to this Exhibition there had been few displays of photography that were not either illustrations accompanying a lecture, demonstrations of the process, or advertisements for a studio. In the art world, French artist Gustave Le Gray (France, No. 585, p. 1206) had submitted photographs featuring landscapes to a French art salon in 1850 . They were accepted by a jury, hung alongside lithographs and listed as such in the catalogue, but were later withdrawn from the show by a sub-committee as inappropriate. ${ }^{41}$

\section{Definition}

The difficulty in understanding photography within a context of fine art dates back to its inception. ${ }^{42}$ Even the founders of photography initially approached the medium through its relationship to art. Louis Jacques Mandé Daguerre (1787-1851), the celebrated inventor of the daguerreotype, was an artist and creator of large tableau dioramas. His interest in capturing permanent images was driven by his desire for an aid to painting. ${ }^{43}$ Concurrently, William Henry Fox Talbot discovered how to make "photogenic drawings" while looking for a way to compensate for his lack of drawing skills. Talbot named his negative/positive process "calotype" after the Greek words kalos and tupos, or "beautiful

\footnotetext{
${ }^{41}$ Wey, Frances, "Of the Influence of Heliography upon the Fine Arts" in Photographic Art Journal, Vol. II (1951) 105, republished from La Lumière.

${ }^{42}$ Waggoner, Diane, The Pre-Raphaelite Lens: British Photography and Painting (Washington D.C.: National Gallery of Art, 2010) 8. ${ }^{43}$ Rosenblum, Naomi, A World History of Photography (New York: Abbeville Press, 1989) 36.
} 
print", ${ }^{44}$ hardly an indication of scientific intent. Yet when he first presented his invention to the Royal Institution of Great Britain in 1839, and again when he published The Pencil of Nature (1844-1846), it was as a demonstration of photography's practical uses. ${ }^{45}$ Many men of science in the mid-nineteenth century embraced photography as a chemical means of replicating the natural world without the interpretation of an artist, ${ }^{46}$ while at the same time equally respected scientists acknowledged that a good photograph required skills beyond those of chemistry. ${ }^{47}$ The Great Exhibition Jury agreed that, "Photography may be said to be too faithfully exact in its results, for the purposes of art." ${ }^{48}$ But then it also admitted that it was likely, "...that time will show that this beautiful compound of art and science will essentially cast its weight into the balance of art, and in future render itself more and more inseparable from, and essential to, her interests." ${ }^{49}$

The use of the term "Fine Arts" in the Exhibition itself may be somewhat misleading. In an attempt to maintain the overall agenda of promoting industry, the commissioners placed restrictions on what was eligible to be submitted in the Fine Arts class:

${ }^{44}$ Greenough, Sarah, \& etc., On the Art of Fixing a Shadow (Washington D.C.: National Gallery of Art, 1989) 13.

${ }^{45}$ Rosenblum, World History, 27.

46 "The Art of Photography," in The Photographic Art Journal, Vol. 1, No. 1 (Jan., 1851) 1-3.

47 Fisher, J.K., "Photography, the Handmaid of Art" in The Photographic Art-Journal, Vol. 1, H.H. Snelling, ed. (New York: W.B. Smith, 1851) 19-20.

${ }^{48}$ Reports, 600.

${ }^{49}$ Reports, 521. 
"The exhibition having relations far more extensive with the industrial occupations defined with considerable strictness. Those departments of art which are, in a degree, connected with mechanical processes, which relate to metals, wood, or marble, and those mechanical processes which are applicable to the arts, but which, notwithstanding this, still preserve their mechanical character, as printing in colour, come properly with this class..."

The goal was to accept items that illustrated a special material or process, but this proved awkward and inconsistent. Sculpture was allowed, but paintings, for the most part, were not, unless they demonstrated some new method of color or process. Drawings and prints could be included only if they acted as illustrations. ${ }^{51}$ What was ultimately accepted was an odd assortment of pottery and glass, metal work, models, carvings, and etc., with grand sculptures scattered throughout as decoration.

\section{The Seven}

Of the 31 photographers from the United Kingdom who exhibited, seven were classified under the rubric of "fine art." The descriptions of what they exhibited may offer some explanation as to why they were classified this way, although it does not necessarily have to do with special techniques, but rather for their beauty and subject matter. Both Craddock (No. 227) and Laroche (No. 252) displayed daguerreotypes featuring copies of artwork such as sculpture, prints, and paintings, making it appropriate to display them as art. Buckle (No. 301), Harmer (No. 298), and Ross \& Thomson (No. 299) all

${ }^{50}$ Cat, Introduction to Class XXX, 819.

${ }^{51}$ Cat., 819. 
exhibited calotypes featuring nature and landscape in keeping with some of the most admired British painters of the time such as John Constable (1776-1837) and J.M.W. Turner (1775-1851), who were known for their picturesque views and romantic landscapes. ${ }^{52}$ These photographers captured similar vistas, and the calotype mimicked painterly effects, such as the suppression of detail to emphasize form, and the contrast of light and shadow. ${ }^{53}$ The jury praised these photographs as having, "shadows deep and Rembrandt-looking," and as being, "...very beautiful and true to nature."

David Octavius Hill (No. 300, p. 839) was a trained painter and (along with his partner, Robert Adamson) created calotypes known for their artful composition and use of light. By 1851 they had already entered their work in three exhibitions at the Royal Scottish Academy. ${ }^{55}$ They are recorded as showing "Calotypes of fishermen and women of Newhaven, near Edinburgh," ${ }^{56}$ a body of work still admired and included in many histories of the medium. The jury describes the work as, "... after Rembrandt, being made in broad and deep-toned masses of light and shade," but they also note that Hill and Adamson produced them. ${ }^{57}$ This is one example where any new display of technique or process would have been impossible. The prints would have been at least two years old, since Adamson (known to handle the technical side of the business) had

${ }^{52}$ Brettell, Richard R., Paper and Light: the Calotype in France and Great Britain, 18391870 (Boston: David R. Godine, 1984) 18.

${ }^{53}$ Borcoman, James, "The Painter as Photographer" from the exhibition catalogue: Works from the National Gallery of Canada at the Vancouver Art Gallery, December 9, 1978 - January 14, 1979, introduction.

${ }^{54}$ Reports, 604.

${ }^{55}$ Borcoman, The Painter, introduction.

${ }^{56}$ Cat., 839.

${ }^{57}$ Reports, 605. 
died in 1848. Of the seven in "Fine Arts", only Voigtlander, Evans \& Co. (No. 254, p. 837) make unequivocal claim to a new instantaneous process for the daguerreotypes they exhibited. Unfortunately, there is no description of what the photographs were, only that the artist E.T. Pickering was involved, presumably for adding color. ${ }^{58}$ The jury makes a comment about the colored daguerreotypes of Maucomble (France, No. 620, p. 1207) suggesting their attitude toward this technique: "These are excellent, but possibly being more to the fine arts than to photographic science. ${ }^{\text {"59 }}$ As a foreign exhibitor, Maucomble was restricted to exhibiting within his own country's section, but he, among other foreigners, might have been classified as Fine Art if the national restrictions for organizing had not been applied.

Many of the other British exhibitors who would have been eligible for the class 30 classification displayed some sort of apparatus or scientific principle in addition to photography, making it increasingly unlikely that they would have been seen as artists. There were additional displays of calotypes (Bingham-No. 302, Colls-No. 303, OwenNo. 670, Paine-No. 295), but the Jury Reports are less enthusiastic about their contributions. ${ }^{60}$ Of the remaining photographers exhibiting daguerreotypes, only Beard and Mayall elicit any kind of attention from the jury ${ }^{61}$ Beard (No. 292, p. 440) used a newly patented process to enamel the photograph, but the reaction from the jury is little more than an acknowledgement. Mayall (UK, No. 291, pp. 439, 440) is the lone British photographer whose body of work described in the Catalogue and Jury Reports seems

\footnotetext{
${ }^{58}$ Reports, 601.

${ }^{59}$ Reports, 603.

${ }^{60}$ Reports, 601, 605, 606.

${ }^{61}$ Reports, 524, 601.
} 
to warrant inclusion into the classification of fine-arts both for its content (daguerreotypes of Niagara and other picturesque settings) and for the praise it received.$^{62}$ It may have been an oversight, or it may have had something to do with the fact that Mayall entered twice, as both an American and a British exhibitor. ${ }^{63}$

There is no mention of photography in the Catalogue introduction to the Fine Arts section, and all photographs in this section were ultimately judged within the Machinery, Class 10 classification, but the duality of science and art in photography is a subject addressed at length in the Jury Reports. ${ }^{64}$

${ }^{62}$ Reports, 524, 601 .

${ }^{63}$ Cat., 439, 440, 1465

${ }^{64}$ Reports, 520-523. 


\section{Process and Language}

1851 was a watershed year in photography. Many of the processes and improvements that would change the ways photographs were produced and viewed were announced in this year. It is a testament to the technical aspirations of the Great Exhibition that examples of nearly all of the newest experiments were represented. While the annotators and jurists made every attempt to explain these entries, it can still be difficult to figure out exactly what was exhibited. Language changes over time, and what might have been clearly understood by a reader in 1851, can be more difficult to understand today. For example, the majority of photography was classified as Class 10:

Philosophical, Musical, Horological, and Surgical Instruments. In the first half of the nineteenth century scientists were still considered "natural philosophers" and scientific apparatuses, including microscopes, telegraphs, and cameras, were categorized as "philosophical instruments." These terms had been in use since the beginning of the eighteenth century to describe the basic principles of the experimental science that was popular among learned men. ${ }^{65}$ Their observation and notation method of science continues to this day, but much of the scientific terminology used in these volumes fell out of favor shortly after these volumes were published.

Other terms that are common today were not used or had a different meaning in the mid-nineteenth century. The term "photography" appears in the volumes under discussion, but "photographer" does not. In The Daguerreotype in America photographic historian Beaumont Newhall claims that the designation of "photography" was used by

${ }^{65}$ Pritchard, Michael, "Philosophical Instruments," in Hannavy, Encyclopedia, 1069. 
daguerreotypists of this era to refer to the wet-plate or collodion process, ${ }^{66}$ while Gustave Le Gray states in an 1851 essay that it designates, "more particularly the production of the image upon paper by the camera obscura. ${ }^{\text {67 }}$ However, the term is continuously used in the Exhibition volumes for photographic objects in all processes. It is used as an overall section title on page 597 of the Jury Reports, followed by the discussion of both Daguerre's and Talbot's processes. In the Catalogue's introduction to Class 10 the overarching meaning of the word is stated even more clearly:

"Photography is included in this Class, both on plates of silver and glass, and on paper." ${ }^{18}$ Although the word photography may have come to mean other things in following years, in the 1851 Great Exhibition publications it is applied to all photographic processes.

\section{Paper prints}

It is generally accepted terminology today that a positive paper print made by contact from a calotype negative is called a "salted paper print," but this term does not appear anywhere in the Catalogue or Jury Reports. Inventor William Henry Fox Talbot (18001877) coined his paper process "calotype," but many of his supporters preferred to acknowledge his discovery by using the term "Talbotype." Even the inventor himself was known to use these terms interchangeably in his commercial printing and

\footnotetext{
${ }^{66}$ Newhall, Daguerreotype in America, 65, 107.

${ }^{67}$ Le Gray, Gustave, "Of the Actual State of Photography and the Perfection to which it has been Brought," in The Photographic Art-Journal, Vol. 1, 1851, from La Lumiere, translated by J. Russell Snelling, M.D. (New York: W.B. Smith, 1851).

${ }^{68}$ Cat., 404.
} 
publishing. ${ }^{69}$ Annotator James Glaisher explains in the Official Catalogue, "The calotype picture is a negative one, in which the lights of nature are represented by shades; but copies from them can readily be made in which the lights are conformable to nature. ${ }^{70}$ This would conform to the concept of the negative print that we now call a "calotype." However, the terms "calotype" and "Talbotype" as used in the Catalogue and Jury Reports are not necessarily restricted to negative images. They are, instead, usually referring to Talbot's process, and act as a descriptive word. Sometimes "pictures," is added, as in "calotype-pictures" or "Talbotype pictures," or other descriptives like "calotype processes" or "calotype negatives." They can also refer simply to a positive proof, as in the case of Rippingham (UK, No. 304) who is described in the Jury Reports as exhibiting "several talbotypes, being a series of untouched positives..."71 or Cousin (France, No. 1572) who "exhibits a series of positive talbotypes, from negatives on paper." ${ }^{72}$ The term Talbotype is both capitalized and lower case. Also used throughout the official volumes to indicate works on paper are the terms "photographic proofs" and "photographic pictures," as well as "sun-pictures," with or without the hyphenation, although these can also refer to prints taken from albumen on glass negatives.

French photographer Gustave Le Gray (1820-1884) is listed as exhibiting "Specimens of Photography."73 1851 is the year that Le Gray published his treatise, Nouveau Traité théorique et pratique de photographie sur papier et sur verre in which he described

${ }^{69}$ Daffner, Lee Ann, "Calotype and Talbotype," in Hannavy, Encyclopedia, 239.

${ }^{70}$ Cat., 435.

${ }_{72}^{71}$ Reports, 606.

${ }^{72}$ Reports, 607.

${ }^{73}$ Cat., 1206. 
waxing papers prior to sensitizing them to strengthen the papers and allow for finer detail. ${ }^{74}$ Strengthening papers must have been a priority, as it is suggested that he sometimes soaked his photographs in a bath for three to four days to achieve sepia or yellowish tones. ${ }^{75}$ These waxed negatives became very popular in the following years, especially among travel photographers, but no mention is given in the Reports as to whether this process was used by Le Gray or anyone else. They merely mention Le Gray's sun-pictures as "heavy and wanting in detail,"76 which is not a very hearty recommendation either way.

The Jury Report also notes that Talbot himself was not an exhibitor, but his "productions will be recognized among those exhibited by Henneman and Malone..77 Nicolaas Henneman (1813-1898) had been Talbot's assistant before setting up his own photography business. In addition to Talbotypes, this pair of exhibitors also showed cyanotypes, chrysotypes, and chromotypes. Cyanotypes are readily identifiable by their Prussian-blue coloring and are still common today, mostly due to their use as architectural blueprints, but also persisting as an art medium. The scientist Sir John Herschel (1792-1871) discovered the process. Also credited to Herschel is the chrysotype, which uses gold compounds. ${ }^{78}$ Robert Hunt, the inventor of the chromatype, describes the process in an annotation as being formed "by washing paper with a mixture of the bichromate of potash and sulphate of copper; and after the picture has

\footnotetext{
${ }^{74}$ Taylor, Impressed by Light, 29.

75 Jammes, French Calotype, 33.

${ }^{76}$ Reports, 606.

${ }_{78}^{77}$ Reports, 599.

${ }^{78}$ Ware, Mike, "Prints of Gold," in Alternative Photography, http://www.mikeware.co.uk/mikeware/Prints of Gold.html, accessed May 7, 2013.
} 
been faintly developed by the chemical principle of the solar beam, it is washed with nitrate of silver, by which a positive picture, or one with correct lights and shadows, is produced by one operation." ${ }^{79}$ Henneman and Malone were the only photographers to enter cyanotypes, chrysotypes, and chromotypes into the Exhibition, indicating the rarity of these processes at that time.

Perhaps one of the more confusing terms used to describe a paper process in the Great Exhibition was "heliograph." This was a version of Talbot's process adapted by French photographer Louis Désiré Blanquart-Evrard (France, No. 1551). Talbot claimed that the process was based on the same principles as his invention and later raised an unsuccessful patent lawsuit against Blanquart-Evrard. ${ }^{80}$ While Blanquart-Evrard himself is listed as showing "photographs," at least one of his fellow French exhibitors (Thierry, No. 1038) lists heliographic prints, ${ }^{81}$ yet the jury describes them as daguerreotypes. ${ }^{82}$ French photographer Cousin (No. 1572) is listed in the Catalogue as exhibiting "lithographic drawings on paper," ${ }^{83}$ but the Jury Reports state that he showed, "a series of positive Talbotypes, from negatives on paper." ${ }^{84}$ It is possible that whoever transcribed the hand-written entry form might have confused lithograph for heliograph, since the words are similar and the term heliograph would not have been as familiar to the British. There is a small indication of the controversy between Talbot and BlanquartEvrard discernable when Catalogue annotator Robert Ellis points out that Talbot, and

\footnotetext{
${ }^{79}$ Hunt, Robert, Cat., 442.

${ }^{80}$ Taylor, Impressed by Light, 28.

${ }^{81}$ Cat., 1228.

${ }^{82}$ Reports, 603.

${ }^{83}$ Cat., 1252.

${ }^{84}$ Reports, 607.
} 
thus Britain, is the father of superior photography on paper: "The art of producing pictures by the aid of sunlight commonly called photography, is due, so far as the processes on paper are concerned, to Mr. Fox Talbot. Other methods of obtaining photographic pictures on paper, equally expeditiously, are known; but the principles embodied in Mr. Talbot's patent are those which in actual practice produce the finest and best pictures." ${ }^{85}$

\section{Collodion}

Frederick Scott Archer was not an official exhibitor at the 1851 Great Exhibition, but his instructions for the collodion wet-plate process were published in the Chemist a few months before the May opening. ${ }^{86}$ The accounts regarding the presence of collodion photography in the Great Exhibition vary widely. Hannavy suggests that Archer himself was given permission to display some of his collodion negatives shortly before the October ending of the fair, but Steve Edwards in this same book says that "Archer's process was represented by only one picture at the Great Exhibition." ${ }^{87}$ Roger Taylor incorrectly claims that Peter Wickens Fry added the first display of photographs by the collodion process to the display of Horne and Thornthwaite (UK, No. 220) after the

opening. ${ }^{88}$ While both of these additions may have occurred, the Catalogue and Jury Reports reveal other possibilities. The jury questions whether the Langenheims' (US, No. 62) self-named "hyalotypes" utilized the collodion process. The confusion is

\footnotetext{
${ }^{85}$ Cat., 442.

86 Hannavy, "History: 4" in Encyclopedia, 682.

87 Barnes, Martin and Steve Edwards, in Hannavy, Encyclopedia, 56, 608.

88 Taylor, Impressed by Light, Chapter 3 notes.
} 
furthered by an article published in the May, 1851 London Illustrated News that suggested:

“...a collection of slides adapted to the magic lantern and prepared by photography, are shown, but no description of them is given in the present Catalogue. They are Labelled 'specimens of hyalotype, by Mr. Langenheim,' but, if we mistake not, they are identical with a specimen executed by Mr. P. V. Fry, of the Calotype Club, by one of Mssrs. Horne and Thornthwaite's camera...he washes over the glass with a mixture of week collodion, nitrate of silver, and iodide of potassium..." 89

These specimens displayed at the Calotype Club by Fry may have been the exact ones that Taylor describes as having been added to the Exhibition. Perhaps this addition was meant to clear up confusion regarding the new process. An annotation in the Catalogue by Robert Ellis says that the lantern slides were formed by an adaptation of Talbot's process "with the substitution of plates of glass for receiving the pristine images upon, in lieu of paper." ${ }^{90}$ However, Newhall notes in The Daguerreotype in America that an 1850 U.S. patent shows that the Langenheims' (two brothers, Frederick and William) selfnamed hyalotypes were an adaption of Niépce de Saint-Victor's albumen on glass process. ${ }^{91}$ So new was the collodion practice that even scientists versed in the process had difficulty in its identification. Hannavy states that Martens (France, No. 610) was

\footnotetext{
${ }^{89}$ London, Illustrated News, May 17, 1851.

${ }^{90}$ Ellis, Cat., 1437.

${ }^{91}$ Newhall, Daguerreotype in America, 53.
} 
already using collodion in $1851 .^{92}$ The Official Catalogue lists Martens as exhibiting daguerreotypes, but the Jury Report praises his work and says that he exhibited "several large and beautiful photographic proofs, on glass and paper" as well as "several large photographs from negatives on glass." ${ }^{93}$ While Marten's photographs are praised as being the best in the Exhibition for "colour, arrangement, and perfect finish," there is no evidence that any of them were created by the wet-collodion method. The only definitive listing of the use of collodion in the Catalogue is for M. J. Rippingham (UK, No. 14), which states that he exhibited, "A case of photographic portraits, on paper, from negatives, taken with collodion on plate glass, ${ }^{94}$ indicating that more than one were shown. This is confirmed by the Jury Reports. This process, which was so new and barely present at the 1851 Exhibition, would become the dominant photographic process for the prints exhibited eleven years later at the Great London Exposition of $1862 .^{95}$

\section{Albumen}

Unlike the wet collodion process, Niépce de Saint-Victor's (1805-1870) albumen on glass process had already been in existence since 1847, and became more popular after Louis-Désiré Blanquart-Evrard (1802-1872) improved it in 1849. Several of the exhibitors displayed works created by this method, which employs the albumen of egg whites. Johann Pucher (Austria, No. 740) also made claims that he had invented

\footnotetext{
92 Hannavy, Encyclopedia, 898.

${ }^{93}$ Reports, 606.

${ }^{94}$ Cat., , 442

${ }^{95}$ Edwards, "Great Britain," in Hannavy, Encyclopedia, 608.
} 
photography on glass independently of the French as early as $1843 .{ }^{96}$ In the Official Catalogue, Pucher is said to have shown, "Photographs on glass, by a new method."97 Surprisingly, he is omitted from the Jury Reports. Ross and Thomson (UK, Class 30, No. 299) are praised as having made photography by the albumen process to: "...a high state of perfection, and having not only substituted it for the old method of taking the negative proofs on paper, but having, in more than one instance, exhibited the positive proof upon the albumenized glass itself." ${ }^{98}$ A lengthy description of their very complicated process is given in the Jury Reports, including the transfer of the image from a glass plate to paper that required as many as 24 hours to accomplish. ${ }^{99}$ Theirs are the only prints designated explicitly as using albumen, although as stated before, Martens (France, No. 610) and Langenheim (US, No. 62) probably also utilized this process. Both spellings "albuminized" and "albumised" are used in the volumes, while the process is consistently called "albuminous."

\section{Daguerreotypes and Stereoviews}

The most common process among the photographs on display in 1851 was the daguerreotype, named after its inventor Louis-Jacques-Mandé Daguerre (1787-1851).

Derivatives of his name are used as adjective, noun and verb. A photographer working

${ }^{96}$ The Photographic Times, vol. 32 (NY: The Photographic Times Publishing Association, 1900) from http://books.google.com/books?id=57gaAAAAYAAJ\&pg=PA187\&lpg=PA187\&dq=Johan n+Pucher+photography\&source=bl\&ots=PpEueX3POt\&sig=A6-

o YJdxVSU59miqMyaFixG59A\&hl=en\&sa=X\&ei=KJ2BUeOiC9S84AOv54HoDw\&ved $=0$ CFUQ6AEwBw\#v=onepage\&q=Johann\%20Pucher\%20photography\&f=false, accessed May 1, 2013.

${ }_{97}$ Cat.,, 1044.

${ }^{98}$ Reports, 604.

${ }^{99}$ Reports, 523, 524. 
in this process was often called a "daguerreotypist," the action of making the photos as "daguerreotyping," and anything having to do with the process as "daguerrian," or even "daguerreotypic." All of these terms are used in the volumes under consideration.

The handheld stereoscope was one of the newest photographic discoveries exhibited at the Fair, and in its early days used stereoscopic daguerreotype images, as well as paper and glass. In the year prior to the Exhibition, Scottish scientist and scholar Sir David Brewster (1783-1868) had partnered with the French optician Jules Duboscq (1817-1886) to produce a handheld lenticular stereoscope. ${ }^{100}$ While the stereoscope had already been in existence for years, Brewster's idea utilized the addition of lenses to unite the images. Duboscq and Soleil (France, No. 1197) entered numerous cameras and apparatus into the Fair, including Brewster's stereoscope. It is of interest that Brewster is clearly given credit by Dubocsq for the stereoscope in the Official Catalogue, but the very next year he acquired a patent that neglected to credit Brewster at all. ${ }^{101}$ Historical accounts claim that Antoine Claudet (UK, No. 296) exhibited stereoscopic photographs nearby and even sent some to Queen Victoria after she became enamored with the novelty, ${ }^{102}$ but nowhere in the very long and very specific Catalogue listing or in the Jury Reports regarding Claudet does it mention anything that would indicate that stereoviews were among the photographs he exhibited.

\footnotetext{
${ }^{100}$ Herbert, Stephen, "Louis Jules Dubosq" in Hannavy, Encyclopedia, 445, 446.

101 Herbert, Hannavy, Encyclopedia, 446.

102 Claudet, Laura, "Claudet" in Hannavy, Encyclopedia, 303.
} 


\section{Illustration}

There were very few instances in which photographs were used in a display as the illustration of something other than the photographic process itself or the apparatus used to make them. Von Minutoli (Zollverein, No. 191, p. 1058) used photographs by a photographer named Birk to copy models of his manufactures. John Badcock (UK, No. 732, p. 475) included photographs of smallpox vaccinations taken by a Mr. Constable from Brighton. The Jury Report complains in the closing remarks of the photography section about the lack of applied photography. The jurors profess regret at the lack of copies of ancient inscriptions and manuscripts, scientific uses such as microscopic representations and illustrations of dissected animals and plants, and copied miniatures of books. ${ }^{103}$ It became a common practice in future fairs to use photographs as illustration to show what could not be exhibited because of size, complexity, or perishability.

${ }^{103}$ Reports, 607, 608. 


\section{Jury Reports}

The Reports by the Juries on the Subjects in the Thirty Classes into which the Exhibition was Divided is contained in four volumes that were published in 1852 after the closing of the Great Exhibition. In the Presentation Edition referenced for this thesis, the volumes were created as a set and are presented in the same Red Moroccan leather with gold embossed lettering as the Official Catalogue discussed earlier. However, instead of the engravings that are used as illustrations in the Catalogue, the Reports feature 154 salted paper prints taken of the Exhibition by Claude-Marie Ferrier (18111889) and Hugh Owen (1808-1901). It is estimated that 20,000 photographs were printed and mounted to be included in the 137 presentation sets that were created (Figure 3). ${ }^{104}$ These volumes provide: a report by Viscount Canning, the President of the Council of the Chairmen of the Juries; a listing of the jurors and medal winners; an explanation of how the Juries were formed; instructions to the Juries; an answer by His Royal Highness Prince Albert to Lord Canning's Report, and the full Reports by the Juries. It does not, however, give a full listing of individual entries or complete descriptions. Other editions of the Jury Reports that were printed at the same time did not include photographs, including a condensed version that was given to each of the Exhibitors. The Reports by the Juries provide the information that follows in this section, unless otherwise noted.

104 Bocard, Helene, "Great Exhibition of the Works of Industry of All Nations," in Hannavy, Encyclopedia, 616. 

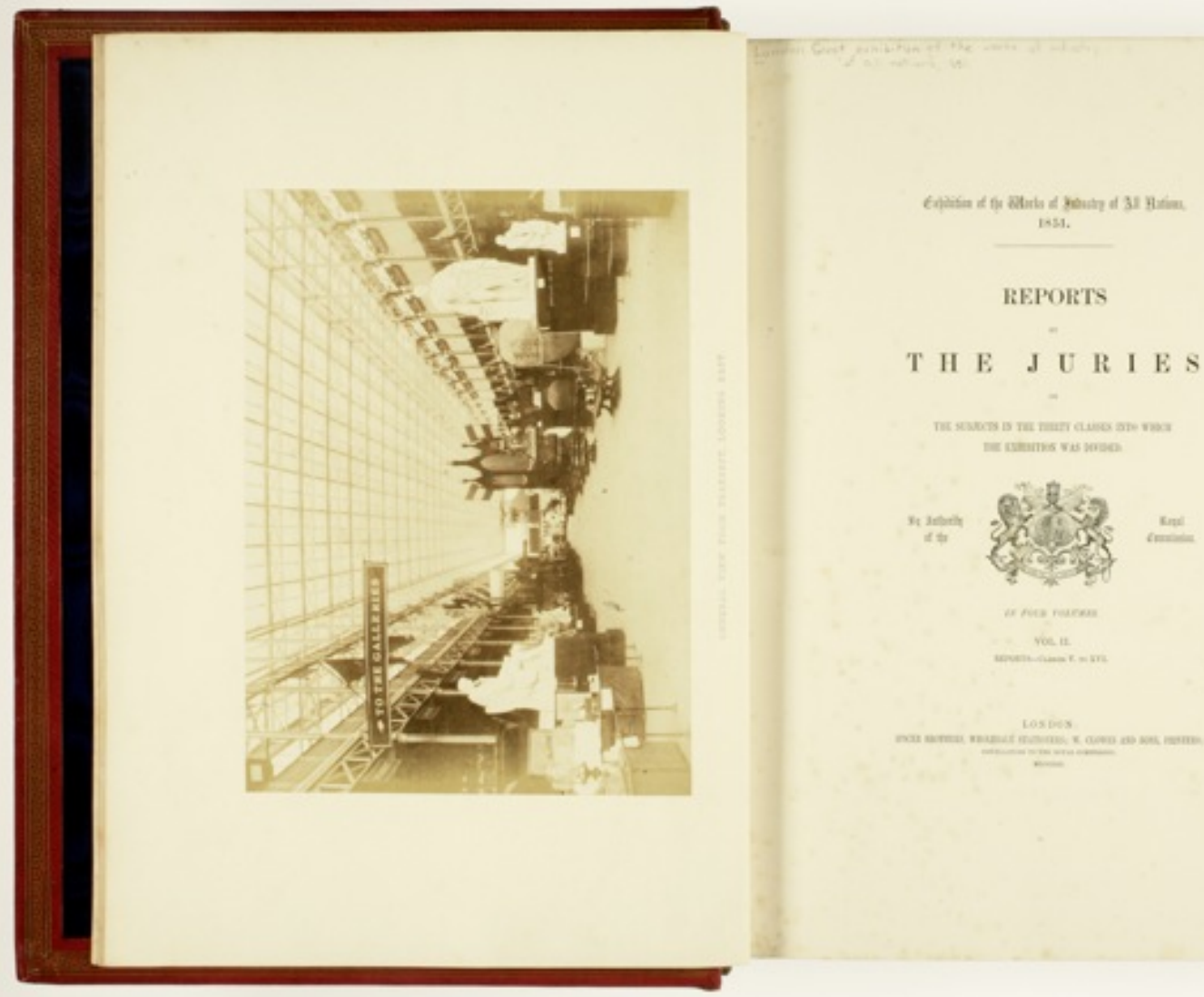

T H E J U R I E S

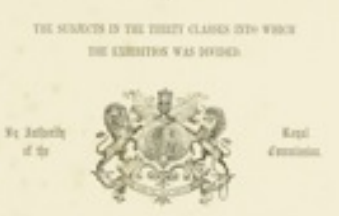

(Figure 3) Reports by the Juries on the Subjects in the Thirty Classes Into Which the Exhibition was Divided, Volume 2, frontispiece. Photograph by Hugh Owen, General View from Transept, Looking East, 1851, 25 x $35 \mathrm{~cm}$. Courtesy of George Eastman House International Museum of Photography and Film.

\section{The Jury}

A jury was assigned for each of the thirty classes into which the Exhibition was divided, with the addition of four more for classes that were thought to be too large for a single jury. Photography was judged under Class X (10): Philosophical Instruments, and Processes Depending Upon Their Use, Musical, Horological, and Surgical Instruments. This class included instruments for measuring space, the effects of physical forces, and 
illustrations of the laws of science. This grouping was further broken out for the sake of judging into six subjects, with photography falling under Class 10, letter D: Application of Mechanical and Physical Science to Useful Purposes, Not Included in any of the Proceeding or Subsequent Sections. Section D was then further divided into five sections with photography falling under number three: Light—Instruments to assist Vision, as Smaller Telescopes, Lenses, Mirrors, Signals, Visual Telegraphs, Lighthouses, Optical Illusions, Gas and Solar Microscopes, Cameras, Photography, Polarization of Light, \&c. ${ }^{105}$ While this may seem overly complicated, it is easy to understand that having almost 17,000 exhibitors and an estimated one million items would necessitate dividing the items into workable groups for the purpose of judging.

An attempt was made to have an equal number of British and foreign jurors for each Class so that there would be no question of favoritism, but this was not always possible due to the number of available jurors. The British jurors were selected by the commissioners from lists offered by committees in towns showing strength in a particular area. Authorities in foreign countries appointed their own jurors, the majority of whom came from France, the United States and Zollverein (which became Germany). Jurors who also exhibited were not eligible to win prizes in the area they were judging. Originally these prizes were to offer a financial award as well, but this was later eliminated.

${ }^{105}$ Reports, Appendix A-1. 
Class 10 had twelve members in its jury: ${ }^{106}$

Sir David Brewster, F.R.S., Chairman

Professor Daniel Calladon, Switzerland

E.B. Denison

J. Glaisher, F.R.S., Reporter

Sir John Herschel, Bart., F.R.S.

Professor Hetsch, Denmark

E.R. Leslie, R.A., United States

L. Mathieu, France

W.H. Miller, F.R.S.

Richard Potter, A.M.

Professor Schubarth, Zollverein

Baron Armond Segueir, France

Associates were also consulted if needed for scientific or specialized knowledge. For Class 10 these included: ${ }^{107}$
J.S. Bowerbank
Rev. W.S. Kingsley
Lambert A.J. Quetelet (Juror in Class 30), Belgium
Lord Wrottesley

F.R.S. stands for Fellow of the Royal Society, which is especially pertinent in this context as the Royal Society was instrumental in the creation and organization of the Great Exhibition. The Class 10 jury was composed of notable men who were knowledgeable about photography, despite it being only one small part of this class of exhibited items. The Chairman, Sir David Brewster (1781-1868), was a Scottish physicist who is credited with inventing the kaleidoscope and the lenticular stereoscope. ${ }^{108} \mathrm{~A}$ friend of Talbot, he was actively interested in photography and helped to teach Robert Adamson (1821-1848) the technique of the calotype and introduced him to his future studio partner David Octavius Hill (1802-1870). Photographs by Hill

\footnotetext{
106 Reports, 519.

107 Reports, 519.

108 Jay, Bill and Dana Allen, Critics: 1840-1880, History of photography monograph series, Special Edition (Phoenix: Arizona Board of Regents) 101.
} 
and Adamson received an Honourable Mention in the Great Exhibition, despite the fact that Adamson had died three years before. ${ }^{109}$ Brewster is listed in the Catalogue as both Chairman and Reporter, but for unexplained reasons this had changed by the time the Jury Reports were created. ${ }^{110}$ The Reporter for the class was astronomer and meteorologist James Glaisher (1809-1903). As the person responsible for compiling and writing the Class 10 Reports by the Juries, as well as serving as an annotator in this class in the Official Catalogue, he must have been privy to an enormous amount of information. His photographic knowledge was sufficient for him to deliver a paper to the Society of Arts in 1852 regarding his opinions on the newest processes of photography. ${ }^{111}$ Also on this jury was Sir John Herschel (1792-1871) who invented the cyanotype and its variation, the chrysotype. Henneman and Malone (UK, No. 297) exhibited cyanotypes and chrysotypes and won a Prize Medal for their examples of calotypes. ${ }^{112}$ Herschel also discovered hyposulphate of soda (hypo), a variant of which is still used today as a photographic fixing agent.

A council was created, made up of the chairmen of all the juries. Its purpose was to frame rules regarding the judging, distinguish the conditions for awarding prizes, and to "secure uniformity" between the various classes. In addition, before any prize was to be awarded, it also had to be approved by a group of six juries gathered by similarity of

${ }^{109}$ Daniel, Malcolm R., Inventing a New Art (New York: The Metropolitan Museum of Art Bulletin, spring, 1999) 13.

${ }^{110}$ Cat., 46.

${ }^{111}$ Glaisher, Esq. F.R.S., James, Lectures on the Results of the Exhibition, delivered before the Society of Arts, Manufactures, and Commerce, at the suggestion of H.R.H. Prince Albert, Pres. of Society (London: David Bogue, 1852).

112 Cat., 441, 442. 
subjects. ${ }^{113}$ This was to act as an additional safety so that foreign interests would not be overlooked. However, the only record mentioned in the Reports of the group acting to change something photography-related was to deny a Council Medal to a non-British exhibitor, M.M. Lawrence (US, No. 151), after he had been approved by the jury. ${ }^{114}$ The jurors began work on May 12, less than two weeks after the Exhibition opened, and did not present their findings until after the October 11 closing.

\section{The Medals}

From the very outset there was confusion over what the prize medals should signify. The Royal Commission had originally planned that three medals would be awarded for excellence, but had expressed that they wanted to "avoid the recognition of competition between individual Exhibitors." ${ }^{\text {115 }}$ When faced with this paradox, the Council of Jurors suggested that only two medals be awarded: a Council Medal, given not for superiority of skill, but for "novelty in invention or application, either in material, or processes of manufacture, or originality combined with beauty of design;" and a Prize Medal for excellence in execution and workmanship including, "utility, beauty, cheapness, adaptation to particular markets and other elements of merit." ${ }^{116}$ The Council Medal was to be awarded by the Council of Chairmen after recommendation by the Jury and Group. The Jury, also with the approval of the Group, awarded the Prize Medal. In Lord Canning's report he admits that there was confusion, especially among the foreign jurists who had participated in other domestic fairs where prizes had been awarded for

\footnotetext{
${ }_{113}^{113}$ Reports, i.

${ }_{114}^{114}$ Reports, 602.

115 Reports, i.

${ }^{116}$ Reports, "Report of Viscount Canning".
} 
degrees of merit. In addition, the overall instructions given to the jurors in Class 10 (x) for all awards included:

"In the department of Machinery, the Prizes will be given with reference to novelty in the invention, superiority in the execution, increased efficiency, or increased economy, in the use of the article exhibited. The importance, in a social or other point of view, of the purposes to which the article is to be applied, will also be taken into consideration, as will also the amount of the difficulties overcome in bringing the invention to perfection." ${ }^{117}$

The jurors of Class 10 were therefore tasked with judging all works by originality and excellence, but could award medals only for one or the other. If the actual bronze medals awarded had been created of equal size, it might have helped make clear that subject as well as merit defined the prizes, but the Council Medal was significantly larger. To complicate it even more, an exhibitor could receive only one medal, regardless of how many qualified items he entered. Furthermore, the juries decided that an "Honourable Mention" should also be given to exhibitors whose "...contributions were not such as to entitle them to receive a medal," but who, "...furnished articles of manufacture which, without reaching a high degree of excellence are interesting examples of the process." ${ }^{118}$ While these exhibitors did not officially win a medal, in the spirit of noncompetition that the Commissioners were striving for, all exhibitors received a bronze medal, although it was smaller in size than the Council and Prize awards.

117 Cat., 30, introduction.

${ }^{118}$ Reports, "Report of Viscount Canning". 
Bronze medals of a smaller size were also given to the jurors and to people who contributed essential services to the Exhibition (Figure 4).
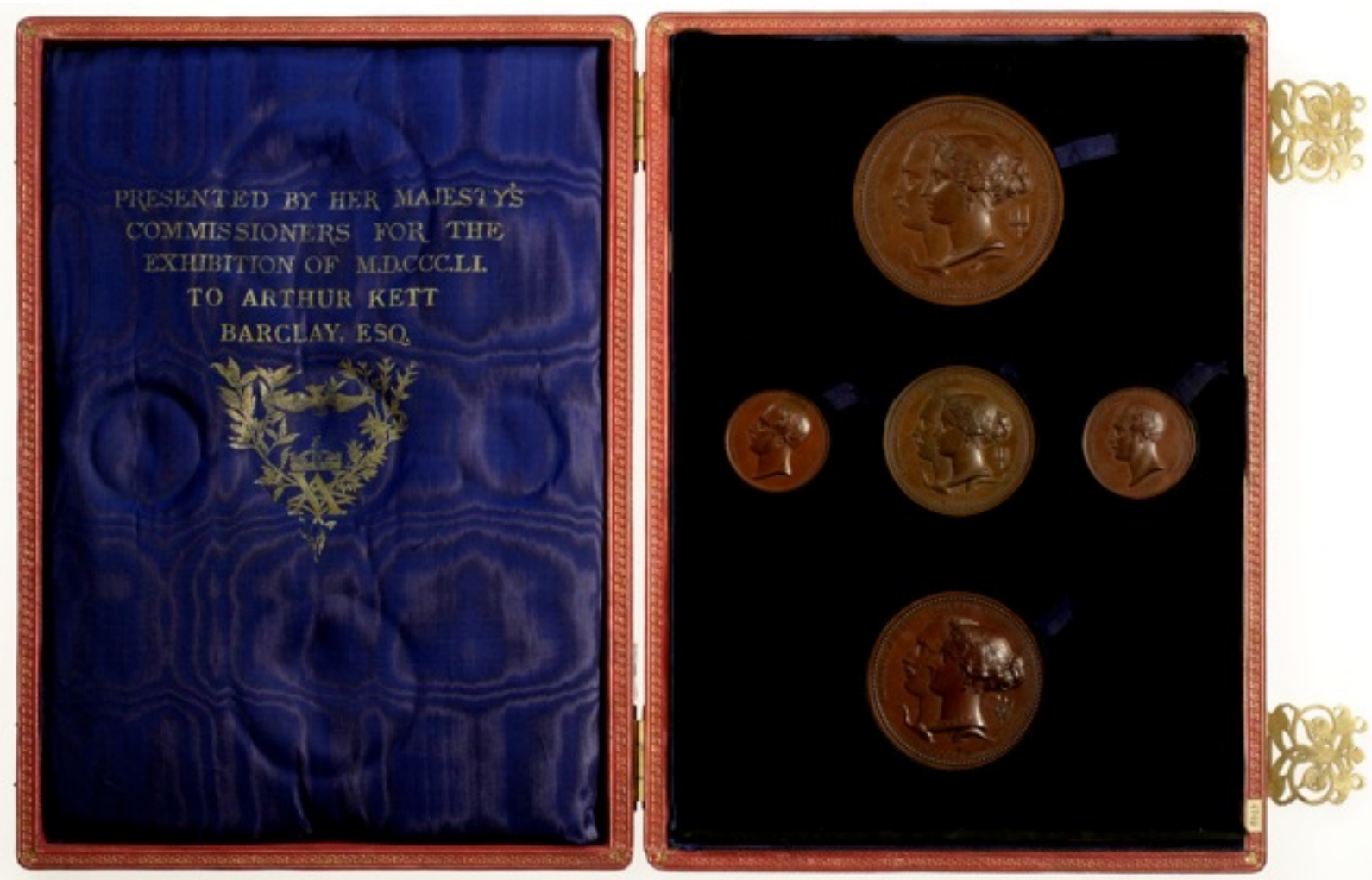

(Figure 4) Arthur Kett Barclay Presentation Set of Medals, Collection of the Richard and Ronay Menschel Library, Courtesy of George Eastman House International Museum of Photography and Film. 


\section{Reactions}

While the method of judging caused confusion among the jurors, it caused even more among the general population. The London Art Journal complained that, "the declaration of the awards has been received with a dissatisfaction so general; and the feeling has been provoked by so much want of judgment, and even common tact, in the composition of many of the juries, and the instructions by which the operations of all were to be influenced and guided as to merit the most severe reprobation.." ${ }^{119}$ The North American Review stated that the prizes, "...spoken of with great respect at first, got to have no other value than that of advertising cards." ${ }^{120}$ Even Prince Albert suggested in his reply to Lord Canning's Report that it might have been better for the general public if the awards had followed the precedence of other exhibitions and granted medals, "... of different degrees to mark the gradations of excellence among the Exhibitors." ${ }^{121}$

That an item demonstrating innovation but lesser skill could win the more prestigious Council Award over an item of greater quality does not seem equitable. However, these guidelines do not seem to have been necessarily adhered to in the case of photography. If the reward had been merely for innovation, then Rippingham (UK, No. 304) as being the first and only exhibitor listed in the Official Catalogue to exhibit photographs by the brand new collodion method should have been noted, but he was not commended for doing so. Richard Beard (UK, No. 292) displayed daguerreotypes by his own newly patented "enameled" method, but received no medal. Mayall hedged

119 The Art Journal, (London: George Virtue, Vol. I, 1851) 303

120 "The Great Exhibition," in North American Review, 75:2 (1852) 357, accessed from ProQuest Information and Learning, June 8, 2013.

${ }^{121}$ Reports, xxxiii. 
his bets and entered under both the United Kingdom (No. 291) and the United States (No. 491), but his original "crayon daguerreotype" technique displayed within the U.K. received no notice, while his plain daguerreotypes submitted with the U.S. received an Honourable Mention. In all, 2,918 Prize Medals and 170 Council medals were awarded.

\section{The Winners}

Below is a listing of photography-related exhibitors who earned distinction in Class 10

( ${ }^{*}$ indicates award for non-photographic entry): ${ }^{122}$

\section{Council Medal}

United Kingdom - 144 Brook, Charles, The invention of a means of self-registering natural phenomena, by photography.

United Kingdom - 301 Buckle, S. (class 30), Photographs of paper.

${ }^{*}$ France -443 Buron, Good telescopes, the object-glass being of rock crystal.

*United Kingdom - 22 Chance Brothers \& Co. (Class 24), A disc of flint glass, 29 inches in diameter.

United Kingdom - 296 Claudet, A.F., Inventions based upon experiments in the practice of photography; and non-inverted pictures.

*France - 1197 Duboscq-Soleil, A very ingenious heliostat, on a new construction, by Silberman; the invention of an apparatus for fixing the charcoal points for electric light; a saccharometer of delicate structure, and much ingenuity, and an elegant and novel instrument, by Brevais, for exhibiting the phenomena of polarized light.

France -610 Martens, F., Talbotypes on glass by the albuminous process.

*United Kingdom - 254 Ross, A., Great improvements in microscopes, and for the solidity of structure, good mechanism, and distribution of strength, great size, \&c., of his large equatorial.

United Kingdom - 299 Ross and Thomson (class 30), Great improvements in photography.

\section{Prize Medal}

France - 414 Bayard, H., Talbotypes.

United States - 137 Brady, M.B., Daguerreotypes.

France - 836 Flacheron-Hayard, Talbotypes.

United Kingdom - 297 Henneman \& Malone, Talbotypes.

${ }^{122}$ Reports, Jury Awards, Class X, p. CXV. 
United Kingdom - 220 Horne, Thornthwaite, \& Wood,

Good work in photograph apparatus.

United Kingdom - 294 Kilburn, W.E., Photographs.

United States - 151 Lawrence, M.W., Daguerreotypes.

France - 1679 Plagniol, Camera obscura.

Austria - 362 Pretsch, Paul, Photographs.

France - 999 Schiertz, J.G., Photographic apparatus.

*United Kingdom - 257 Varlet and Son, Telescopic camera lucida.

Honourable Mention

Frankfort-on-Maine - 7 Albert, J.W., Photographs

*France - 1729 Chevalier, C., Microscopes.

United Kingdom - 300 Hill and Adamson (Class 10), Talbotype groups.

France - 620 Maucomble, Coloured daguerreotypes.

United States - 491 Mayall, J.E., Photographs.

*France - 649 Motteni and Siegler, Reflecting circles, \&c.

France - 1038 Thierry, J., Daguerreotypes.

Austria - 739 Vogel, C.F., Photographs.

Of the nine photographic-related exhibitors who won a Council Medal, only three were for photography: Buckle, Martens, and Ross \& Thomson. Upon reading the Reports by the Juries, it becomes apparent why the latter two were so rewarded. They are much praised for their quality of prints and numerous tints, but also for the originality of their techniques. Both exhibitors used albumen on glass and paper, as well as other processes. Samuel Buckle seems to be the only Council Medal winner who displays no evidence of innovation, exhibiting calotypes from paper negatives, although the jury does hint that he used a process that enabled him to create superior prints of great beauty. ${ }^{123}$

It appears that the jurors of Class 10 tried to adhere to the difficult parameters given to them while still rewarding those exhibitors who presented superior work. It follows that

${ }^{123}$ Reports, 604. 
the photographers winning Prize Medals and given Honourable Mention were rewarded solely for the quality and beauty of their prints without any need of innovation. The distribution of awards seems fairly equal among countries and photographic types despite the jury's suggestion in the introduction to Class 10 that some countries were better than others at particular processes: “...for daguerreotype portraits, America stands prominently forward;-France, first in order of merit for calotypes, or sunpictures." ${ }^{124}$ A rather backhanded compliment assured the British that England possessed "...a distinct character of her own." The overall judgment displayed elicited harsh reactions from the press such as: "genius perforce is doomed to penance whilst dunces hold a jubilee, ${ }^{125}$ but this does not seem to hold true in the area of photography. Perhaps the greatest testament to the extent of controversy this method of judging raised is that Great Britain's 1853 Great Industrial Exhibition in Dublin awarded no medals whatsoever. ${ }^{126}$

\footnotetext{
${ }^{124}$ Reports, 522.

${ }^{125}$ The Art Journal, (London: George Virtue, Vol. IV, 1851) 376.

${ }^{126}$ The Art Journal, (London: George Virtue, Vol. IV, 1851) 378.
} 


\section{PART TWO: THE SUMMARY}

All of the information pertaining to photography from the Catalogue and Jury Reports has been transcribed into this summary exactly as it is contained within the volumes. I have attempted to replicate exactly the grammar, spelling, and punctuation. However, original sources should always be checked, as this is an unavoidably imperfect document. Content added by the author is in BOLD TYPEFACE.

The annotators include: Robert Hunt (R.H.), Robert Ellis (R.E.) and James Glaisher (J.G.). ${ }^{127}$

\section{Alphabetical Listing of Exhibitors}

\section{A}

\section{ABRAHAM, ABRAHAM, \& CO., Cat. 1, United Kingdom, p. 436}

263 ABRAHAM, ABRAHAM, \& CO., 20 Lord Street, Liverpool-Manufacturers.

Trinoptric prismatic lantern, with apparatus for making oxygen gas, viz.: gas bag, retort, and purifier, invented by the Rev. St. Vincent Beechy. It combines the powers of three lanterns, with one small lamp of intense brightness. A disc of 25 feet for each tube may be obtained, and each disc is capable of being darkened to any required extent, without shadow on any portion of the picture.

Dioptric prismatic lantern, producing two in lieu of three discs.

Compound microscope, exhibited for workmanship.

Portable sketching camera obscura. In the optical arrangement, a meniscus and prism are employed in lieu of a lens and mirror, and a vivid flat picture is obtained.

[The trinoptric and dioptric lanterns exhibited, are for the purpose of producing panoramic and other pictures, generally displayed by means of the phantasmagoria

${ }^{127}$ Cat., 88. 
lanterns and dissolving-view apparatus. The lamp employed is an oil-lamp, supplied with oxygen gas, on the principle of the Bude light.]

\section{Reports by the Juries, p. 596}

ABRAHAM, ABRAHAM, and Co. (No. 263) exhibit a portable sketching camera, furnished with a meniscus and prism in the place of a lens and mirror. When down, the size of the box is 15 inches in length, 8 in width, and $3 \frac{1 / 4}{4}$ in depth.

\section{ALBERT, J.W., Vol. 3, p. 1121, Frankfort-on-the-Maine}

7 ALBERT, J.W., Frankfort-on-the-Maine-Manufacturer. (Agents, Tootal and Browne, Piccadilly, and 11 Bond Place, London.)

Daguerreotype apparatus, with double achromatic lenses of $51 / 2$ inches in diameter; with specimens produced by it.

\section{Reports by the Juries, p. 597}

ALBERT (Frankfort-on-Maine, No. 7) exhibits a camera, with a double achromatic object-glass, $5 \frac{1 / 4}{4}$ inches clear aperture; there is a slight stop placed between the two glasses, but it cuts off only the reflected light at the sides. The pictures produced are 14 by 11 inches; but the area fully illuminated is only $41 / 4$ inches in diameter, and the corners are very dark. With the full aperture the image in the centre of the field is somewhat imperfect; it will not bear magnifying, and sharp clear definition cannot be attained. Honourable Mention was awarded to Mr. Albert.

Reports by the Juries, p. 607

ALBERT (Frankfort-on-the-Maine, No. 7) has exhibited sun-pictures of large size, but they are fuzzy, being ill-defined and void of effect. Two specimens of smaller size, one of them coloured, are good.

B

\section{BADCOCK, JOHN, Vol. 1, p. 475*, United Kingdom, Class 10}

732 BADCOCK, JOHN, Brighton—Producer.

Photographic specimens of vaccine, produced by inoculating the cow with smallpox, showing the character of the vesicles in their different stages. The specimens, furnished by Mr. Constable of Brighton, show the genuine vaccine and its characteristic areola as described by Dr. Jenner.

\section{BAYARD, HIPPOLYTE, Vol. 3, p. 1198, France, received Prize Medal 414 BAYARD, HIPPOLYTE, 81 Rue de la Paix à Batignolles (Seine)—Producer.}


Seventeen photographic drawings contained in three frames

[These photographs are "prints" to use a recognised term among calotypists, from glass negatives. They represent views of buildings, architecture, \&c., statues, and bas-reliefs. They have not been touched by the artist after having been fixed. The sharpness of outline of proofs obtained from glass negatives, and the freedom from a certain wooliness of texture inseparable from proofs obtained from paper negatives, afford a certain recognition of them.-R.E.]

\section{Reports by the Juries, p. 599}

The Exhibition presents many fine calotypes, or as they are sometimes called in the Catalogue sun-pictures, for the production of which the preparations of Mr. Talbot hold the first rank. M. BAYARD, also, has been celebrated for his achievements in this line, and has contributed many splendid proofs obtained on various sensitive papers.

\section{Reports by the Juries, p. 606}

BAYARD (France, No. 414) has exhibited several sun-pictures, the subjects of which are chiefly selected portions from the public buildings in Paris. One of the cases exhibited by M. Bayard contains five pictures, all excellent; though to the Bibliothèque de Louvre we may give preference for its judicious arrangement of light and shade and elaborate representation of detail. The interior of a church is deserving of a separate mention; the figures, which are numerous, are admirable, and their perfect delineation, even when remote from the eye and in deep shadow, is worthy of commendation. Also a calotype of Venus and Cupid, from a bas-relief is worthy of mention, owing to the beautiful tint which pervades the picture.

In M. Bayard's representations of sculpture, the difference of surface and texture between the plaster cast and marble statue is marked with perfect distinctness. A Prize Medal was awarded M. Bayard.

\section{BEARD, RICHARD, Vol. 1, p. 440, United Kingdom, Class 10}

292 BEARD, RICHARD, 85 King William Street, City_Producer and Patentee.

Photographic pictures by a new patent process, whereby daguerreotypes are "enameled."

[The enamelling referred to would appear to consist in removing the glare of the polished plate by a transparent covering, resembling a varnish. The present method of fixing a daguerreotype picture is by gilding, with a solution of the hypo-sulphite or chloride of gold. - R.E.]

\section{Reports by the Juries, p. 524}

Whether the followers of Talbot will ever obtain a pre-eminence over those of Daguerre, or vice-versâ, is a question for time to solve; at present the two systems appear in the British Department of the Exhibition to be equally well represented; the followers of each, with few exceptions, laying claim to some improvement or peculiarity of manipulation. For example, in addition to the cases already mentioned may be 
included those of MAYALL who calls attention to his crayon daguerreotype, an invention of his own, and BEARD, whose patent enamelled process is one of the very few instances of a patent having been obtained for any improvement connected with this art.

Reports by the Juries, p. 601

BEARD (No. 292, p. 440) has exhibited a case of daguerreotypes, some of them enameled, according to a process invented by himself. $\dagger$ † See the Illustrated Catalogue, note ii. P. 428

\section{BEAUFORD, R., Vol. 1, pp. 453, 454, United Kingdom, Class 10} 406 BEAUFORD, R., Hastings-Inventor.

Registered daguerreotype accelerator. This consists of a properly-constructed lens, applied in a particular manner to the ordinary daguerreotype instrument. Its advantages are assumed to be as follow:-

The actinic rays (which have their primitive source in the solar beam, and which produce the photographic effect) diverge from the object of which an image is to be produced on the photographic plate. These rays are made, by the action of the ordinary daguerreotype instrument, to converge to a point at a certain distance within the camera. By applying the accelerator, these rays are made to converge more rapidly: and, by putting the prepared plate more forward, a smaller image is procured by means of the accelerator than could be obtained without it. Hence, by means of the accelerator, the actinic rays are condensed into a smaller area, and the intensity of the effect is heightened.

This latter fact is considered to include three others, namely-photographic effects can be obtained by the application of the accelerator, when, without its aid, the desired effect could not be obtained: as, for instance, on a dark and cloudy day. Again, all other things bring the same, the image of the object is much more intense and welldefined with the accelerator than without it - the flatness and deadness generally observable in photographic portraits being exchanged for a roundness of surface, and a natural projection or "bringing out" of the parts, which constitute an effect highly pleasing. A third benefit secured by the accelerator is observable in the diminished time required for producing a photographic effect, owing to the actinic rays being intensified by the introduction of the accelerator. The time required for producing a photographic picture with the aid of the accelerator, is only one-half or two-thirds of that required with the ordinary apparatus alone.

A further advantage obtained is the economy of space. When the daguerreotype instrument is used without the accelerator, the artist, if he wish to obtain actinic rays of less divergence (which is often the case), must remove from the object. In removing further, he must use (in most cases) a large instrument. Such inconvenience is avoided by means of the accelerator; for when this is stated to be applied, the rays can be at once refracted into the right course, whereby the increase of distance and the change of instrument are avoided; the accelerator therefore favours not only the economy of space, but also the economy of means, the use of the larger instrument being in this case obviated. This will appear to be still further the case, when we consider that by 
applying accelerators of different foci, we can produce portraits or views of proportional magnitudes; so that from one daguerreotype instrument both large and small plates can be produced.

Another advantage of the accelerator is, that it prevents that distortion of the image often observable in photographic portraits. Without the application of the accelerator, the image produced is of such a size that any exaggeration of the relative magnitude due to the superior forwardness of any part of the object, is magnified to an inconvenient extent. The image produced by the accelerator is reduced in size, and this exaggeration is reduced in equal degree, so that it appears free from all distortion; by this means, the ingenious but troublesome contrivances hitherto adopted to avoid this source of annoyance are superseded.

\section{BIEFANG, CHRISTIAN, Vol. 3, p. 1086, Zollverein-Prussia.- Electoral Hesse.-Lippe. \\ 661 BIEFANG, CHRISTIAN, Duisburg-Manufacturer.}

Paste and pasteboard articles.

Various frames for daguerreotypes and pictures, in velvet, bronze, and marble.

One étuis.

Lithographs in plain colours.

\section{BINGHAM, ROBERT JAMES, Vol. 1, p. 442, United Kingdom, Class 10 \\ 302 BINGHAM, ROBERT JAMES—Producer. Photographs, from paper negatives.}

\section{Reports by the Juries, p. 606}

BINGHAM (Class X, No. 302) is an exhibitor of talbotype pictures, landscapes chiefly. Being near objects, such as cottages, trees, \&c., there is no room for aërial perspective. They are very cleanly executed.

\section{BLANQUART-EVRARD, Vol. 3, p. 1251, France 1551 BLANQUART, EVRARD, Lille (Nord). \\ A frame containing photographs of various objects.}

[The photographs here exhibited are shown as illustrations of a new and rapid process of obtaining proofs from photographic negatives. A considerable time is generally necessary in taking a print from a negative, in order to give depth and definition to it. In the present instance, the proofs were obtained in one minute at the utmost, by a new process, the particulars of which are not given. By this process, the inventor states, it is possible to obtain three hundred proofs in one day, even in winter.-R.E.] 


\section{Reports by the Juries, p. 594}

One of the exhibitors of photographs, M. EVERARD BLANQUART, proposed the use of a white chamber, for accelerating the process; but there are serious objections to its adoptions, and therefore it is not used.

The object-glasses exhibited are, for the most part, achromatic and double, and consist of two lenses placed at a distance from each other. A photographic object-glass without defect is yet a desideratum.

Reports by the Juries, p. 599

This branch of the art offers inestimable advantages, viz.: $1^{\text {st }}$, That the papers may be prepared at leisure, some time before an occasion for using them arrives; 2ndly, That when pressed and fixed, they may be carried without injury in a portfolio, like other drawings; 3rdly, That from one good negative original, any number of positive copies may be taken, to the extent, indeed, of two or three hundred copies in a rainy day, as proved by the practice of M. EVERARD BLANQUART (France, No. 1551), and supplied to the public at a cheap rate; 4thly, That they may be wholly obliterated so as to reduce them apparently to the original condition of white paper, and carried about in that state for an indefinite period, though susceptible to revival at any instant.

Reports by the Juries, p. 607

BLANQUART, EVRARD (France, No. 1551) has exhibited several talbotype pictures, the positive proofs being obtained by a process which admits of 200 or 300 impressions being taken from the same negative proof; the price varying from five to fifteen centimes, according to the size. These are not wholly successful; several of the pictures are dark and blotty, and somewhat resemble engravings taken from a worn-out plate.

\section{BRADY, M. B., Vol. 3, p. 1441, United States, received Prize Medal} 137 BRADY, M. B., New York.

Daguerreotypes: likenesses of illustrious Americans.

\section{Reports by the Juries, p. 602}

BRADY (United States, No. 137) has exhibited forty-eight daguerreotypes, uncoloured. These are excellent for beauty of execution. The portraits stand forward in bold relief, upon a plain background. The artist having placed reliance upon his knowledge of photographic science, has neglected to avail himself of the resources of art. The portraits of General Taylor, Calhoun, General Cass, and James Perry, are strikingly excellent; but all are so good that selection is almost impossible. The Jury awarded the Prize Medal to Mr. Brady.

\section{BRAINARD, C. H., Vol. 3, p. 1470, United States} 599 BRAINARD, C. H., New York.

Daguerreotypes of the President and Cabinet of the United States. 


\section{BREWSTER, See DUBOSCQ-SOLEIL, France, no. 1197, 35 Rue de l'Odéon, Paris-Optician. Brewster's stereoscope}

BROOK, CHARLES, Vol. 1, p. 422, United Kingdom, Class 10 144 BROOK, CHARLES, 29 Keppel Street_-Inventor and Designer.

Photographic self-registering magnetic, and meteorological apparatus.

The object of this apparatus is to obtain a more perfect knowledge of magnetic and meteorological phenomena, by continuous observation of all the changes that occur simultaneously in the various instruments. As the magnetic changes are too minute to actuate continuously any mechanisms, however delicate, a record can be obtained by an imponderable agent only, as light.

Even with a staff of assistants so large that the eye of one of them should be constantly applied to every telescope, the results would be liable to errors of observation; besides which, the magnetic changes occasionally occur too rapidly to be continuously recorded by an observer. Since the apparatus has been employed at the Royal Observatory, Greenwich, the number of the staff has been reduced, and the fatiguing process of nocturnal observations in the magnetic department has been entirely superseded. (cont.)

[The skillful application of photography, by Mr. Brooke, to register natural phenomena, with no more labour than that of supplying the cylinder punctually with prepared paper, is one of the most useful and beautiful uses to which photography has yet been applied. The paper is prepared so as to render it extremely sensitive to light, being first washed with a solution of isinglass, bromide of potassium, and iodide of potassium, in the proportion of 1,3 , and 2, respectively; and when required for use, it is washed with an aqueous solution of nitrate of silver, which causes the paper to be sufficiently sensitive to the action of light, so that if a beam of light be allowed to fall upon it, an impression is made upon that part where the light falls, which becomes visible on being washed with a solution of gallic acid, with a small admixture of acetic acid. A light is placed near a small aperture, through which rays pass and fall upon a concave mirror carried by a part of the suspension apparatus of the magnet, and this reflection falls upon a planocylindrical lens of glass placed at the distance of its focal length from the paper on the cylinder. As the magnet is ever varying, and making small excursions on one or other side of its mean position, the point of light traces a corresponding zigzag line on the paper. (cont.)

\section{Reports by the Juries, p. 522, introduction}

Another illustration is afforded by the self-registering apparatus of Mr. Brooke, in which nature is made to perform the operations of a corps of observers, by an application of what must be considered a few only of the first principles of photography. That its application is causing instruments which are continuous and delicate in their action, to register their own work, must be attended with advantages-is evident to every reflecting mind; and points to some of the further advantages science is likely to derive from the ultimate perfection of the photographic processes. 
Reports by the Juries, p. $\mathbf{6 1 0}$

BROOKE (No. 144) exhibits photographic apparatus for the self-registration of the changes in position of the declination magnet of the horizontal-force magnet, and the vertical-force magnet.

The three magnets are so placed that the residual effect of each pair upon the third is a minimum, which is to be determined by experiment.

The principle is the same for all, viz, wrapping prepared photographic paper around a cylinder whose axis is placed parallel to the direction of movement to be registered, and which is turned round uniformly by clockwork.

The light, from a gas lamp, passes through a small aperture placed near it, and falls upon a concave mirror of speculum metal, which rests in a stirrup firmly connected to the magnet, so that it partakes of all the angular movements of the magnet. The pencil of light is then deflected from the mirror to a plano-convex lens, placed parallel to the axis of the cylinder and near to it: this lens condenses the line of light to a definite spot of light on the paper. This spot of light, therefore, moves with the movements to be registered, to the right and left, in a horizontal plane, in the case of the delineation magnet and horizontal magnet; and up and down, in a vertical plane, to register the movement of the vertical-force magnet, the cylinder, as before stated, being turned around by clockwork. Consequently, there is traced upon the paper a curve, of which the abscissa, measured in the direction of a line round the cylinder, is proportional to the time, while the ordinate, measured in the direction of the axis of the cylinder, is proportional to the movement of the magnet. (cont.)

\section{BUCKLE, SAMUEL, Vol. 2, p. 840, United Kingdom, Class 30, received Council Medal} 301, BUCKLE, SAMUEL, Peterborough-Producer.

A series of pictures from nature, taken by Talbot's photographic process called calotype.

The subjects are in Peterborough and its neighborhood, and are at Bury St. Edmund's. Printed from paper negatives. (Main Avenue West.)

[A paper negative is the picture impressed in the camera. It is so called because the lights and shadows are all reversed in it, that which is shaded in nature being represented in the photograph by light parts, and the reverse. By laying the negative upon a paper covered with chloride of silver, and exposing to sunshine, a correct picture is obtained on the latter. This is called "printing" in the language of photography.-R.E.]

\section{Reports by the Juries, p. 524}

This admirable system is, we believe, entirely due to Messrs. Ross and Thomson, whose collection of Talbotypes amply attests the superiority of their method; and indeed, as in the case of Mr. BUCKLE of M. MARTEN, or of any highly-successful photographist, it is but fair to infer that the superiority observable in their productions is due to their improvement of the processes which they have adopted. 
Reports by the Juries, p. 604

BUCKLE (Class XXX., No. 301), of Peterborough, has exhibited a great many calotype pictures, all of which are characterized by a great delicacy of tint and exquisite cleanness of execution, and deserve to be ranked amongst the finest specimens of photography in the Exhibition. The process adopted by Mr. Buckle, he has described at some length; it is not subjoined here for want of sufficient space, but the beauty of Mr. Buckle's calotypes sufficiently testify to the superiority of his method. He observes that, with regard to the adjustment of the focus, no rule can be laid down; but, having himself a knowledge of art, practical as well as theoretical, he applies it to the arrangement of the subject and to deciding on that point of the picture best calculated to be in focus. The size of the aperture of the lens, as also the time of exposure, are so much matters to be decided on at the time of taking the picture, as to render the laying down of a rule next to impossible. The paper employed, Mr. Buckle observes, is made by Mr. Turner, of Chafford Mills, and is, he considers, unequalled. He does not employ the albuminous process. A Council Medal was awarded to Mr. Buckle.

\section{BURON,-, Vol. 3, p. 1199, France]}

443 BURON, -, 8 Rue des Trois Pavillous, Paris-Manufacturer.

Optical and mathematical instruments; telescopes, of various shapes and sizes; telegraphic and marine telescope, astronomical telescopes, of various novel and improved constructions; opera glasses, plain, double, and cylindrical; geodesical and nautical instruments; microscopes and achromatic lenses, mounted for Daguerreotypes, of different sizes.

Reports by the Jury, p. 597

BURON (France, No. 443) has exhibited a collection of glasses of 6, 8, 10, and 12 inches diameter for dissolving views.

\section{Reports by the Jury, p. 541}

BURON (France, No. 443) has exhibited various sextants and octants in ebony and brass, furnished with coloured glasses to the number of five or seven, and with both direct and inverting telescopes. The sextants are divided to 10', and sub-divided by verniers to 10". The size and the construction of these instruments are in every respect like those made in England. Their divisions are good and their price is low.

\section{C}

CHANCE BROTHERS \& CO., Vol. 2, Class 24, p. 700, 701, United Kingdom

22 CHANCE BROTHERS \& CO., Glass Works, near Birmingham-Manufacturers.

...Optical glass:-Flint and crown glass in discs of various sizes; and plates, for the use of opticians; and thin glass used for the polarization of light. 
Reports by the Juries, p. 597

Messrs. CHANCE and Co. (Class XXIV, No. 22) have exhibited flint glass, in discs and in plates, adapted for the construction of object-glasses for Daguerreotype apparatus and cameras. Of these discs one is as large as 20 inches in diameter, and there are some thin plates of the same kind of glass for cutting up.

The density of this glass is $3^{\prime} 20$; the index of the refractive power is $1^{\prime} 60$.

\section{CHEVALIER, CHARLES, Vol. 3, p. 1259, France} 1729 CHEVALIER, CHARLES, 158 Palais National, Paris-Optician.

Magnifying glasses; improved camera lucida; photographic apparatus, with compound glasses; magnifying opera glasses; improved telescopes, photographic impressions.

Reports by the Juries, p. 607

CHEVALIER (France, No. 1729) exhibits some photographic proofs.

\section{CLAUDET, ANTOINE FRANÇOIS JEAN, Vol. 1, pp. 440-441, United Kingdom} 296 CLAUDET, ANTOINE FRANÇOIS JEAN, 18 King William Street, Charing CrossInventor.

Multiplying camera-obscura, to represent on the same surface a number of different pictures, or the same surface in various aspects, the portraits of several persons, \&c. The novelty consists in moving the prepared plate by means of racks and pinions in a vertical and horizontal direction, thus making several parts of the surface pass alternatively before an opening placed at the focus of the lens. A sculptor being supplied with seven different aspects of the features of the same person, is enabled, without seeing that person, to make a perfect bust or model.

Photographometer, to measure the intensity of the direct photogenic rays, and to compare the sensitiveness of various photographic preparations.

[It is of the utmost importance in practice to know, at all times, the amount of chemical agency (actinism) which may be associated with the light of the sun, as they bear no direct relation to each other; the light may be intense and the chemical power very deficient, or the contrary: hence the value to the daguerreotypist of an instrument of this kind.-R.H.]

Dynactimometer, to measure the intensity of the reflected photogenic radiation, and to compare the power of lens or object-glasses.

[Lenses vary very considerably in their powers of transmitting radiations; the difference arising from the molecular condition of the glass itself, which varies, and also from very slight deviations from the true curve, which in the delicate operation of grinding it is exceedingly difficult to avoid.-R.H.] 
Focimeter. It is impossible to obtain well-defined photographic pictures without previously ascertaining the exact position of the photogenic focus, which is easily done by taking the image of the focimeter on a photographic surface, and comparing the segments of the apparatus with the image, then on the ground glass and the photographic surface.

[Mr. Towson first observed that the focus of the chemical rays was not identical with the luminous focus; that the best photographic picture was always produced at a short distance nearer the lens, than the point at which the most perfect visible image is produced: M. Claudet has shown that this applies equally to achromatic lenses as to non-achromatic lenses; and this instrument is for the purpose of determining the chemical focus with facility.-R.H.]

Screens, to modify the action of lights on the various parts of the figure in taking portraits, and thus obtain artistic effects.

Patent photographic camera-obscura. The novelty consists in its being possible to adapt to it with the greatest facility any system of object-glasses, to change them at will according to the power wanted, and also to use plates of any size; each having a separate moving frame, in which the ground glass and plate fit the same groove. Without the least alteration it will serve for silver plates or paper, and answer for views or portraits.

[The photographic camera is a modified form of the camera obscura, invented by Baptista Porta, the principle in both cases being the same, the arrangements only being modified to allow of the easy introduction of the daguerreotype plate or photographic paper. The principle is often popularly studied by simply making a hole in the window shutter of a dark room and examining the images of external objects on a sheet of paper at a certain distance from it.-R.H.]

Dark boxes, for containing the prepared plates, and carrying them to and from the camera-obscura.

Brass frames, to hold two plates, face to face without contact.

Mercury box. The novelty is that a number of plates of various sizes may be mercurialized at once, in a vertical position, and that the heat is applied by the uniform temperature of boiling water.

Apparatus for cleaning and finishing a daguerreotype plate, without burning the oil which has been used for polishing, and without applying cotton wool, spirit of wine, or any powder.

Bromide of iodine. lodine and bromine combined in proportions found to afford means giving the plate the highest state of sensitiveness.

[In preparing a daguerreotype plate, it is essential that the agent employed to act chemically on the polished silver surface should be in such a condition, that the affinity may be easily upset by solar agency. This is peculiarly the case with compounds of bromine, iodine, and chlorine. The balance of action is very easily disturbed, and hence the extreme sensibility of plates prepared with these compounds.- R.H 
Daguerreotype pictures, plain and coloured. Representations of objects of art, scientific experiments on the effect of the various rays, illustrations of the noncoincidence of the visual and photogenic foci, portraits from nature, taken by means of a prism placed before the object-glass, in order to obtain an non-inverted picture.

[The effects shown in these experiments illustrate the influences exerted by various media, natural and artificial, upon the solar rays. In some examples, the luminous rays are shown to act as protecting the plates from change, and in others the energetic power of the chemical rays (actinism) is separated to a great extent from the luminous rays (light). The general result is to prove that the radiations which give rise to photographic phenomena, although associated with light and heat in the sunbeams, are not identical with it in their action on material bodies. - R.H.]

Photographic table; showing that photographic productions may be employed in various ways, as in the ornament part of drawing-room furniture.

Daguerreotype plates, perfectly plain and free from specks, forming true mirrors.

[Daguerreotype plates are of copper, plated with silver; by placing two pieces of these metals in contact with very clean surfaces, and thus passing them through steel rollers, they are pressed so closely together that the full action of cohesive force is exerted between their particles, and they adhere with great firmness. The silver is subsequently polished, and by nice manipulation prepared for the use of the daguerreotype artist.R.H.]

Photogenic paradox, showing that what is light for the eyes is darkness for the photogenic action; a frame containing, on one half, the portrait of the Queen, covered with yellow glass, and on the other half the portrait of Prince Albert, covered with deep blue glass, being represented on a daguerreotype plate. The result is that the yellow glass, although showing clearly to the eyes the picture of Her Majesty, has prevented the photogenic action, and the deep blue glass, although completely hiding the portrait of Prince Albert, the photogenic rays reflected by his picture through the blue glass have had the same action on the daguerreotype as if the engraving had been covered with transparent glass, or with no glass at all. This experiment proves why when light appears yellow on account of vapours existing in the atmosphere, the photogenic action is always so feeble and altogether impeded.

Frame containing six specimens.

(1) Light of a candle represented on a daguerreotype plate.

(2) Image of a statue produced by the continued action of light on a daguerreotype plate, without any mercury; the white forming the image is due to a fine precipitate of the silver combined with iodine, taking place under the action of light during the decomposition of the compound.

(3) Negative portrait produced on a plate first exposed to light, and in that state having received the image of the camera obscura through yellow glass; this proves the destructive action of the yellow rays in the photographic operation, 
and that the yellow rays are not only antagonistic to the photogenic rays, but that they destroy the effect produced by the last.

(4) Image of the sun produced during a clear atmosphere.

(5) Image of the sun when it appears red through a fog.

(6) Image of the moon produced during a clear night.

Frame containing four specimens-

(1) Image of the solar spectrum on iodide of silver.

(2) Image of the solar spectrum on bromo iodine of silver.

(3) Experiment of the focimeter, showing the difference between the visual focus and photogenic focus and their variation.

(4) Experiment of the dynactiometer, showing the intensity of the photogenic light at any given moment, for the various spaces of time in a geometrical progression. It is curious to observe the small differences produced by a double intensity.

Image of clouds, taken instantaneously during boisterous weather. Interesting study for artists.

Frame containing the various colours of water colour, and another the daguerreotype representation of the first. This experiment shows that all the tints of blue, indigo, and violet produce white in photography, and that all the tints of green, yellow, orange, and red, produce black, or rather that they have no photogenic action.

\section{Reports by the Juries, p. 523}

On turning to the photography exhibited by the United Kingdom, we find CLAUDET (296, p. 440) leading the way, and adding to the many improvements introduced by him into the various processes of the art by presenting the image direct instead of inverted: this is the distinguishing feature of his collection, and is the result of patient and untiring research in that class of investigation peculiar to himself.

\section{Reports by the Juries, p. 595}

CLAUDET (No. 296) has exhibited cameras: the largest has an aperture of 3 inches in diameter; double achromatic object-glass; when the whole aperture is open, about onethird of the breadth of the lens is cut off on either side, so that only about one-third of the breadth of the picture receives full light from the lens, and the illumination is in consequence very unequal. The image is good and the field is flat. In Claudet's multiplying camera the multiplying is performed by cross-sliding motions of the picture-plate, performed by two racks, working at right angles to each other, so as to present different parts of the picture-plate successively to the axis of the lens, exactness being secured by the division of the racks into inches and tenths of inches. The camera is short-focussed, to give small miniature portraits, either the same individual in different aspects, or several

\section{p. 596}

grouped together. The object-glass is double achromatic: its aperture is 3 inches, separated by 6 inches on a slide-rack to work in and out of the box: there are no diaphragms interposed. The front of the box carrying the object-glass opens with a 
hinge. The tube projects one-eighth of an inch in front outside of the object-glass, to cut off stray light. The focus is very short, having about 5 inches, extensible to about 8 inches by approach, within limits of motion. By focus is meant the distance of the picture-frame from the hinder surface of the hinder lens.

\section{Reports by the Juries, p. 598}

It is not the object of this report to trace the history of inventions, nor to decide on claims of priority, especially in relation to a subject which has received accessions from such innumerable quarters, and called into action the skill of so many eminent chemists and photologists of every nation. Suffice it to say, that after the introduction of M. Claudet's accelerating process by the by the application of chloride of iodine and chloride of bromine (an invention which he liberally gave to the public through the medium of the Royal Society and the Académie des Sciences); the daguerreotype process, as publically practised, became reduced to some system, and two Daguerreotype establishments were formed in London. The portraits taken at this time were, however, deficient in expression; but in spite of all deficiencies, the receipts of these establishments several times amounted to $60 \mathrm{l}$. in one day.

\section{Reports by the Juries, p. 599}

M. Claudet, who, from the earliest time of the daguerrian invention, displayed great genius and ability in perfecting the various processes, first perceived the necessity of aiding the artistic effect of his representations by subsidiary adjuncts of a different kind. $\mathrm{He}$ it was who first practiced the placing of painted back-grounds behind the persons whose portraits were to be taken. Thus an infinite variety of scene might be afforded by the operator simply providing himself with a few subjects skillfully adapted to the requirements of the occasion. To him also we owe that extremely pleasing adaptation of mechanical adjustments for bringing many miniature representations of the same individual under different aspects, to be impressed in regular compartments of the same plate and framed together, of which we find specimens exhibited in his collection.

It is not necessary to detail step by step the successive improvements in the different processes and apparatus for daguerreotypic photography, though we may mention that to the exertions of Messrs. Claudet, Gaudin, Fizeau, and Draper, the public are indebted for many improvements. To M. Fizeau is due the reproduction of the proofs of electrotype; also a new process for engraving the Daguerrian image, and of preserving that image from destruction by gilding the surface.

\section{Reports by the Juries, p. 600}

CLAUDET (No. 296) has exhibited a large collection of daguerreotype portraits, both plain and coloured. Amongst various excellences of which they are possessed, we may particularly mention that of their non-inverting. This is a great improvement, and by it M. Claudet has annulled the superiority which the sun-pictures have so long possessed, in this particular, over the daguerreotypes.

On examining the uncoloured specimens exhibited by Claudet, it will be found that they are distinguished by artistic arrangement, judicious distribution of light and shade, and great clearness of definition. The general tone is good, M. Claudet having uniformly avoided violent contrasts of light and shade; a circumstance to which much of his success can be attributed. In this collection are several female portraits in white 
draperies which pictures deserve commendation for their beauty of detail and freedom of solarization. Many of the above remarks apply equally to the coloured specimens, most of which are portraits, and are distinguished by careful harmonious colouring, the focus having been so judiciously selected, and most of them present an artistic and natural appearance, seldom hitherto obtained by daguerreotypists.

Photography may be said to be too faithfully exact in its results, for the purposes of art, detailing as it does the accessories in the back ground and the main object of the group with equal fidelity. When blending colour with photographic works, or in visibly uniting art and science on the same plate, the operator should be possessed of knowledge and feeling sufficient to know the proportions in which art and science should intermingle so as to be subservient to each other: in this knowledge, which is chiefly dependent upon the proper focal adjustments of the picture, M. Claudet excels; and the admirable manner in which he sacrifices the details afforded him by science to the requirements of his subject is the result of long and laborious investigation.

An uncoloured daguerreotype by Claudet is worthy of particular mention; it represents various articles of vertu, pictures, \&c., grouped together: the perfect focus of each part and general relief of the whole prove to be a successful application of his focimeter.

M. Claudet also exhibits the dynactimometer* and focimeter. He also exhibits the effects of the spectrum on the daguerreotype plate, as prepared by him, and a variety of curious and instructive specimens illustrative of the different refrangible rays. The Council Medal was awarded to M. Claudet.

*The reader is referred for an account of the dynactimometer to the "Reports by the British Association," August 1850, and to the "Philosophical Magazine," June 1851, and for the focimeter, to the "British Association Reports," September 1849, and "Philosophical Magazine," November 1849.

\section{COLLIE WILLIAM, Vol. 2, p. 941, British Possessions in Europe. Channel Islands.- Mediterranean Jersey and Guernsey}

22 COLLIE WILLIAM, Belmont House, St. Helier, Jersey—Producer. Calotype pictures from life-_French and Jersey Market-women."

[Preceding notes, in Classes of the United Kingdom, have explained the use of this term calotype-originally a derivative from the Greek. It is now generally superseded by that of Talbotype, implying the name of the inventor of the art of photography on paper. The peculiar brilliancy of the atmosphere of these islands, combined with the abundance of blue light reflected by the sea, was found by the writer to communicate an almost instantaneous impression to paper or plates.-R.E.]

\section{Reports by the Juries, p. 606}

COLLIE (No. 22), of Jersey, has exhibited a frame, containing several calotype pictures, chiefly portraits and domestic scenes. These are not all equally good; many of them are blotty and wanting in depth. 
COLLS, R. \& L., Vol. 1, p. 442, United Kingdom, Class 10

303 COLLS, R. \& L., 168 New Bond Street-Producers.

Sun pictures, on paper.

[The art of producing pictures by the aid of sunlight commonly called photography, is due, so far as the processes on paper are concerned, to Mr. Fox Talbot. Other methods of obtaining photographic pictures on paper, equally expeditiously, are known; but the principles embodied in Mr. Talbot's patent are those which in actual practice produce the finest and best pictures.-R.E.]

Reports by the Juries, p. 605

COLLS, R. and L. (No. 303) have exhibited several sun-pictures on paper. They are rather blotty in appearance, but are good in colour. Views of Windsor Castle and Stoke Church deserve high commendation.

CONSTABLE, Brighton - See 732 BADCOCK, JOHN, BrightonProducer. Vol. 1, p. 475*, United Kingdom, Class 10

\section{COUSIN, Vol. 3, p. 1252, France}

1572 COUSIN,-, 30 Grande Rue Verte, Paris.

Specimens of lithographic drawings on paper.

Reports by the Juries, p. 607

COUSIN (France, No. 1572) exhibits a series of positive talbotypes, from negatives on paper, in all seven subjects, six of which are of exquisite beauty.

CRADDOCK, THOMAS, Vol. 2, p. 834, United Kingdom, Class 30 227 CRADDOCK, THOMAS, Wisbech-Producer.

View of Peterborough Cathedral from the east; the west front from the market place. Gates entering the Precincts, Peterborough. Porch entrance to Peterborough Cathedral. New iron bridge of the Great Northern Railway, and wooden bridge over the Nare, Peterborough.

Photographic copy of Holloway's print of Raphael's Elymas. Cloisters, Peterborough Cathedral.

Photographic copy of Vandyke's "St. Ambrose refusing Theodosius admittance into the church."

Reports by the Juries, p. 601

Of the remaining exhibitors in England...CRADDOCK (No. 227), photographic copies of various engravings. 


\section{D}

\section{DUBOSCQ-SOLEIL, Vol. 3, p. 1235, France}

1197 DUBOSCQ-SOLEIL, -, 35 Rue de l'Odéon, Paris-Optician.

Optical apparatus and instruments of all kinds; solar light conductor, consisting of a mirror with two glasses, the one of plated glass for reflection, the other blackened glass for polarization. Large photogenic apparatus for supplying sun-light, and by the help of a lamp only, to practise experiments in optics. Apparatus for regulating electric light. Large apparatus of rotary polarization for liquids and solids. Saccharometer or apparatus for determining the nature and the quantity of sugar contained in any sacchariferous liquid. Arago's polariscope for rendering conspicuous the smallest vestiges of polarized light. Mr. Jamin's apparatus for investigating the laws of polarization. Brewster's stereoscope, Apparatus for the hyperbole of compensation. Fresnel's press. Apparatus of Norremberg, the most convenient practical polarizing apparatus. Cyano-polarimeter of Arago for measuring the intensity of the polarization, and the blue colour of the sky. Arago's sciepelescope, by means of which a person can distinguish by polarized light the rocks hidden beneath the water.

\section{Reports by the Juries, Physical Optics, p. 589-591}

...Duboscq-Soleil, besides these, exhibits a very great variety of delicately-constructed philosophical instruments, for exhibiting the phenomena of polarized light and other physical experiments; such as a cyano-polarimeter, for observing the polarization of the sky; Arago's apparatus for exhibiting the interference of polarized light; Fresnel's screw for polarizing glass by compression; Babinet's goniometer; Brewster's stereoscope, \&c. M. Duboscq-Soleil also exhibits an apparatus, invented by himself, for fixing the charcoal points for electric light.

A Council Medal was awarded to M. Duboscq-Soleil.

E

EVANS, O. B., Vol. 3, p. 1440, United States

105 EVANS, O. B., Buffalo, New York.

Specimens of daguerreotyping.

Reports by the Juries, p. 602

EVANS, New York (United States, No. 105), has exhibited several portraits of great merit. Those of the Rev. - Ingersoll, Dr. Nott, Dr. Lord, and Dr. Shelton, are characterized by peculiar excellence; also two portraits, each of a lady sitting near a table upon which a group of flowers is displayed, deserve to be noticed as fair specimens of the perfection to which this application of science, to the purpose of art, has been carried. 
FIELD, ROBERT, \& SON, Vol. 1, p. 435, United Kingdom, Class 10 250 FIELD, ROBERT, \& SON, 113 New Street, Birmingham-Manufacturers.

Large and small achromatic microscopes, with moveable stage.

Dissecting microscope, with Wollaston's doublets.

Calotype pictures; scene: Forest of Arden, Warwickshire; staircase, Haddon Hall, Derbyshire; and Wych Elm, Packington churchyard, Warwickshire.

[The calotype picture is a negative one, in which the lights of nature are represented by shades; but copies from them can readily be made in which the lights are conformable to nature.-J.G.]

Reports by the Juries, p. 606

FIELD and SON (No. 250) have exhibited calotypes.

FLACHERON-HAYARD, Vol. 3, p. 1220, France, received Prize Medal 836 FLACHERON-HAYARD, Place d'Espagne, Bonne-Designer; and at M.

DURAN'S, 17 Rue de Lille, Paris, Architect.

Seven views of Rome; and album, with various other views.

Reports by the Juries, p. 606

FLACHERON-HAYARD (France, No. 836) has exhibited several sun-pictures of ruins in Spain, Rome, and Paris. These are all excellent; the colour is good, and the artistic effect admirable. They appear to be possessed of nearly equal merit. The "Arch of Titus" deserves special mention for the perfectly artistic expression of the whole, combined with a singularly accurate representation of the superficial texture of the material. A Prize Medal was awarded to M. Flacheron.

\section{FOUNTAIN \& PORTER, Vol. 3, p. 1468, United States}

550 FOUNTAIN \& PORTER, Cincinnati, Ohio.

Daguerreotype of the city.

Reports by the Juries, p. 603

A daguerreotype view of Cincinnati, by FONTYNE and PORTER (United States, No. 550 ), is more successful. This is also taken in separate compartments: it is clear and good in colour, and forms an effective picture. 


\section{G}

GAVIT, D. E., Vol. 3, p. 1441, United States 125 GAVIT, D. E., New York.

Daguerreotypes.

Reports by the Juries, p. 603

GAVIT (United State, No. 125), ROOT (United States, No. 42), WHITEHURST (United States, No. 525), and HOGG (United States), all of whom have exhibited daguerreotypes, but not distinguished by any striking degree of excellence.

GOUIN, A. Vol. 3, p. 1188, France

241 GOUIN, A. 37 Rue Louis-le-Grand, Paris-Painter.

Coloured daguerreotypes, exhibited for novelty and beauty of colouring, and similarity to miniature painting.

Reports by the Juries, p. 604

GOUIN (France, No. 241), exhibits a series of coloured daguerreotypes, which, however, want brilliancy and purity of colour; the backgrounds are also out of focus. An uncoloured portrait, $7 \frac{1}{2}$ in. by 6 , does better justice to the powers of this exhibitor.

GRIFFITHS \& LE BEAU, Vol. 1, p. 453, United Kingdom, Class 10 404 GRIFFITHS \& LE BEAU, 15 Coborn Road, Mile End-Producer.

Daguerreotype portraits and pictures, with electrotype copies taken from them.

[The daguerreotype picture being produced by a film of mercury upon a silvered plate, there is necessarily an irregularity over its surface. If a plate thus prepared is connected with a galvanic battery, and placed in a solution of sulphate of copper, the copper precipitated on the surface receives a most delicate impression of the daguerreotype image. In addition to the differences produced by the varying thickness of the mercurial film, there is not unfrequently a slight difference in the colour of the copper deposited over those parts thickly coated with mercury, and those over which the silver is exposed.-R.H.]

Reports by the Juries, p. 601

Of the remaining exhibitors in England,-GRIFFITHS and LEBEAU (No. 404) have exhibited a case of daguerreotype miniatures, coloured. 


\section{H}

HARMER, H. R., Vol. 2, p. 839, United Kingdom, Class 30

298 HARMER, H. R., Greater Yarmouth-Producer.

Four "sun" pictures of various subjects.

[It may be almost regretted that the term "sun painting" has not been substituted for that of photography or light-painting. Many phenomena appear to indicate the existence of at least three distinct principles, or modifications of one principle, in the solar ray-light, heat, and actinism; and those effects upon substances sensitive to impression, by which pictures are produced, are apparently produced principally by the actinic, and not by the luminous or calorific rays. Photographic pictures, therefore, whether on plate, paper, glass, or porcelain, are most properly described as light-drawn.-R.E.]

\section{Reports by the Juries, p. 605}

HARMER (Class XXX, No. 298) has exhibited two calotype pictures, one a landscape: the reflections as shown on the water are excellent. The fluctuation of the reflections caused by the ripple of water is very beautiful, and true to nature. The execution of the picture is good, and the tints are clear and delicate.

\section{HARRISON, C.C., Vol. 3, p. 1450, United States} 223 HARRISON, C.C., New York.

Specimens of daguerreotypes, exhibited for sharpness of outline, distinctness, and delicacy of shading. The camera obscuras with which they were taken accompany them. These instruments are exhibited both for their construction, and for the perfect manufacture of their achromatic glasses.

[The accuracy of manipulation in working an achromatic lens is readily tested by the resulting daguerreotype obtained from its employment. A slight departure from the true curve will render the picture ill-defined and imperfect. In order to test the developing and defining powers of a daguerreotype lens, which is most frequently a double achromatic of various diameters, such objects as the human head, or the fur of an animal, or an extremely minutely printed page, are daguerreotyped, and the result pretty accurately indicates the capabilities of the instrument.-R.E.]

\section{Reports by the Juries, p. 597}

HARRISON (United States, No. 223) has exhibited two or three cameras, but they are not mounted in boxes, and consist only of the brass-work and lenses, there were no means of trying their performance. They are constructed on the usual principle of double achromatic object-glasses, to give a flat field. The largest is about 4 inches aperture. 
Reports by the Juries, p. 603

HARRISON (United States, No. 223), has also some daguerreotypes of a very superior description.

\section{HENNEMAN \& MALONE, Vol. 1, pp. 441, 442, United Kingdom, Class 10, received Prize Medal} 297 HENNEMAN \& MALONE, 122 Regent Street, Westminster-Designers.

1. Talbotype apparatus of improved design, made by J. Newman, of 122 Regent Street.

2. Talbotype pictures produced on paper, silk, \& other fabrics; and on porcelain, coated glass, stone, steel, wood, and ivory.

3. Talbotypes treated with caustic potash and a lead salt, in order to produce an agreeable tint of colour, and to render more secure fixation.

4. Specimens of Sir J. Herschel's cyanotype and chrysotype, and of Mr. Robert Hunt's chromatype pictures.

[Talbotype is the name applied, in the first instance, by Sir David Brewster, to the calotype pictures, his object being to distinguish by the name the discoverer a photographic process which is little, if anything, inferior to the daguerreotype of the French. Paper being covered with a pure iodide of silver, is rendered sensitive to luminous radiations by being washed over with a mixture of gallic acid and nitrate of silver; and after the paper is taken from the camera, a dormant picture being produced upon it, it is developed by a second application of gallic acid.

Sir John Hershel's cyanotype and chrysotype processes admit of many modifications, the former consisting of the change of a persalt of iron into a protosalt by the solar rays; the paper being then washed with a compound of cyanogen (hence its name), the picture is represented in Prussian blue.

The latter is in most respects similar, only that a solution of gold is applied to the altered iron slat, and oxide of gold is formed in the place of Prussian blue.

The chromatype is formed by washing paper with a mixture of the bichromate of potash and sulphate of copper; and after the picture has been faintly developed by the chemical principle of the solar beam, it is washed with nitrate of silver, by which a positive picture, or one with correct lights and shadows, is produced by one operation.R.H.]

\section{Reports by the Juries, p. 595}

HENNEMAN and MALONE (No. 297) exhibit a camera by Ross. It is furnished with a single object-glass, aperture $4 \frac{1}{2}$ inches: the light is admitted through apertures O'2 in., O'4 in., O'8 in. diameter, at about $4 \frac{1}{2}$ inches, or at about one diameter of the lens from its surface, the combination being mounted on a brass cone attached to a mahogany plate, which slides and revolves on the front of the box, to allow any given point of the picture-plate to become the center of the field. The picture-board is $81 / 2$ by 10 inches; the focus varies from 10 inches to 17 inches according to the distance. 
Reports by the Juries, p. 599

Mr. Talbot has, himself, exhibited nothing; but many of his productions will be recognized among those exhibited by HENNEMAN and MALONE, as adapted to the practical wants of travelers, collectors, \&c.

Reports by the Juries, p. 605

HENNEMAN and MALONE (No. 297) have exhibited talbotypes on paper, consisting of copies of small intaglios, portraits, both plain and coloured, and various small groups, \&c. These are all natural and pleasing, and great delicacy is observable in the lights and shades, the tone of which is a fine warm sepia brown. The greater part of these pictures are small portraits; one, however, which is 8 in. by $61 / 2$ in., is very good, and evenly illuminated. The colour portraits in this collection are very good, and no little credit is due to the artistic skill which they display.

Messrs. Henneman and Malone also exhibit specimens of the cyanotype and chrysotype processes of Sir J. Herschel, the chromotype of Mr. Hunt, and talbotypes tinted by the application of caustic potash and a lead salt. A Prize Medal was awarded by the Jury to Messrs. Henneman and Malone.

\section{HILL, DAVID OCTAVIUS, Vol. 2, p. 839, United Kingdom, Class 30, received Honorable Mention \\ 300 HILL, DAVID OCTAVIUS, Calton Hill Stairs, Edinburgh—Producer \& Designer.}

Calotype portraits, individuals, groups, \&c. Calotypes of fishermen and women of Newhaven, near Edinburgh. Produced by the exhibitor and the late R. Adamson.

[The calotype process consists essentially in spreading upon paper a uniform film of iodide of silver, and of exciting this by the action of a combination of gallic acid and nitrate of silver previously to its being placed in the camera obscura.-R.H.]

Reports by the Juries, p. 605

HILL and ADAMSON (Class XXX, No. 300) have exhibited very many talbotype groups, remarkable for easy and graceful arrangement. They are in effect after Rembrandt, being made out in broad and deep-toned masses of light and shade. As a whole, they are very sketchy and spirited. The tints are rich and varied both in depth and colour, and are of a rich sepia. They have received Honourable Mention from the Jury.

HOGG is mentioned in the Jury Reports, but is not listed in the Catalogue index, Reports by the Juries, p. 603

GAVIT (United State, No. 125), ROOT (United States, No. 42), WHITEHURST (United States, No. 525), and HOGG (United States), all of whom have exhibited daguerreotypes, but not distinguished by any striking degree of excellence. 


\section{HORNE, THORNTHWAITE, \& WOOD, Vol. 1, p. 434, United Kingdom,}

Class 10

220 HORNE, THORNTHWAITE, \& WOOD, 123 Newgate St.-Manufacturers.

Electro-galvanic machine and set of instruments, for medical galvanism. The current of galvanism produced by this machine "flows only in one direction," and the quantity and intensity of the current are capable of being easily regulated. Represented in the following cut:- (engraving inserted)

Apparatus for exhibiting dissolving views, chromatropes, \&c., by the oxyhydrogen lime light, with illustrative paintings and apparatus, showing the method of producing the light, the arrangement of the lenses, and contrivance for dissolving the pictures.

Oxyhydrogen microscope and apparatus, in case.

Daguerreotype apparatus, consisting of an adjusting back camera, with compound achromatic lens, an improved bromine and iodine box, with contrivance for transferring the prepared plate to the frame of the camera, mercury box, plate-box, chemical-chest, buffs, plate-holders, gilding stand, tripod, \&c. The parts of the apparatus are so arranged that the process may be entirely performed in the light, without necessity of a dark room.

Registered portable folding calotype camera, with achromatic lenses, for portraits and views, \&c.

Improved reversing frame, for producing positive pictures from calotype negatives and other photogenic processes.

Registered improved agricultural drainage-level. weights.

Balance galvanometer, for indicating the strength of galvanic currents in grain

"Optimeter," and instrument for ascertaining the existence of any defect in the refracting media of the eye, and for determining the range of adjustment for distances which it possesses.

Patent electric indicator, for fire and thieves.

Planning rule, comprising the chief scales required by architects and surveyors, with peculiar arrangement of the odd and even scales, and reading from the edges.

Chemico-mechanical voltaic battery.

Registering hygrometer.

Bust of Napoleon Bonaparte, from a model by Canova, executed by the electrotype process.

Similar bust of Sir Walter Scott, from a model by Chantrey.

Transparency, exhibiting the appearance of the lunar disc when in direct opposition to the sun, as seen through Herschel's 40 feet reflecting telescope.

\section{Reports by the Juries, p. 594}

HORNE, THORNTHWAITE, and WOOD (No. 220) exhibit a dissolving apparatus for the oxyhydrogen limelight, showing the contrivance for dissolving the pictures; also an oxyhydrogen microscope, and a series of paintings for dissolving views. The novelty of this arrangement consists in the shutters being placed so that they cut off the rays where they cross in front of the lenses, by which means a more perfect dissolution takes place. The quality of the manufacture and the general arrangement of the various parts are good. 
Reports by the Jury, p. 594

HORNE, THORNTHWAITE, and WOOD (No. 220) exhibit a camera with a double achromatic object-glass, whose aperture is about $2 \frac{1}{2}$ inches. The size of the picture is 8 by 7 inches. The frame allows of two papers being placed at one time. The box is made to fold together, and is a fine specimen of beautiful, neat, mahogany work, with many good contrivances to keep out light. There is no speciality in the construction of the daguerreotype and calotype apparatus of these exhibitors, excepting a mode of iodizing and bromizing the plates, by sliders of great neatness; the exquisite workmanship of their several articles; and the general arrangements for their use in daylight. Some very fine specimens of chemicals used in the process of photography are also exhibited. A prize medal was awarded to Messrs. Horne and Co.

\section{IMPERIAL COURT AND GOVERNMENT PRINTING OFFICE, Vol. 3, pp.} 1025, 1026, 1027 Austria-received Prize Medal

362 IMPERIAL COURT AND GOVERNMENT PRINTING OFFICE, Vienna.

Specimens of typography and printing of all descriptions.

Photography.-Specimens of, by Paul Pretsch, Lower Road, Islington, London. Size $16 \frac{1}{2}$ by $21 \frac{1}{2}$ inches, the largest photographic picture hitherto made.

Views of Schöbrunn (the usual summer residence of the Imperial Court) and of Vienna.

View of a garden.

Neptune Group.

Gloriette (an elevated point, from which a most extensive view is enjoyed),

Schönbrunn.

Entrance, with the obelisk of trophies.

Entrance to the Gloriette.

Interior of the Gloriette.

Three Heads.

Two heads, Niobe and Caracalla.

A courtyard in the suburb of Neubau.

KILBURN, WILLIAM EDWARD, Vol. 1, p. 440, United Kingdom, Class 10, received Prize Medal

294 KILBURN, WILLIAM EDWARD, 234 Regent Street-Producer.

Photographic miniatures. 
Reports by the Juries, p. 600

KILBURN (No. 294) has exhibited a case containing several carefully-selected specimens of coloured daguerreotypes. The subjects of these pictures are confined to groups of figures of small size, and are very brilliant and elaborate in their details, too much so for artistic effect. For novelty of design we may mention a p. 601 small picture of the interior of a room, including a whole length portrait of Jenny Lind: beside, and near her, is a large mirror, in which the figure is reflected. That the reflection in the glass is equally perfect with the original is the point worthy of remark and commendation. Towards the centre of this case is a plain daguerreotype portrait of the Queen. The finish and execution of this little work are very great. The Jury awarded a Prize Medal to Mr. Kilburn.

\section{KNIGHT, GEORGE, \& SONS, Vol. 1, p. 462, United Kingdom, Class 10} $453 \mathrm{KNIGHT}$, GEORGE, \& SONS, Foster Lane-Manufacturers.

...Photographic apparatus, an horizontal lathe, or machine of a novel construction, for cleaning and polishing daguerreotype plates. Invented by the exhibitor. Daguerreotype sliding camera, fitted with various plate frames on different plans. Improved double box with sliding covers and frames, for applying sensitive coatings.

Portable mercury box. Plate-holders on different plans.

A series of buffs, with the different preparations necessary for cleaning plates.

Focimeter, an instrument for ascertaining the difference in the lengths of the optical and chemical focus of photographic lenses.

Camera-stand, designed by W. Matthews, Esq.

Camera-stand, and head-rest, with a series of ball and socket joints, designed by the exhibitor.

Portable folding camera and stand, for paper processes, with frames on different plans.

Pressure frames on different plans.

Glass and porcelain dishes for preparing sensitive paper and glass plates.

\section{Reports by the Juries, p. 595}

KNIGHT and SONS (No. 453) exhibit a camera, the oak stand of which is solidly constructed and pretty firm. It has adjustments for height and azimuth, but not for angular altitude, and has no level. It is furnished with a double picture-plate. The box expands from $9 \frac{1}{2}$ to 14 inches. There is no lens, and consequently the image could not be examined. The same exhibitor has a second camera, in a neat, flat, folding mahogany box, with hinges, which close up lengthways. It is on a slight, unstable tripod stand, made up of cross bracings. The aperture of the object-glass (a single achromatic for landscapes) is about $2 \frac{1}{4}$ inches; the aperture in front of the glass is $0^{\prime} 6$ inches, placed at $3 \frac{1}{2}$ inches in front of the lens. A projection placed in front of the aperture keeps off any stray light. The lens is mounted on a slide to adjust to focus, and its focal 
length is about 12 inches. No ray can reach the corners of the picture when the lens is brought home, and only very little light when out as far as it will go.

\section{Reports by the Juries}

KNIGHT and SONS (No. 453) exhibit a machine for cleaning and polishing daguerreotype plates; portable mercury box; plate-holders; head rests, with a series of bolt ad socket joints; glass and porcelain dishes for preparing sensitive paper.

\section{KOHNKE, F.J., Vol. 3, p. 1140, Hanse Towns. Hamburgh.}

$103 \mathrm{KOHNKE}$, F.J.-Producer.

A daguerreotype painting, coloured.

[The colouring of the daguerreotype paintings is effected by using a delicate brush, and applying colours to the surface of the silver plate in a state of fine powder. The colours are not generally very permanent. The effect of their application is more popularly pleasing than that of the uncoloured pictures; but the exquisite gradations of light and shadow observable in the latter, when untouched by human art, renders the appearance of paint generally distasteful to the daguerreotypist himself.-R.E.]

A glass plate, with inlaid figures, blue on one side and brown on the other. Subject: Cromwell at Marston Moor.

\section{Reports by the Juries, p. 604}

KOHNKE (Hamburgh, No. 103), and VON MINUTOLI (Prussia, No. 191), have exhibited daguerreotypes.

KORLAN, G., Vol. 3, p. 1138, Hanse Towns. Hamburgh.-Lubeck. 53 KORLAN, G.-Producer.

Frames for daguerreotypes.

[The vast extension of the beautiful art discovered by Daguerre has called into existence a number of trades of more or less consequence. Among these is that of the maker of frames for daguerreotypes. These frames are often made of very simple materials, but are occasionally of a more costly kind. They are rendered necessary, in consequence of the liability to injury of the delicate surface of the impressed plate, even after it has been well gilded by the usual process.-R.E.]

\section{LANGENHEIM, W. F., Vol. 3, p. 1437, United States 62 LANGENHEIM, W. F., Philadelphia.}


Photographic magic lantern slides. These slides are produced by the action of light alone on a prepared glass plate, by means of the camera obscura, without the use of the brush; whereby the smallest details are accurately given and fixed on the glass from nature.

[This application of photography is a modification of the Talbotype process, with the substitution of plates of glass for receiving the pristine images upon, in lieu of paper. The delicacy of the outlines, together with the accuracy of the detail of all photographic pictures, appears in great beauty when magnified as they are in the present instance of their application to the magic lantern.-R.E.]

\section{Reports by the Juries, p. 603}

LANGENHEIM (United States, No. 62) has exhibited two large talbotypes, one of which is a panoramic view of Philadelphia, executed in compartments, but wanting unity of effect. This artist, also, exhibits a series of subjects on glass, designated by his under the name of hyalotypes, being delicate miniatures, excellently adapted for magic-lantern subjects. The material would appear to be collodion, albumen, or some similar preparation, forming a film on the glass, capable of receiving the impression.

\section{LAROCHE, MARTIN, Vol. 2, p. 837, United Kingdom, Class 30}

252 LAROCHE, MARTIN, 65 Oxford Street-Designer and Producer.

Three daguerreotypes: a composition—“The Bath;" a subject—“The Evening

Star;" Daguerreotype as applied to sculpture.

Reports by the Juries, p. 601

LAROCHE (Class XXX, No. 252) has exhibited three small daguerreotypes: two are coloured: the third, a group of statuary, is good.

\section{LAWRENCE, M. M., Vol. 3, p. 1446, United States, received Prize Medal} 151 LAWRENCE, M. M., New York.

Daguerreotypes.

[A variety of information on this interesting art will be found in Class 10 of the United Kingdom. Every recent process is there exhibited and described.-R.E.]

Reports by the Juries, p. 601, 602

LAWRENCE, of New York (United States, No. 151), has exhibited several daguerreotype portraits, uncoloured. They are remarkable for clear definition and general excellence of execution. In this series two large portraits of General J. Watson and W. Bryant, Esq., each of which measures $121 / 2$ in. by $101 / 2$ in., deserve particular commendation. Notwithstanding their large size, they are, throughout perfectly in focus, and are beautifully finished in all their details. These are two of the best pictures in the American collection. A portrait of General J. W. Wells, and of a lady in a black silk 
dress, of a smaller size, are also remarkable. A Council Medal was awarded to Mr. Lawrence by the Jury, but not confirmed by the Group.

\section{LE GRAY, GUSTAVE, Vol. 3, p. 1206, France}

585 LE GRAY, GUSTAVE, Chemin de Ronde de la Barrière de Clichy, ParisProducer.

Specimens of photography.

\section{Reports by the Juries, p. 606}

LE GRAY (France, No. 585) has exhibited several sun-pictures. Some of these are good, but many are heavy and wanting in detail. These pictures vary in tint, from sepia to olive citrine.

\section{LE SECQ, HENRI, Vol. 3, p. 1206, France}

592 LE SECQ, HENRI, 35 Quai Boubon, Paris-Designer.

Two Frames, with specimens of photography.

Reports by the Juries, p. 607

HENRI LE SECQ (France, No. 592) has exhibited several calotypes; the subjects are architectural. These pictures may be mentioned with great commendation as regards their finish; but nearly all of them exhibit a degree of negligence in adjusting the visual axis of the camera to the true horizontal direction, which, by making all the vertical lines of the buildings visibly convergent in the picture, contravenes the rules of perspective, and produces an effect highly unpleasing. This is the most common fault of photographic representation by the aid of a camera, and it is right to notice it to put artists on their guard. Every photographic camera ought to be provided with a small spirit-level to secure adjustments in the field, independent of trial.

\section{M}

MARTENS, FREDERIC, Vol. 3, p. 1207, France, received Council Medal 610 MARTENS, FREDERIC, 6 Rue du Pot de Fer, Paris-Producer. Three frames with daguerreotypes.

\section{Reports by the Juries, p. 522}

Eminent amidst the exhibitors of calotypes, is M. MARTENS (610, p. 1207), whose works we may say with certainty, have never been surpassed; their colour, arrangement, and perfect finish, call forth the highest admiration: his success is not confined to one class of delineation in particular, the individual works comprising his collection, being nearly all equal of merit. 


\section{Reports by the Juries, p. 524}

This admirable system is, we believe, entirely due to Messrs. Ross and Thomson, whose collection of Talbotypes amply attests the superiority of their method; and indeed, as in the case of Mr. BUCKLE, of M. MARTEN, or of any highly-successful photographist, it is but fair to infer that the superiority observable in their productions is due to their improvement of the processes which they hove adopted.

\section{Reports by the Juries, p. 606}

MARTENS (France, No. 610) has contributed several large and beautiful photographic proofs, on glass and paper, obtained by an apparatus made by Lerebours and Secretan: also several large photographs from negatives on glass, five of which (views of "Nôtre Dame, the Louvre, and St. Germaine-de-l'Auxerrois), measure 12 in. x 9 1/2 in., and are pre-eminently beautiful. Two pieces of sculpture, from the Arche de Triomphe, Barrière de l'Etoile, call forth the highest admiration. One of these groups contains seven full-length figures, together with their accoutrements, in a space of $3 \frac{1}{2} \mathrm{in}$. by 3 in.: the great finish and beauty of execution here displayed have never been excelled. Space does not permit us to individualize all M. Martens' works, most of which are equally good, such as the Ceiling of the Louvre, the Château de Vincennes, \&c.; but we may say that for richness of effect and perfection of definition, they are the finest specimens which seem possible to produce, exhibiting as they do a most successful combination of careful execution delicacy of colour, and great artistic merit. No trace of the brush is visible. A daguerreotype view of Paris, by the same exhibitor, is good, and evidently not retouched. A Council Medal was awarded to M. Martens.

\section{MAUCOMBLE, Vol. 3, p. 1207, France, received Honorable Mention} 620 MAUCOMBLE, —, 26 Rue de Grammont, Paris_-Producer.

Five coloured portraits in Daguerreotype.

Reports by the Juries, p. 603

MAUCOMBLE (France, No. 620) has exhibited a case of very highly-coloured daguerreotype portraits. They are excellent, but possibly being more to the fine arts than to photographic science. It is difficult to say whether the harmonious and rich colouring of the French school, as applied to these portraits, or the masterly blending of the colour and daguerreotype, deserve most commendation. Art is here engrafted on science, the latter being merged in the former, and the impression left on the mind is that naturally produced by the view of a beautiful artistic production. They are charming, but we repeat belong more to art than to science. The Jury have awarded these works Honourable Mention.

MAYALL, J. E., Vol. 1, pp. 439, 440, United Kingdom, Class 10 291 MAYALL, J. E., 433 West Strand-Producer.

Daguerreotypes of various kinds. 
Daguerreotype panoramas.-Niagara Falls. Fairmount Water Works, Philadelphia. Birthplace of Shakespeare. River Avon, with a view of Stratford Church. Anne Hathaway's House.

[By a little expenditure of ingenuity, it is perfectly possible to take daguerreotype views of nature in the open fields, by the river, or on the sea-shore. All that is necessary is to obtain a means of transferring the prepared plate, and also of mercurializing it when impressed, in the dark; and by a small amount of manual dexterity, with the assistance of a piece of black velvet, this may be accomplished.-R.E.]

Daguerreotype pictures to illustrate poetry and sentiment, the backgrounds in some cases being sketched, and the sitter posed so as to make the whole harmonise together; The Soldier's Dream (Campbell), an illustrated poem (from life), in four tableaux. The Venerable Bede blessing an Anglo-Saxon child (after nature). The Lord's Prayer, in a series of ten designs (from life). The Fisher Boys, a study from nature; and a variety of others.

[The application of daguerreotype to the production of the pictures referred to is effected in the following manner:-The sitter, or the persons comprising the group, dressed in appropriate costume, are artistically posed as to form a tableau vivant, and in this position are taken by the ordinary process. The background is procured either by placing the sitters in front of a scene painted upon canvas, in which case the plate receives the impression as usual, and the scene appears as a natural back-ground to the figures; or, in other cases, the plate is painted with a fine brush, and the landscape, \&c., are thus artificially sketched upon its surface. The practiced eye will immediately decide which of these methods have been adopted.-R.E.]

Frame of interesting specimens, including a portrait of Daguerre, the inventor of the art.

[The discovery by M. Daguerre of the sensitiveness to luminous impressions of an iodized silver plate, and of the development of the picture by mercurial vapour, was first announced to the French Academy of Sciences, by M. Arago, in January, 1839. The original process is not now pursued, bromine and iodine, in combination or succession, being employed to render the plate sensitive to light.-R.E.]

Daguerreotypes of sculpture and novel applications of art to a variety of subjects. "Crayon daguerreotypes."

[This peculiar process is understood to be a French invention. In No. 1197 of the Athenaeum, Mr. Mayall has described, in the following terms, the method of producing crayon daguerreotypes:-

"First. Take a daguerreotype image on a prepared plate as usual, taking care to mark the end of the plate on which the head is produced. When taken, and before mercurializing, remove the plate and place on it a plate of glass, prepared as follows: Second. Cut a piece of thin plate glass of the same size as the daguerreotype plate; 
gum upon one side of it a thin oval piece of blackened zinc, the centre of the oval to coincide with the centre of the image upon the plate. Having carefully placed the glass thus prepared, with the centre of the zinc disc, upon the centre of the image, expose the whole to daylight for twenty seconds. The action of the light will obliterate every trace of the image from every part of the plate, except that which is covered with the blackened zinc, and also from the thickness of the glass the action will be refracted under the edges of the zinc disc, and will soften into the dark parts. Third. Mercurialize the plate as usual; the image will be found with a halo of light around it, gradually softening into the background. By grinding the glass on which the disc is fixed, and by altering the size and shape of the disc, a variety effects may be produced."

The appearance of these pictures is extremely singular. The fact that the exposure of plates already impressed with an image in the camera obscura to daylight entirely removed the original impression, is one of the practical discoveries made by every daguerreotypist who has accidentally lifted the shutter of the plate-holder after removing it from the camera. But such an application of this fact could scarcely have been anticipated.-R.E.]

\section{Reports by the Juries, p. 524}

Whether the followers of Talbot will ever obtain a pre-eminence over those of Daguerre, or vice-versâ, is a question for time to solve; at present the two systems appear in the British Department of the Exhibition to be equally well represented; the followers of each, with few exceptions, laying claim to some improvement or peculiarity of manipulation. For example, in addition to the cases already mentioned may be included those of MAYALL, who calls attention to his crayon daguerreotype, an invention of his own, and BEARD, whose patent enamelled process is one of the very few instances of a patent having been obtained for any improvement connected with this art.

Reports by the Juries, p. 601

MAYALL (No. 291) has exhibited in this department a large collection of daguerreotypes, uncoloured. They are by great contrast of light and shade, disposed in large masses. Among the subjects exhibited are four tableaux from the "Soldier's Dream," and several groups from nature variously arranged. Mr. Mayall's strong and broad masses of light and shade are better adapted for landscape scenery, of which the Falls of Niagara is a favourable specimen. His Bacchus and Ariadne, 24 inches by 15, is, perhaps, the largest daguerreotype which has yet been executed. The difficulty of duly preparing so great a surface must be extreme. He has also exhibited a crayon daguerreotype, produced by a process of his own invention. *

*See the illustrated Catalogue, and the Athenaeum for 1850, p. 1048.

\section{MAYALL, JOHN E., Vol. 3, p. 1465, United States, received Honorable Mention}

491 MAYALL, JOHN E., Philadelphia.

A variety of daguerreotypes. 
[The Americans, from the first announcement of the wonderful art of sun-painting, have zealously made the subject one of much patient experiment. The first portraits from life were taken by the daguerreotype, in New York, and a variety of valuable manipulatory processes have originated in that country. The success with which the art is practised, and the degree of perfection to which it has been brought, may be estimated by the specimens exhibited by various artists. The brilliancy and sharpness of some of these are highly remarkable. Of late an American has announced the discovery of a method of obtaining coloured pictures from nature, the ordinary colours being communicated by a brush. The process is not, however, published. M. Becquerel, a French chemist, has partially succeeded in obtaining a coloured impression on plates; and, more recently still, photographs in natural colours have actually been exhibited in this country. These remarkable pictures are taken by a process discovered by a relative of $\mathrm{M}$. Niepce, the originator of those principles which were brought to a successful accomplishment by Daguerre. The ordinary daguerreotype process only produces pictures with light and shade. -R.E.]

\section{Reports by the Juries, p. 602}

MAYALL (United States, No. 491) has contributed largely to the American collection, his works here being characterized by the same broad masses of light and shadow as those which he has exhibited in the British Department (No. 291). The subjects of the pictures in the present series consist chiefly of small groups and portraits; also two cases containing illustrations of the Lord's Prayer. The majority of these (most of which are uncoloured) are effective, verging upon the theatrical in point of style, but are not all equally well defined. We should be doing Mr. Mayall an injustice, were we not to mention as a brilliant exception to the above criticism, a small figure of a female reclining: it is exquisite in delicacy of execution, harmonious distribution of light and shade, whilst an admirable tone pervades the whole picture; this, the finest of $\mathrm{Mr}$. Mayall's contributions, is free from colour, and is daguerreotyped from a classic work of art. The Jury awarded Honourable Mention to this exhibitor.

\section{MAYER BROTHERS, Vol. 3, p. 1207, France}

622 MAYER BROTHERS, 48 Rue Vivienne, Paris-Manufacturers. chamber.

A complete Daguerreotype apparatus, with a new and improved system of dark-

A patent multiplicator, by use of which an unlimited number of portraits may be had successfully upon the same plate, and with a single sitting.

A patent regulating lamp, designed to obtain and to keep an equal volume of alcoholic flame under the mercury box.

Three frames, containing specimens of photographic portraits upon paper, and Daguerreotype plates painted with colours, invented and prepared by the exhibitors.

\section{Reports by the Juries, p. 607}

MAYER (France, No. 622) has a series of miniatures, coloured on talbotype grounds. They are of exquisite beauty, and give the idea of perfect likeness; but the use 
of the brush being obvious, they are rather to be regarded as works of art than of science.

\section{MEADE BROTHERS, Vol. 3, p. 1440, United States}

109 MEADE BROTHERS, New York.

Daguerreotypes.

Reports by the Juries, p. 602

MEADE BROTHERS (United States, No. 109) have exhibited a series of portraits of more than ordinary size. Conspicuous among this collection are the heads of Wallack and $\mathrm{H}$. W. Meade. The modulation of light and shade upon these last is admirable, as well as the details of the features, and the total absence of all harshness: the artistic effect is excellent. Greater credit is due to this collection of portraits than to the series of allegorical subjects exhibited by Mr. Meade.

\section{MOLTENI \& SIÉGLER, Vol. 3, p. 1209, France, received Honorable Mention}

649 MOLTENI \& SIÉGLER, 62 Rue Neuve St. Nicolas, Paris-Opticians.

Optical and mathematical instruments. Model of a theodolite with concentric circles. Barometers, thermometers, aerometers. Magic lanterns-dissolving views; improved Daguerreotypes and pantographs of a new description. New machine for making telescope lenses.

\section{Reports by the Juries, p. 541, Nautical Astronomical Instruments}

MOLTENI and SIEGLER (France, No. 649) exhibits sextants and reflecting circles, pretty good in all respects, the divisions excepted. The Jury awarded these instruments Honourable Mention.

\section{0}

OWEN, H., Vol. 1, p. 467*, United Kingdom, Class 10 670 OWEN, H., 3 Somerset Terrace, Bristol-Producer.

Series of views in Somerset, Wilts, and Devon, by the calotype process, from negatives on paper.

Reports by the Juries, p. 605

OWEN (No. 670) of Bristol, has exhibited a series of calotype pictures, most of them landscapes and wood scenery. They want clearness of definition, being somewhat black and heavy. Mr. Owen states himself to have been able to execute in a single day, in a journey of 300 miles, ten large-sized talbotypes of local scenery, each paper being 
prepared on the spot. The preparation is greatly facilitated by a glass spreader, of his own invention, by which the solutions are evenly applied.

$\mathbf{P}$

PAINE, WILLIAM, Vol. 1, p. 440, United Kingdom, Class 10 295 PAINE, WILLIAM, 5 Trinity Row, Islington-Producer.

Photographic pictures, to exhibit the progress of the art.

Reports by the Juries, p. 601

Of the remaining exhibitors in England...PAINE (No. 295) a series of photographic pictures, intended to show the processes of the art.

PICKERING, E.T. - See VOIGTLANDER, EVANS, \& CO., 3 Lowndes Terrace, Knightsbridge-Proprietors. Daguerreotype portraits by an improved instantaneous process. Artist, E.T. Pickering.

\section{PLAGNIOL, Vol. 3, p. 1257, France}

1679 PLAGNIOL, -, 5 Rue Pastourelle, Paris-Optician.

A variety of spectacles. Ivory and polished opera glasses. Daguerreotype pictures.

Reports by the Juries, p. 596

PLAGNIOL (France, No. 1679). This is by far the largest camera in the

Exhibition; the picture-board is 24 inches square, and the object lens is 8 in diameter, double and achromatic. The picture was clear and distinct, as far as unfavourable circumstances would allow of the examination. It is furnished with a clear guard-tube in front of the object-glass, of 4 inches projection, amply sufficient to cut off side light. The object-glasses are separated by 15 inches, or about double their aperture. The clear space which all the object-glass illumines, scarcely exceeds $61 / 2$ inches in the centre of the picture; at the edges and corners the defalcation of light is very great. This, however, seems to be unavoidable.

Large as is this camera, it is very far from bring the largest that has been constructed. The use of great cameras for copying photographic plates and MSS, especially tables, is becoming common in France. We have heard of some cameras which give pictures nearly a metre in length. A Prize Medal was awarded to M. Plagniol.

Reports by the Juries, p. 603, 604

PLAIGNOL (France, No. 1679), exhibits daguerreotypes rather as specimens of the production of his large camera (though not of the full size which that instrument is 
capable of producing), than as claiming especial distinction in this particular department of art.

PRATT, W. A. \& CO., Vol. 3, p. 1452, United States

264 PRATT, W. A. \& CO., Richmond, Virginia.

Daguerreotypes.

Reports by the Juries, p. 603

PRATT, RICHMOND, and Co. (United States, No. 264), have exhibited several daguerreotypes, of various degrees of excellence. The profile of an old man, assisted by colour, is the best.

PRETSCH, PAUL, see IMPERIAL COURT AND GOVERNMENT PRINTING OFFICE, Vienna., Vol. 3, pp. 1025, 1026, 1027, received Prize Medal

Photography.-Specimens of, by Paul Pretsch, Lower Road, Islington, London. Size $16 \frac{1}{2}$ by $21 \frac{1}{2}$ inches, the largest photographic picture hitherto made.

Reports by the Juries, p. 607

PRETSCH (Austria, No. 362) has exhibited several large photographic pictures from nature. The subjects are various, comprising groups of statuary, architectural buildings, landscapes, \&c. The subjects are well chosen, and show good execution and artistic management. Mr. Pretsch was awarded the Prize Medal by the Jury.

PUCHER, JOHANN, Vol. 3, p. 1044, Austria

740 PUCHER, JOHANN, Veldes, Upper Carniola—Inventor.

Photographs on glass, by a new method.

$\mathbf{R}$

RIPPINGHAM, M. J., Vol. 1, p. 442, United Kingdom, Class 10 304 RIPPINGHAM, M. J., 17 Great Prescott Street.

A case of photographic portraits, on paper, from negatives, taken with collodion on plate glass.

Reports by the Juries, p. 606

RIPPINGHAM (Class X., No. 304) has exhibited several talbotypes, being a series of untouched positives, from collodion negatives, on plate glass. He also exhibits other photographs from paper negatives, but they are blotty and want more light. 
42 ROOT, M. A., Philadelphia.

Daguerreotypes.

Reports by the Juries, p. 603

GAVIT (United State, No. 125), ROOT (United States, No. 42), WHITEHURST

(United States, No. 525), and HOGG (United States), all of whom have exhibited daguerreotypes, but not distinguished by any striking degree of excellence.

\section{ROSS, A., Vol. 1, pp. 435, 436, United Kingdom}

254 ROSS, A., 2 Featherstone Buildings, Holborn-Inventor and Manufacturer.

Astronomical telescope, the diameter of the object glass is $11 \frac{1}{2}$ inches in diameter, mounted on a stand, with equatorial movements and complete adjustments. The optical part wrought by Ross's improved system and machinery.

(plus chemical pottery wares and additional astronomical telescopes) Improved photographic camera obscura.

\section{Reports by the Juries, p. 594}

By degrees a lens concave towards the object and convex towards the image was adopted; the picture was thus rendered clearer, but the colours of the spectrum were not corrected. At length an achromatic lens was used, the flint glass being towards the object. M. Daguerre went a step further, and determined those relative proportions of the camera, which, for the most part, are still adopted; the interior being carefully darkened, for the purpose of avoiding casual reflection upon the field of view.

Mr. Ross, in addition, prepares those for portraiture with the greatest intensity yet produced, by procuring the coincidence of the chemical actinic and visual foci. The spherical aberration is also corrected very carefully, both in the central and oblique pencils.

\section{Reports by the Juries, p. 594}

Ross (No. 254) has exhibited the best camera in the Exhibition. It is furnished with a double achromatic object-lens, about 3 inches aperture; there is no stop, and no part of the field employed which does not receive plenty of light, so that the corners as well as the middle of the picture are well illuminated. The field is flat, and the image is very perfect up to the edge. It has a revolving and adjusting

\section{p. 595}

back-board for the reception of two plates. The same exhibitor has a second camera, furnished with a single achromatic lens of small aperture. The glass of this instrument having been removed, the image could not be examined.

Mr. Ross, in addition, prepares those for portraiture with the greatest intensity yet produced, by procuring the coincidence of the chemical actinic and visual foci. The spherical aberration is also corrected very carefully, both in the central and oblique pencils. 


\section{ROSS \& THOMSON, Vol. 2, p. 839, United Kingdom, Class 30, awarded Council Medal}

299 ROSS \& THOMSON, Edinburgh-Producers.

Frames containing Talbotype pictures from negatives on albuminized glass.

[The albuminised glass is prepared by mixing a small quantity of iodide of potassium with the white of an egg, and uniformly spreading this solution on a glass plate. The thin film being carefully dried, is rendered sensitive by being washed with gallo-nitrate of silver previously to being placed in the camera. ]

\section{Reports by the Juries, p. 523}

ROSS and THOMSON, of Edinburgh are fairly entitled to attentive consideration from their successful use of the albumenized glass, which they prepare by a process different to that adopted by M. Niepce, its originator, applying the albumen so as to ensure its even distribution, upon which evenness the success of the picture is mainly dependent. The pictures in their collection combine, with exceeding delicacy of execution, a richness of colour equal to that of Martens', but surpass him in the diversity of tints; the collection, besides embracing a long range of sepia tints and Vandyke browns, includes a small picture the colour of which is blue, and as this is a hitherto unprecedented result, we are led to give it weight, and will, in another place, describe process by which it is produced. Some details connected with the methods adopted by Messrs. Ross and Thomson, and kindly furnished by them, are subjoined.

The process for producing negative Talbotypes, on glass, is as follows:-The whites of two eggs, being a quantity sufficient for coating a plate of glass 12 inches square, are placed in a bowl, and cleared from all opaque particles; ten drops of a saturated solution of iodide of potassium are added for each egg, and two-thirds of a wine-glass of water for both, the whole being then beaten up to a light froth and carefully covered up and left to regain its liquid state; the glass to be coated is well cleaned with a solution of pure water and soda, or potass, and rubbed quite dry with a silk rag. The mixture is then poured on as evenly as possible, and fastening a piece of wire to the opposite corners, the excess of albumen is poured off by turning the plate gently upside down; it is afterwards made to revolve before a clear fire, by a thread of worsted tied to the suspending wire: when the albumen begins to crack, the plate should be removed to a greater distance, and there suffered to remain until equally cracked all over. To render the plate so prepared fit for the camera, it is breathed upon, to give it a degree of softness, and to cause it to absorb as much silver as possible; it is then dipped (the prepared side undermost) very gently in a bath of nitrate of silver, prepared in the proportion of 60 or 70 grains to an ounce of water, the plate being prevented from touching the bottom of the vessel by a piece of bent glass, or metal covered with wax. It is then washed in a large dish of clean water, by repeated dippings, care being taken to keep the water running in the same direction. The plate is then placed in the camera, and if the picture when taken, is to be immediately developed, a quantity of acetic acid is added.

The mode of developing the image is as follows:-a quantity of saturated gallic acid is poured on the plate, and spread evenly with soft cotton-wool, after which, when the picture has well appeared, a small quantity of gallic acid is mixed with the nitrate of 
silver solution, and spread over the glass, which gives the development strength, and renders it more rapid. At this stage of the operation, a solution of hyposulphate of soda (50 grains to an ounce of water) is poured over

\section{p. 524}

the picture, and carefully spread with clean cotton; the process is then completed by pouring some water from a jug very gently over the surface.

The negative proof so obtained is transferred to paper by floating the latter on a solution of common salt ( 5 grains to an ounce of water) for a space of two minutes; it is then pinned up to dry, and floated on a solution of nitrate of silver (70 grains to an ounce of water) for three minutes; it is then dried in the dark, and afterwards placed with its prepared side to the prepared side of the glass negative, and screwed in the pressure-frame with a plate of glass below to ensure its close contact. The pressureframe should be surrounded with black boards to cut off the rays of light from the sides. To fix the impression, it should be first washed in cold water, then in hyposulphate of soda (100 grains to an ounce of water) for 15 minutes. It is then washed once in cold water, five or six times in boiling water, and finally suffered to remain an entire night in cold water, so as to remove entirely the remaining hyposulphate of soda, which would, in course of time, eat out the picture if allowed to remain.

The photograph thus obtained is afterwards mounted upon card-board, and pressed on a warm plate of steel, to communicate a slight glaze, which may be considered an improvement to its appearance.

The process we have just detailed is good in many points, but defective chiefly in one-sensitiveness; every effort to increase which has hitherto been attended with a softening of the albumen. This is a difficulty, but one which Messrs. Ross and Thomson will doubtless overcome.

The positives on glass are transferred and fixed in the usual manner (the albumen being mixed with salt instead of iodide of potassium), with the addition of pure plaster of Paris, which being mixed with the solution is poured on the face of the picture, and adhering to the albumen in a manner hermetically seals it, and thus effectually preserves it from injury.

This admirable system is, we believe, entirely due to Messrs. Ross and Thomson, whose collection of Talbotypes amply attests the superiority of their method; and indeed, as in the case of Mr. BUCKLE, of M. MARTEN, or of any highly-successful photographist, it is but fair to infer that the superiority observable in their productions is due to their improvement of the processes which they hove adopted.

\section{Reports by the Juries, p. 604}

ROSS and THOMSON (Class XXX., No. 299) have exhibited several beautiful talbotype pictures, consisting of views of nature, interiors, groups, \&c., and they are the only exhibitors, in the British section, of photography by the albuminous process; which, in practice, they appear to have carried to a high state of perfection, and having not only substituted it for the old method of taking the negative proofs on paper, but having, in more than one instance, exhibited the positive proof upon the albumenized glass itself. In addition to the extreme clearness observable in the details of their landscape scenery, and the great delicacy of the delineation of objects in general, we may take 
notice of the excessive beauty of the tints which their works exhibit; not only are the shadows deep and Rembrandt-looking, where suitable to the effect required, but the middle distances display a beauty of colour nowhere equaled excepting the very superior works by M. Martens, in the French Department.

As an illustration of the variation of tints which these works present, in contradistinction to the fine Vandyke brown and deep shadows, we may mention a small picture (a group of statuary), the peculiarity of which consists in the colour, which is blue, an effect produced by taking the negative proof on albuminized glass, and rendering it positive by repeated washing in hyposulphate of soda, the proof being originally laid upon a black ground. By this process the whites become black, and vice versâ. The hyposulphate of soda is a most helpful agent in the colouring of both negative and positive proofs, and affords a vast range of beautiful tints of inexhaustible richness; but it is difficult of application, and is available only in the hands of a skilful operator.

The coating of the glass with albumen is a difficult operation: the method adopted by Ross and Thomson differs from the French process (which is due to M. Niepsce, and is usually called the "albuminous process"), and consists in pouring a quantity of albumen on the plate and revolving it over a slow heat, for the purpose of ensuring its even distribution. As shown in the practice of these exhibitors, this method would seem to be perfectly successful; and indeed the beautiful and extreme delicacy and variety of tint, the aërial perspective by which the background is made to recede by imperceptible gradations into the horizon, all amply attest the powers of Mrssrs. Ross and Thomson.

A number of talbotypes, also exhibited, display equal variety of tint, and depth and richness of tone without any straining for effect.

A Council Medal was awarded to Messrs. Ross and Thomson.

S

SABATIER, HENRI, Vol. 3, p. 1246, France

1467 SABATIER, HENRI, 65 Palais National, Paris-Producer. Daguerreotype portraits.

Reports by the Juries, p. 603

SABATIER (France, No. 1467) exhibits a single daguerreotype portrait of large size ( 8 in. by 6 in.), which is every way excellent. It is entirely free from glare (to which its low position contributes not a little, the light coming from above), and in expression, freedom from constraint, and perfect representation of texture, may rank with any single piece in the Exhibition.

SAUGRIN, Vol. 3, p. 1212, France

690 SAUGRIN, -, 11 Boulevard Montmarte, Paris_Producer.

Daguerreotype miniatures. 
SCHIERTZ, JULES GUSTAV, Vol. 3, p. 1227, France, awarded Prize medal

999 SCHIERTZ, JULES GUSTAV, 27 Rue de la Huchette, Paris-Cabinet-maker. Apparatus and stands for Daguerreotyping.

Stands for astronomical telescopes.

Reports by the Juries, p. 596

SCHIERTZ (France, No. 999, p. 1227) exhibits a camera, the object-glass of which is $23 / 4$ inches in diameter. There is a stop, and the light is so effectively intercepted by the cell and tube of the object-glass, that the sides of the field are rendered obscure, and the top, bottom, and corners very dark; not one-fifth of the central light is effective. The plate for receiving the image is 9 by 7 inches, and the focal distance from the hinder lens about 8 inches; the field is flat, and the image clear and good. The mahogany stand is good, but is not well adapted for the taking panoramic views. A Prize Medal was awarded to M. Schiertz.

SCHNEIDER, F., Vol. 3, p. 1059, Zollverein-Prussia, Baden, and other States of Northern Germany

203 SCHNEIDER, F., Berlin-Inventor.

Writing-stand, partly of gilt and partly of gold, under a glass cupola, upon a rosewood column.

Daguerreotype-plates, plated by galvanic process, and leveled without hammering.

\section{STRAUCH, FREDERIK, Vol. 3, p. 1124, Frankfort-on-the-Maine 33 STRAUCH, FREDERIK-Producer. \\ Specimens of plain and coloured photography.}

$\mathbf{T}$

THIERRY, JEAN, Vol. 3, p. 1228, France, received Honorable Mention 1038 THIERRY, JEAN, Rue Bat d'Argent Hotel des Négociants, Lyons (Rhône)Manufacturer.

A frame, containing nine heliographic pictures.

Reports by the Juries, p. 603

THIERRY (France, No. 1038), has exhibited eight daguerreotype views of Lyons; they have a sunny look and are very brilliant, but are wanting in artistic effects of light and shade. A portrait of $\mathrm{M}$. Thierry himself deserves particular commendation, and is far superior to the above-mentioned pictures. The Jury considered this exhibitor as deserving Honourable Mention. 
TYREE BROTHERS, Vol. 1, p. 442, United Kingdom, Class 10 299 TYREE BROTHERS, 44 Regent's Circus, Piccadilly_Inventors.

Daguerreotypes, including several, in which is introduced a new and ornamental process. The colouring by Mr. Alfred Tyree.

[In these daguerreotypes an effect somewhat resembling that of an engraved border has been produced. Such a result is capable of being attained by means of a perforated plate of metal laid over the picture and momentarily exposed to light. The action of the light through the perforated parts will produce, on exposure to the mercury, the engraved appearance.-R.E.]

Reports by the Juries, p. 601

Of the remaining exhibitors in England...TYREE (No. 299), coloured daguerreotype portraits.

\section{V}

VAN (or VON) MINUTOLI, ALEXANDER, Vol. 3, p. 1058, Zollverein-Prussia, Baden, and other States of Northern Germany 191 VAN MINUTOLI, ALEXANDER, Councillor, Liegnitz-Proprietor.

Samples of Silesian marble plates, sketched by the exhibitor; executed by Mr. Laverdare, sculptor in Breslau.

Photographic copies of models for manufactories in clay, glass, or wood, executed by the photographer Birk, at Hirschberg.

Phelloplastic model of the ruins of a Gothic church; an attempt to execute Gothic architecture instead of Roman in cork.

Parts of chimney-pieces in a greenish glaze and in a brown glaze, and gilt. A square of the same material.

Brown-glazed chimney-piece, to exhibit the application of clay, formerly, only used for pottery to finer objects. The designs and models were produced by the exhibitor, and executed by Mr. Pockle.

Crystal glass decanter, after a sketch by the exhibitor, executed by the glasspainter Finsch, at Warmbrunn.

\section{Reports by the Juries, p. 604}

KOHNKE (Hamburgh, No. 103), and VON MINUTOLI (Prussia, No. 191), have exhibited daguerreotypes.

\section{VARLET \& SON, Vol. 1, p. 436, United Kingdom}

257, VARLET \& SON, 1 Charles Street, Clarendon Square-Inventors and Makers.

Graphic telescopes, by which general views or images of objects, either far or near, may be accurately traced, of any size. 
Reversing camera, by which pictures or objects may be traced the reverse way. Microscope, in which the moveable stage is kept parallel to one position whilst freely moved about in any direction.

Reflecting telescopes.

Model of the apparatus for mounting together and changing three small speculums of large Gregorian telescopes, so as not to lose sight of the object; thus the power may be doubled, or quadrupled, or reduced without loss of time.

Air-pump, with crank motion and double-acting single barrel.

New double-acting exhausting air-pump, with increased power.

Portable electrical apparatus; on moving the inner tubes to and fro, the outer tubes becomes charged in the same manner as the Leyden Phial.

\section{Reports by the Juries, p. 596}

VARLET and SON (No. 257) exhibit a single reflecting camera. This is a plain speculum with thin edges, placed at an angle of $45^{\circ}$, and designed for making reversed copies of drawings on lithographic stone or wood blocks. It may also be fitted with lenses for enlarging or reducing copies, and for sketching from nature upon a stone. A prize medal was awarded to Mssrs. Varley and Son.

\section{VOGEL, CARL FRIEDRICH, Vol. 3, p. 1044, Austria, received Honorable Mention} 739 VOGEL, CARL FRIEDRICH, Milan. Photographs.

Reports by the Juries, p. 604

VOGEL (Austria, No. 739) exhibits daguerreotypes, to which Honourable Mention was awarded by the Jury.

\section{VOIGTLANDER, EVANS, \& CO., Vol. 2, p. 837, United Kingdom, Class 30}

254 VOIGTLANDER, EVANS, \& CO., 3 Lowndes Terrace, Knightsbridge-Proprietors. Pickering. Daguerreotype portraits by an improved instantaneous process. Artist, E.T.

Reports by the Juries, p. 601

VOIGTLANDER and EVANS (Class XXX, No. 254), Knightsbridge, have exhibited coloured daguerreotypes.

\section{W}

WHIPPLE, JOHN A., Vol. 3, p. 1464, United States, received Prize Medal 
451 WHIPPLE, JOHN A., Boston.

Daguerreotypes.

[Among these daguerreotypes is a remarkable one of the moon's surface. In this picture, which must have been taken by a large equatorial, the peculiar characteristics of the moon's surface are beautifully displayed. At the recent meeting of the British Association for the Advancement of Science, Mr. Bond, an American astronomer, exhibited daguerreotypes of the moon taken with the 23-feet equatorial of Cambridge (U.S.) Observatory. These daguerreotypes were very beautiful, and admitted of being very considerably magnified; but Mr. Bond stated that the motion of the equatorial, although very steady, was not yet sufficiently so to admit of their being examined by very high magnifying powers. Sir David Brewster stated, that if these daguerreotype impressions were taken on transparent sheets of gelatine paper, and so placed before a telescope as to subtend accurately thirty minutes of a degree, they would assume all the appearance of the moon itself.-R.E.]

\section{Reports by the Juries, pp. 521, 522, introduction}

Let us now view Photography in its application to science. A process by which transient actions are rendered permanent, and which enables nature to do her own work, or in other words, which causes facts permanently to record themselves, is too well fitted for the purposes of science to be long overlooked; but the difficulties to be overcome in its application, have been, and still are great, and the results proportionately few in number: we consider, however, that the commencement of a systematic application of the photographic process to the purposes of astronomy is indicated by the daguerreotype of the moon by Mr. Whipple; and great indeed will be the benefit conferred upon astronomical science, when we obtain permanent representations of the celestial bodies and their relative positions, transmitted through the agency of light. ${ }^{*}$

*The success of this application of photography must be dependent, to a considerable extent, on the object-glass of the telescope. The Report on Telescopes will show further improvements in this department of optics are commensurate with the requirements of photographic reproductions of this class.

Reports by the Juries, p. 602

WHIPPLE (United States, No. 451) has exhibited several specimens of daguerreotypes, amongst which one of the moon may be mentioned with the highest commendation: this is, perhaps, one of the most satisfactory attempts that has yet been made to realize, by a photographic process, the telescope appearance of a heavenly body, and must be regarded as indicating the commencement of a new era in astronomical representation. The same exhibitor has included in his collection three pictures, containing several full-length figures, well grouped, artistically arranged. Each part is well in focus, and the definition is admirable. An agreeable tone pervades all these pictures. A Prize Medal was awarded to Mr. Whipple. 


\section{WHITEHURST, J., Vol. 3, p. 1467, United States}

525 WHITEHURST, J., Washington.

Daguerreotypes.

\section{Reports by the Juries, p. 603}

GAVIT (United State, No. 125), ROOT (United States, No. 42), WHITEHURST

(United States, No. 525), and HOGG (United States), all of whom have exhibited daguerreotypes, but not distinguished by any striking degree of excellence.

\section{WHITEHURST, J.H., Vol. 3, p. 1461, United States}

377 WHITEHURST, J.H., Baltimore, Maryland.

Daguerreotypes: Falls of Niagara.

[These wonderful falls have been repeatedly represented by the daguerreotype. The cloud of spray rising from the bottom, and the white sheets of foam on the waters, contrasted with the trees and land, always exhibit a remarkable and interesting appearance in a daguerreotype. There is thought to be a difficulty in taking the image of falling water; but in practice this doses not exist, as the form is always similar. The water of the falls in question appears as a white cloud.-R.E.]

Reports by the Juries, p. 603

WHITEHURST, Virginia (United States, No. 377), has exhibited twelve views of the Falls of Niagara. These are admirable, and possess a degree of reality not always attained in landscapes produced by the daguerreotype process.

\section{WILLATS, T. \& R., Vol. 1, p. 437, United Kingdom, Class 10}

265 WILLATS, T. \& R., 28 Ironmonger Lane, Cheapside-Inventors and Manufacturers. Improved portable photographic camera and stand, for obtaining pictures by any known photographic process, on metal plates, paper, glass, \&c.

The advantages of this form of camera are, the facility with which it can be packed into a small compass; the adjustments for placing the paper or plates at the proper focus without exposing them to daylight; and the comparatively small weight of the apparatus: thus rendering the practice of photography easy to a traveler.

Improved registering thread calculator, or linen prover, to ascertain the number of threads in a given space, of silk, linen, or cotton fabric, and to register this number on paper.

It is of importance in purchasing any woven fabric, to ascertain the number of threads, warp, and woof contained within a square inch, as the knowledge of these enables the purchaser to judge of its strength and durability. The instrument is devised to render the operation easy to a merchant.

Reports by the Juries, p. 596

WILLETTS (No. 265) exhibits a portable photographic camera with a flexible cloth body instead of a wooden one; it is furnished with a horizontal movement, and is adjustable to lenses of various focal lengths; it has also an angular adjustment of the frame of the 
lenses, the latter for the purpose of keeping the image in the centre of the frame without altering the position of the camera. The size of the photographs is $101 / 2$ by $81 / 2$ inches. The cloth body of the instrument is mounted by flexible vulcanized caoutchouc bands at each end, and is thus firmly attached to the ends of the camera. The whole instrument is easily taken to pieces and put together, and occupies but a small space. The image was not examined. 


\section{Additional Text from the Catalogue}

\section{Cat., Vol. 1, p. 404, 405, Britain}

SECT. II. CLASS 10.

PHILOSOPHICAL, MUSICAL, HOROLOGICAL, AND SURGICAL INSTRUMENTS.

North, North Central, and South Central Galleries.

\section{INTRODUCTION.}

The advance of physical science receives its illustration in a variety of directions among the objects collected together under this Class. The progress of experimental philosophy may be gathered, in a degree, from perfection of the instruments it employs; for while it is certain that in some sciences much has been accomplished by the aid of rude and imperfect means, it is equally true that in others the perfection of the apparatus is essential to that of the knowledge sought to be established by deductions drawn from its indications. The delicacy of a balance is necessary to the accuracy of the chemical experiment, and therefore to that of the facts it is used to develop, as also is the achromatism of a microscope, or a photographic lens to the development of the optical images, and to the result sought to be attained therefrom: chemistry, microscopical sciences, and photography, are consequently largely dependent for their progress upon the instruments by the use of which they are to proceed. The same cannot be said of surgical instruments, for in their use the operator may command success by his skills, notwithstanding the imperfections of his apparatus. Nevertheless, the present state of surgery, and the attention bestowed upon it, may be gathered from the inspection of the refined and complicated apparatus offered for its advancement. As one of the results of the splendid and enduring system of knowledge, and its pursuitspromulgated by Bacon in the "Novum Organon, " the system since called Experimental Philosophy-objects in this Class wear a peculiar interest, representing the means employed by man for the establishment and development of inductive science.

This class includes instruments employed for a variety of philosophical purposes; it also comprises musical, horological, and surgical instruments and apparatus. It may consequently be considered under three Sub-Classes. The first comprehends-A. Instruments for the measurement of space, such as Transit Instruments, Quadrants, Sextants, Telescopes, Microscopes, Theodolites, \&c.; B. Instruments to measure the effects of mechanical and physical forces, as Dynamometers, Balances, Thermometers, \&c.; C. Instruments to illustrate the Laws of Mechanical and Physical science; D. Application of mechanical and physical science to useful purposes not included in the preceding or subsequent sections, such as instruments connected with Mechanics, Sound, Light, Heat, Magnetism, and Electricity; E. Comprehends Chemical and Pharmaceutical Apparatus. (cont., subclasses)

...Proceeding westward, in the Central Gallery, from M.3 to M.8, contains various articles included in this Class. Proceeding westward, in the Central North Gallery, musical instruments are first encountered, including a variety of organs, harps, pianos, \&c. Succeeding these are philosophical instruments, electric telegraphs, daguerreotype 
apparatus, and specimens of photography; beyond are globes and astronomical apparatus. (cont, descriptions of locations)

British manufacturers have for some time been making great efforts with a view of producing good optical glass, and a skilful method of working it into forms desired for optical purposes. These efforts have been so highly successful that the glass produced in England is not unfrequently exported and again re-imported as foreign glass at a much higher price. The production of lenses has also greatly improved; and achromatic glasses of considerable size, as well as a smaller kind, are made with success in this country. Microscopes, telescopes, and minor philosophical instruments, are now of excellent quality and highly-wrought character.

Photography is included in this Class, both on plates of silver and glass, and on paper. The most beautiful specimens of sun-drawn pictures are exhibited. Daguerreotypes of every kind, plain and coloured, "enamelled," and "crayon,"improvements of recent introduction, and applied to a variety of purposes,- -are found here. The largest daguerreotype probably yet produced, a group of sculpture, is placed in this Class. The Talbotypes are also very beautiful, and present a charming evidence of the fidelity and artistic effects capable of being produced by the pencil of Nature. Photographic apparatus of various kinds, together with the results of curious photographic experiments, illustrative of the distinct existence of luminous and actinic rays in the solar beam, are also represented.

(cont.) -R.E.

Specimens of photographs, on glass.

[The art of photography on glass is more recent than either the daguerreotype or talbotype processes. But the principles upon which it is successfully practiced are essentially the similar to those involved in the latter art. In consequence of the inequality of the texture of photographic paper, it became desirable to obtain some more homogeneous medium for the reception of the negative talbotype picture. Glass and porcelain have been employed with great success for this purpose. In order to render the surface sufficiently retentive of the sensitive coating of silver, the plates of glass are covered in the first instance with a thin layer of the albumen of an egg, containing a few drops of a solution of iodide of potassium. The sensitive washes are then applied, and the plate is exposed to the lenticular image in the camera. The picture is developed in the usual manner. The "prints" from glass plates are of the most exquisitely beautiful character.-R.E. ]

\section{Cat., Vol. 3, introduction, p. 1005}

AUSTRIA

The Austrian productions form a highly-interesting feature in the Great Exhibition...R.E. (no photography included in this introduction) 


\section{Cat., Vol. 3, introduction, p. 1046 \\ STATES OF THE GERMAN ZOLLVEREIN \\ INTRODUCTION}

GERMANY may be divided into three commercial groups, of which the most extensive, generally designated "The Zollverein," or "Great Custom Union," was constituted in the year 1828 on the invitation of Prussia.

(no photography included in this introduction)

\section{Cat., Vol. 3, introduction, p. 1047 \\ PRUSSIA}

An extensive and highly-important collection of objects us exhibited by Prussia and the conjoined States.

(no photography included in this introduction)

\section{Cat., Vol. 3, introduction, p. 1121 \\ FRANKFORT}

The collection brought over from this State includes articles in most of the Classes of the Exhibition...Various philosophical instruments are also shown, which include a daguerreotype apparatus, with a double achromatic lens of five inches diameter, polarization of light apparatus, \&c. The specimens of ornamental glass are extremely beautiful, and include objects of considerable size. Several exhibitors have sent objects of miscellaneous character; among those of the fine arts are specimens of ivory-carving, models of statues, photography, \&c.-R.E.

\section{Cat., Vol. 3, introduction, p. 1125}

...Musical instruments and some philosophical apparatus will also be found among those articles...

(no photography included in this introduction)

Cat., Vol. 3, introduction, p. 1133

NORTH GERMANY

(no photography included in this introduction)

Cat., Vol. 3, introduction, p. 1136

HANSE TOWNS.

HAMBURGH.-LUBECK.

(no photography included in this introduction) 


\section{Cat., Vol. 3, introduction, pp. 1168, 1169}

FRANCE

...The specimens of paper and printing exhibited include a number of objects of interest; and the coloured and other lithographs, and stereotypes by new processes, evidence much progress in this department. Photographs on paper and on silver (Talbotype and Daguerreotype) are exhibited, and form a very interesting collection. The French photographers have made great progress in the art of the Talbotype (an English discovery) and beautiful pictures taken by modifications of that process are shown. Those taken on glass plates of which the positive pictures or proofs only are shown, are, in some instances, taken by a process largely employed to obtain photographs for the Royal Commissioners in illustration of the Jury's reports. (cont.) -R.E.

\section{Cat., Vol. 3, introduction, pp. 1431, 1432} UNITED STATES

(no photography included in this introduction) 


\section{Additional Text from the Reports by the Juries}

Reports by the Juries, p. 519

CLASS $X$. PHILOSOPHICAL INSTRUMENTS AND PROCESSES DEPENDING UPON THEIR USE.

$$
\text { Jury. }
$$

SIR DAVID BREWSTER, F.R.S. Chairman, St. Andrews, Fifeshire, N.E.; Principal of the University, St. Andrews.

PROFESSOR COLLADON, Switzerland.

E. B. DENISON, 42 Queen Ann Street.

J. GLAISHER, F.R.S., Reporter, 13 Dartmouth Terrace, Lewisham; Observer in Greenwich Observatory.

SIR JOHN HERSCHEL, Bart., F.R.S., 32 Harley Street; Master of the Mint.

PROFESSOR HETSCH, Denmark.

E. R. LESLIE, R. A., United States, Artist.

L. MATHIEU, France; Member of Bureau of Longitude, of Institute, and of Central Jury.

W. H. MILLES, F.R.S., Scroope Terrace, Cambridge; Professor of Mineralogy.

RICHARD POTTER, A.M., University College; Professor of Natural Philosophy.

PROFESSOR SCHUBARTH, Zollverein; Professor of Chemistry and Natural

Philosophy.

BARON ARMAND SEGUIER, France; Member of Institute, \&c.

Associates

J. S. BOWERBANK, 3 Highbury Grove.

REV. W. S. KINGSLEY, Sidney College, Cambridge; Fellow of Sidney College.

L. A. J. QUETELET, Belgium; Secretary to the Royal Academy at Brussels (Juror in Class XXX.)

LORD WROTTESLEY, 34 St. James Place.

The duties of the Jury upon Philosophical Instruments have been found to be very heavy, as indeed might be expected in a field so vast,-including instruments relating to Astronomy, Optics, Light, Heat, Electricity, Magnetism, Acoustics, Meteorology, \&c.; in fact, all relating to Physical Science, collected by a large number of exhibitors.

\section{p. 520}

There are many photographic cameras, to the improvement of which much attention is at present being paid in England and France. This leads us to the most remarkable discovery in modern times,- - the art of Photography,- -and never before was so rich a collection of photographic pictures brought together, the products of England, France, Austria, and America.

Before going further, it would be well to inquire into the utility of the photographic process as regards its application to art and science,-—and, indirectly, to literature, by 
affording a faithful transcript of authentic papers and original documents, upon which subsequent literary and historical research must necessarily be greatly dependent. That photography is yet in its infancy there can be little doubt; and it is more than probable that its present application, which we believe to be well represented in the Exhibition, is no more than its ultimatum than were the first applications of the telescope, shortly after the chance placing of two pieces of glass by Jansen's children led to its invention. Who, at that time, could have predicted the important part that the instrument, based upon that discovery, was destined to play in the world of science? or have foreseen the excellence which it has since attained by successive improvements even now making, and of which the Exhibition affords ample proof.

Viewing Photography in connexion with art, it may at first appear as if a vast and powerful rival had risen up against and was destined to depress her in exact proportion to the superiority of the operations of nature over those of man. In its success, we perhaps expect to behold a transcript of objects and compositions more elaborate and more truthful than any the greatest genius could ever hope to achieve: united to this, and in addition to the rich Vandyke browns and Claude Lorraine tints of many of the works now before us, by the agency of chemicals whose existence is yet unknown, we may see foreshadowed a perfection of colouring as yet never imagined. By improvements in the camera and the daily increasing practical knowledge of experimenters, we may expect to behold compositions,

*See Gould's Astronomical Journal, Vol. i., Nos. 2,7,and 14.

\section{p. 521}

embodying a degree of reality otherwise beyond our power of attainment. The truthful delineation of the various and just relations of the architectural edifice, the groups of figures at its base, the middle distance blended into the horizon by gradations so fine and truthful, as to defy the utmost efforts on our part to surpass or even equal; are indications only of that which will ultimately be achieved by the photographist, rich in experience and knowledge of the processes of photographic art.

But this is a superficial and imperfect view of the case, not as regards the ultimate perfection of photography itself, but as concerning its influence upon art. With art, doubtless, its future destiny will be closely linked; but so far from becoming a rival, it will prove a most useful auxiliary, and a means by which the artist of merit may rise higher in reputation and eminence. By using photography as a means of replacing the purely mechanical parts of his labour, the work of the artist may be much lightened; and as by speedy transit from place to place man's life is virtually lengthened, so by relieving his path from that part of his labour which involves an expenditure of time disproportionate to the end attained, one great obstacle to achievement of success is removed. Never need the artist fear that the employment of its services in conjunction with his pencil, or his adaption of it in any way to his art, will ever derogate from that art, or render him a servile copyist; we may rather predict that each improvement in photography will tend to place both the painter's and the sculptor's art on a firmer and surer basis. It is likely that time will show that this beautiful compound of art and science will essentially cast its weight into the balance of art, and in future render itself more and more inseparable from, the essential to her interests. 
That Photography will have a great tendency to depress mediocrity, we may safely predict; that from the date of the general application of Photography to the illustration of scenes daily passing around us, will commence a new era in pictorial representation; that it will greatly enrich us with authentic records of works, that would otherwise pass away without a single detaining effort from the hand of the artist, owing to their being of too transient of nature to admit to the accuracy and detail necessary to give value in future ages, is attested by the various and excellent representations which we now possess of the Exhibition Building itself, in all its stages, by the faithful and wellexecuted photographic pictures of M.M. Martens, Claudet, \&c. Great is the usefulness as applied to transitory scenes of the above kind, and incalculable will be the advantage posterity is sure to reap from the ever-increasing collection of such truly graphic representations, and great service, too, will the plain and truthful records of photography afford to the historian of future ages. As applied to the illustrations of works of the present day, it may be of two-fold service. By its application may be superseded the works of individuals, in whose hands illustration is rendered a mere trade, and the directing of whose exertions into another channel would be a means of removing many obstructions which hinder the advance of art. At the same time, the many books we possess for the education of the young, which are crowded with illustrations unfortunately but too well calculated to produce most erroneous impressions, would at once give way before the truthful representations of photography, which, by diffusing a more correct taste, would render essential aid to Art herself.

\section{p. 522}

Let us now view Photography in its application to science. A process by which

transient actions are rendered permanent, and which enables nature to do her own work, or in other words, which causes facts permanently to record themselves, is too well fitted for the purposes of science to be long overlooked; but the difficulties to be overcome in its application, have been, and still are great, and the results proportionately few in number: we consider, however, that the commencement of a systematic application of the photographic process to the purposes of astronomy is indicated by the daguerreotype of the moon by Mr. Whipple; and great indeed will be the benefit conferred upon astronomical science, when we obtain permanent representations of the celestial bodies and their relative positions, transmitted through the agency of light. * Another illustration is afforded by the self-registering apparatus of Mr. Brooke, in which nature is made to perform the operations of a corps of observers, by an application of what must be considered a few only of the first principles of photography. That its application is causing instruments which are continuous and delicate in their action, to register their own work, must be attended with advantages-is evident to every reflecting mind; and points to some of the further advantages science is likely to derive from the ultimate perfection of the photographic processes.

As applied to the preservation of documentary collections, and thus indirectly to the purposes of literature, its use is too important to be passed over in silence. How often had the historian, in his search for authentic papers, and original documents, found them only to regret that, to posterity he must be the chronicler of events, the vouchers for which will have perished by the unavoidable ravages of time, or, as in too many cases, by supine neglect. To make use of the means afforded by photography to procure fac-similes of these is a duty we owe not only to posterity, but to our forefathers. 
Again-as applied to valuable documents of the present day, either testamentary or legislative, how important to secure photographic transcripts of these, which, being of indisputable authority, shall be also perfectly unavailable for any purpose other than that intended.

Let us now turn out attention to the collection before us, in which for daguerreotype portraits America stands prominently forward. France first in order of merit for calotypes, or sun-pictures. England possessing a distinct character of her own, and presenting illustrations of nearly all processes which have as yet been adopted. America stands alone for stern development of character: her works, with few exceptions, reject all accessories, present faithful transcript of the subject, and yield to none in excellence of execution. France, in her daguerreotypes, of which she has but few, offers bright sunny representations; their effect rather injured than improved by too great masses of sunlight; but in her calotypes she stands unrivalled, and all but rejecting the processes of Daguerre, has concentrated all her energies in the further development of those of Talbot and his school.

Eminent amidst the exhibitors of calotypes, is M. MARTENS, whose works we may say with certainty, have never been surpassed; their colour, arrangement, and perfect finish, call forth the highest admiration: his success is not confined to

*The success of this application of photography must be dependent, to a considerable extent, on the object-glass of the telescope. The Report on Telescopes will show further improvements in this department of optics are commensurate with the requirements of photographic reproductions of this class.

\section{p. 523}

one class of delineation in particular, the individual works comprising his collection, being nearly all equal of merit.

On turning to the photography exhibited by the United Kingdom, we find CLAUDET leading the way, and adding to the many improvements introduced by him into the various processes of the art by presenting the image direct instead of inverted: this is the distinguishing feature of his collection, and is the result of patient and untiring research in that class of investigation peculiar to himself.

\section{(for Jry Rpt, pp. 523-524, see Ross \& Thomson, the process for producing negative} Talbotypes, on glass)

\section{p. 524}

...This admirable system is, we believe, entirely due to Messrs. Ross and Thomson, whose collection of Talbotypes amply attests the superiority of their method; and indeed, as in the case of Mr. BUCKLE, of M. MARTEN, or of any highly-successful photographist, it is but fair to infer that the superiority observable in their productions is due to their improvement of the processes which they hove adopted.

Whether the followers of Talbot will ever obtain a pre-eminence over those of Daguerre, or vice-versâ, is a question for time to solve; at present the two systems appear in the British Department of the Exhibition to be equally well represented; the followers of each, with few exceptions, laying claim to some improvement or peculiarity 
of manipulation. For example, in addition to the cases already mentioned may be included those of MAYALL, who calls attention to his crayon daguerreotype, an invention of his own, and BEARD, whose patent enamelled process is one of the very few instances of a patent having been obtained for any improvement connected with this art. Great as is the satisfaction with which we regard the efforts made for perfecting the processes of Daguerre and Talbot, still greater is that with which we observe experimenters divulging the processes they have adopted: the hitherto all but total avoidance of patent enrolment must be considered a distinctive feature of this art, to which fact, doubtless, added to the ready divulging of improvements, is chiefly due the rapidity by which up to the present time its progress has been characterized. The p. 525

publication of each new process opens a fresh field of philosophical inquiry, gives to man increased physical knowledge, and may work great changes in his moral destinies.

We cannot pass from the subject of photography without alluding to a loss recently experienced in the death of its founder, M. Daguerre, whilst the Jury were engaged in their duties, and we feel it due from us not to let this memory pass unnoticed. In him was lost one of the lights of the age.

\section{p. 594}

\section{Photographic Cameras}

The camera is the principal instrument of the photographist, as by its means light is made to become a chemical agent.

This instrument, the invention of Baptista Porta, towards the end of the sixteenth century, was simply a dark chamber furnished with a single double-convex lens, fitted in a tube, and serving for the focal adjustment of the image. So constructed it was first applied to the copying of different objects, the outlines of which, as given by the camera, were traced upon paper by a pencil; but the images were reversed. After a time this inconvenience was rectified by a mirror: with an instrument of this kind, A. Canaletti, at the beginning of the eighteenth century, made the drawings for his fine pictures of Venice, which he consequently executed with a perfection of perspective so great as to be regarded as an illusion.

By degrees a lens concave towards the object and convex towards the image was adopted; the picture was thus rendered clearer, but the colours of the spectrum were not corrected. At length an achromatic lens was used, the flint glass being towards the object. M. Daguerre went a step further, and determined those relative proportions of the camera, which, for the most part, are still adopted; the interior being carefully darkened, for the purpose of avoiding casual reflection upon the field of view.

Mr. Ross, in addition, prepares those for portraiture with the greatest intensity yet produced, by procuring the coincidence of the chemical actinic and visual foci. The spherical aberration is also corrected very carefully, both in the central and oblique pencils. 
One of the exhibitors of photographs, M. EVERARD BLANQUART, proposed the use of a white chamber, for accelerating the process; but there are serious objections to its adoptions, and therefore it is not used.

The object-glasses exhibited are, for the most part, achromatic and double, and consist of two lenses placed at a distance from each other. A photographic object-glass without defect is yet a desideratum.

\section{See also Ross, A., Henneman \& Malone, Knight \& Son, Horne, Thornthwaite \& Wood, Claudet, Willetts, Varley \& Sons, Abraham, Abraham, \& Co., Plagniol, Schiertz, Harrison, Albert.}

p. 597

\section{Photographic Glass -See Chance \& Co, Buron \\ Photography}

Rapid as have been the discoveries connected with Photography, and great as are the improvements, since it has received since the invention of M. Daguerre, there is yet much to be done to enable it to rank amongst the sciences of the age. It holds a place at present intermediate between art and a science, a position eminently favorable to development in either direction. Its pursuit, as an elegant and most extensively useful art, affords a strong motive for inquiry and experiment in the improvement of its processes, in the course of which an infinity of facts, new and unexpected, come forward, every one of which may turn out to be the embodiment of some pregnant scientific principle; nay, even the smallest minutiae of manipulation on which it is found that success or failure in the production of artistic effect depends, may, if duly observed and reasoned on, afford indications, linking together the known and unknown in optical science, and tending to bring these mysterious operations of light within the pale of exact reasoning. On the

\section{p. 598}

other hand, science is too much in the habit of repaying to art, with interest, every assistance of that nature, to leave room for doubt of similar results in this instance, when once the principles of operative chemistry shall have assumed a definite form and subjective connection. It is this which affords us full assurance that photography is yet in its infancy, and that all which has been hitherto accomplished-marvelous and exquisite though it is-is as nothing to what will be performed when the veil shall be removed, which, for the present, obscures its true scientific principles. In this point of view the photographic study of the prismatic spectrum per se, apart from all artistic combinations and coloured media, cannot be too strongly recommended to experimenters, and we lament to observe only one instance, in the whole Exhibition only one instance (that of M. Claudet) in which this study appears to have been in any way followed up, so as to afford exhibitable results. Mr. Ross is understood, also, to construct the object-glasses of his photographic cameras, with special reference to the excessive development of the actinic spectrum beyond the luminous one, in the direction of the violet rays. When bromine is used in the preparation of the plate or tablet, it may be questioned how far 
this is really an improvement. Should means be discovered of truly representing the colours of objects, and limiting the action to the luminous ray, the conditions of achromaticity for the photographic camera will be the same as for the telescope.

The fine collection of Photographs now exhibited will tend much to the advancement of this beautiful art, by showing us what has been done, and also by indicating that which it is necessary yet to do; and it will doubtless mark an era from which to date many improvements.

Since the epoch when M. Daguerre and Mr. Talbot first divulged their respective processes for impressing photographic images on silver and on paper, scientific men both at home and abroad have by their increasing researches and improvements, brought Photography to a degree of perfection which, however short of what it may one day acquire, yet seems incredible, considering its brief existence. Perhaps its advance cannot be more strongly proved than by the fact that the method, first adopted but a few years since, for procuring daguerreotype portraits, required that a person should sit without moving for twenty-five minutes in a glaring sunshine. The improvement developed in the almost instantaneous process of the present day is most striking.

It is not the object of this report to trace the history of inventions, nor to decide on claims of priority, especially in relation to a subject which has received accessions from such innumerable quarters, and called into action the skill of so many eminent chemists and photologists of every nation. Suffice it to say, that, after the introduction of M. Claudet's accelerating process by the by the application of chloride of iodine and chloride of bromine (an invention which he liberally gave to the public through the medium of the Royal Society and the Académie des Sciences), the daguerreotype process, as publically practised, became reduced to some system, and two Daguerreotype establishments were formed in London. The portraits taken at this time were, however, deficient in expression; but in spite of all deficiencies, the receipts of these establishments several times amounted to 60l. in one day.

At a somewhat later period that remarkable variety of the Talbotype process, designated by its inventor by the name of "Calotype" was also publically employed for the production of portraits by Mr. Collen: the artistic effect in these representations p. 599 was susceptible of being much heightened by the brush and the defects of expression might be removed, and the likeness in consequence greatly improved by one or more subsequent sittings.

M. Claudet, who, from the earliest time of the daguerrian invention, displayed great genius and ability in perfecting the various processes, first perceived the necessity of aiding the artistic effect of his representations by subsidiary adjuncts of a different kind. He it was who first practiced the placing of painted back-grounds behind the persons whose portraits were to be taken. Thus an infinite variety of scene might be afforded by the operator simply providing himself with a few subjects skilfully adapted to the requirements of the occasion. To him also we owe that extremely pleasing adaptation of mechanical adjustments for bringing many miniature representations of the same individual under different aspects, to be impressed in regular compartments of the same plate and framed together, of which we find specimens exhibited in his collection. 
It is not necessary to detail step by step the successive improvements in the different processes and apparatus for daguerreotypic photography, though we may mention that to the exertions of Messrs. Claudet, Gaudin, Fizeau, and Draper, the public are indebted for many improvements. To M. Fizeau is due the reproduction of the proofs of electrotype; also a new process for engraving the Daguerrian image, and of preserving that image from destruction by gilding the surface.

The Exhibition presents many fine calotypes, or as they are sometimes called in the Catalogue, sun-pictures, for the production of which the preparations of Mr. Talbot hold the first rank. M. BAYARD, also, has been celebrated for his achievements in this line, and has contributed many splendid proofs obtained on various sensitive papers. Mr. Talbot has, himself, exhibited nothing; but many of his productions will be recognized among those exhibited by HENNEMAN and MALONE, as adapted to the practical wants of travelers, collectors, \&c. This branch of the art offers inestimable advantages, viz.: $1^{\text {st }}$, That the papers may be prepared at leisure, some time before an occasion for using them arrives; 2ndly, That when pressed and fixed, they may be carried without injury in a portfolio, like other drawings; 3rdly, That from one good negative original, any number of positive copies may be taken, to the extent, indeed, of two or three hundred copies in a rainy day, as proved by the practice of M. EVERARD BLANQUART (France, No. 1551), and supplied to the public at a cheap rate; 4thly, That they may be wholly obliterated so as to reduce them apparently to the original condition of white paper, and carried about in that state for an indefinite period, though susceptible to revival at any instant. Considering it probable that the following communication, addressed by $\mathrm{M}$. Arago to the Academy of Sciences, on the granting a national recompense to $M$. Daguerre, may be useful to a portion of the public now as then, we subjoin it in the words of M. Arago himself:-

"A short time after the law was voted, granting a national recompense to $\mathrm{M}$. Daguerre, some opinions, which in my idea were very erroneous, were entertained by a small portion of the public, which rendered it necessary for me to show that the discovery, newly made, was not to be estimated in respect to art only, but to the very valuable subjects for investigation which it presented in reference to the physical sciences."

p. 600 exhibited.

Without further remark, we proceed to the discussion of the Photographs Daguerreotype Pictures.

\section{p. 600 - See Claudet, Kilburn}

p. 601 - See Kilburn, Mayall, Beard, Laroche, Voigtlander \& Evans, Griffiths \& Lebeau, Paine, Tyree, Craddock 


\section{p. 601 , cont.}

On examining the daguerreotypes contributed by the United States, every observer must be struck with their beauty of execution, the broad and well-toned masses of light and shade, and the total absence of all glare, which render them so superior to many works of this class. Were we to particularize the individual excellences of the pictures exhibited, we should far exceed the limits of space to which we are necessarily confined. Where all is good, it follows that remarks must be restricted to peculiar excellence alone.

Before speaking of the several works exhibited, it is but fair to our own photographists to observe, that as much as America has produced, and excellent as are her works, every effort has been seconded by all that climate and the purest atmospheres could effect; and when we consider how important an element of the process is a clear atmosphere, we must be careful not to overrate that superiority of execution which America certainly possesses.

\section{p. 601 - See Lawrence}

p. 602, See - Brady, Whipple, Mayall, Evans, Meade Brothers

\section{p. 603, See - Pratt, Richmond \& Co., Whitehurst, Virginia}

Among the remaining exhibitors of daguerreotypes in the United States Department are-

See Gavit, Root, Whitehurst, Langenheim, Fontyne \& Porter, Harrison.

In turning our attention to France, we find several daguerreotypes, which, in contradistinction to those of America, are characterized by large masses of light, in which is expressed the greater amount of detail and minutiae. They are not so entirely free from glare as those of America.

See Thierry; Maucomble; Sabatier; Plaignol

p. 604, See - Gouin, Kohnke, Von Minutoli, Vogel

Talbotypes-Calotypes-Sun Pictures.

p. 604 , See - Buckle, Ross \& Thomson

p. 605 , See - Hill, Henneman \& Malone, Colls, Harmer, Owen

p. 606, See - Collie, Rippingham, Bingham, Field \& Son, Martens, Bayard, Flacheron-Hayard, Le Gray

p. 607, See - Le Secq, Blanquart-Evrard, Cousin, Albert, Chevalier, Mayer, Pretsch 
In closing our remarks on this department of the Exhibition, we may be permitted to record some degree of disappointment at the absence of specimens of the application of photography to any departments of representation, other than such as please the eye or administer to personal feelings. As regards its application to an infinity of useful and instructive purposes, we have literally nothing! We find, for instance, no specimens of copies of ancient inscriptions (a few incidentally occurring on the Roman ruins perfectly familiar to every one, only excepted) —no delineations of tropical or remote scenery-no specimens (for the single exception of Claudet's spectrum is hardly to be cited) of the actinic spectrum on chemical preparations, or on natural vegetables or animal colours-no impressions of the lines in the photographic corresponding to those in the luminous spectrumno magnified representations of the microscopic products of nature, or of the dissected parts of plants or animals-no copies of pages of ancient manuscripts-no miniatures of printed books (holding out the promise of future publications in miniature), or that of condensing in volume for preservation in Museums, ${ }^{*}$

*We are informed that a catalogue of the National Library of Paris, in which the photo-graphic fac-simile of the title-page of each work, in miniature, is registered, is actually in progress.

\section{p. 608}

\&c., the enormous mass of documentary matter which daily more and more defies collection from the mere impossibility of stowage, but which will one day become a matter of history - and a thousand other applications that it would be tedious here to mention.

Connected to photography, we may also notice the absence of any specimens of scotography, or the art of copying engravings by simple juxtaposition in the dark by obscure inter-radiation, invented by Moser.

p. 608 - James Glaisher, Reporter. Lewisham, Nov. 1851 


\section{CONCLUSION}

1851 stands out as a turning point for British photography. Photographic societies, exhibitions, and publications, which were nearly non-existent prior to the Great Exhibition, flourished in the years that followed. ${ }^{128}$ Patent laws were reformed, and the number of both amateur and professional photographers increased dramatically. ${ }^{129}$ The information gathered in the Official Catalogue and Jury Reports adds greatly to the knowledge of how photography was viewed at this time and the potential it had in shaping art and society in Britain, as well as in the rest of the world.

While this thesis has gathered photographic information pertaining to the Great Exhibition into a convenient summary, there is still much that should be done to add context to this data. Many of the photographers exhibiting in the Fair are not well known today; adding a short biography to each entry would be helpful in fully realizing what was exhibited and how it fit into the history of each artist. In addition, there are a few additional first hand accounts of photography in the Exhibition that could further flesh out what was on view. These include J.J. Arnoux's The World's Fair, ${ }^{130}$ and Tallis's History and Description of the Crystal Palace and the Exhibition of the World's Industry in $1851 .^{131}$ It would also be an interesting project to attempt to match known photographs with the descriptions given to ascertain possible matches.

\footnotetext{
128 Haworth-Booth, Photography, 25.

129 Pritchard, Michael, in Hannavy, Encyclopedia, 1054, 1055.

130 Arnoux, J.J. "The World's Fair" in The Photographic Art Journal, vol. 2, p. 153, reprinted from La Lumiere, translated by J. Russell Snelling, MD. (New York: W.B. Smith, 1851).

131 Tallis, John and Jacob George Strutt, Tallis's History and Description of the Crystal Palace and the Exhibition of the World's Industry in 1851 (London, New York: J. Tallis
} 
The jury called the art of photography, "the most remarkable discovery in modern times" and remarked that, "never before was so rich a collection of photographic pictures brought together..."132 That the Royal Commission created these volumes to document the Exhibition and the infancy of photography is remarkable. That we are still discovering information about this event more than 150 years later reveals the complexity and depth of photographic study still untapped.

and Co., 1852).

${ }^{132}$ Reports, 520. 


\section{BIBLIOGRAPHY}

Archer, Frederick Scott. "The Use of Collodion in Photography, 1851" in Photography: Essays \& Images, Beaumont Newhall, ed. New York: The Museum of Modern Art, 1980.

Auerbach, Jeffrey A. The Great Exhibition of 1851: A Nation on Display, New Haven and London: Yale University Press, 1999.

Beaver, Patrick. The Crystal Palace: 1851 1936, A Portrait of Victorian Enterprise. London: Hugh Evelyn Limited, 1970.

Borcoman, James. The Painter as Photographer, from the exhibition catalogue: Works from the National Gallery of Canada at the Vancouver Art Gallery, December 9, 1978 January 14, 1979.

Borcoman, James. $19^{\text {th }}$ Century French Photographs. Ottawa: National Gallery of Ottawa, 2010.

Brettell, Richard R. Paper and Light: the Calotype in France and Great Britain, 18391870, Boston: David R. Godine, 1984.

Buerger, Janet E. French Daguerreotypes. Chicago and London: University of Chicago Press, 1989.

Cantor, Geoffrey. Religion and the Great Exhibition of 1851. Oxford; New York: Oxford University Press, 2011.

Coe, Brian, and Mark Haworth-Booth. A Guide to Early Photographic Processes. London: The Victoria and Albert Museum, 1983.

Daniel, Malcolm R. Inventing a New Art. New York: The Metropolitan Museum of Art Bulletin, spring, 1999.

Davis, John R. The Great Exhibition. Thrupp, Strand, Gloucestershire: Sutton Publishing, 1999.

Findling, John E. and Kimberly D. Pelle, eds. Encyclopedia of World's Fairs and Expositions. Jefferson, NC: McFarland \& Co., 2008.

Findling, John E., ed. Historical Dictionary of World's Fairs and Expositions, 1851-1985. New York: Greenwood Press, 1990.

Foster, Sheila, Manfred Heiting, and Rachel Stuhlman, eds. Imagining Paradise: The Richard and Ronay Menschel Library at the George Eastman House, Rochester. 
Göttingen: Steidl; London: Thomas \& Hudson, 2007.

Glaisher, Esq. F.R.S., James. Lectures on the Results of the Exhibition, delivered before the Society of Arts, Manufactures, and Commerce, at the suggestion of H.R.H. Prince Albert, Pres. of Society. London: David Bogue, 1852.

Greenhalgh, Paul. Ephemeral Vistas: The Expositions Universelles, Great Exhibitions and World's Fairs, 1851-1939, Manchester, UK: Manchester University Press, 1988.

Greenhalgh, Peter. Fair World: A History of World's Fairs and Expositions from London to Shanghai, 1851-2010. Berkshire, UK: Papadakis, 2011.

Greenough, Sarah, \& etc. On the Art of Fixing a Shadow. Washington, D.C.: National Gallery of Art, 1989.

Hannavy, J. Encyclopedia of Nineteenth-Century Photography, London: Routledge, 2008.

Haworth-Booth, Mark, ed. The Golden Age of British Photography, 1839-1900. New York: Aperture, 1984.

Haworth-Booth, Mark, and Anne McCauley. The Museum and The Photograph:

Collecting Photography at the Victoria \& Albert Museum, 1853-1900. Williamstown, MA: Sterling and Francine Clark Institute, 1998.

Hobhouse, Hermione. The Crystal Palace and the Great Exhibition: Art, Science, and Productive Industry: A History of the Royal Commission for the Exhibition of 1851. London, New York: Athlone Press, 2002.

Hunt, Robert. Hunt's Handbook to the Official Catalogues: An Explanatory Guide to the Natural Productions and Manufacturers of the Great Exposition of the Industry of All Nations, 1851. Spicer Brothers and W. Clowes \& Sons, 1851.

Hunt, Robert. A Manual of Photography. New York: Arno Press, 1973, $3^{\text {rd }}$ edition.

Hunt, Robert. A Popular Treatise on the Art of Photography, 1841. Athens: Ohio University Press, 1973, facsimile edition.

Jackson, Anna. Expo: International Expositions 1851-2010. London: V \& A Publishing, 2008.

Jammes, Andrè, and Eugenia Parry Janis. The Art of French Calotype, Princeton, N. J.: Princeton University Press, 1983.

Jay, Bill and Dana Allen. Critics: 1840-1880, History of photography monograph series, Special Edition. Phoenix: Arizona Board of Regents, 1985. 
Kraus, Jr., Hans P. Sun Pictures: Early British Photographs on Paper: catalogue one. New York, NY: Hans P. Kraus, Jr., c. 1987.

Linkman, Audrey. The Victorians: Photographic Portraits. London: Taurus Parke Books, 1993.

Miles, George S. World's Fairs from London 1851 to Chicago 1893. Chicago: Midway Publishing, 1892.

Newhall, Beaumont. The Daguerreotype in America. New York: Duell, Sloan, and Pierce, 1961.

Offenbeck, Jill. The Reports by the Juries: a Finding Aid for a Publication from the Great Exhibition of 1851 in the Collection of The Art Gallery of Ontario. M.A. Thesis, Ryerson University, Toronto, Ontario, 2011.

Pritchard, Michael. A Directory of London Photographers: 1841-1908. Bushey, England: ALLM Books, 1986.

Rosenblum, Naomi. A World History of Photography. New York: Abbeville Press, 1989.

Royal Commissioners. Official Descriptive and Illustrated Catalogue of the Great Exhibition of the Works of Industry of All Nations. London: Spicer Brothers and W. Clowes and Sons, 1851.

Royal Commissioners. Reports by the Commissioners for the Great Exhibition. London: Spicer Brothers and W. Clowes and Sons, 1851.

Royal Commissioners. Reports by the Juries on the Subjects in the Thirty Classes into which the Exhibition was Divided. London: Spicer Brothers and W. Clowes and Sons, 1852.

Royal Society of Arts. Lectures on the Results of the Great Exhibition of 1851 delivered before The Society of Arts, Manufactures, and Commerce, at the suggestion of H.R.H. Prince Albert, President of the Society. London: D. Bogue, 1852.

Rydell, Robert W. The Book of the Fairs: Materials about the World's Fairs, 1834-1916, in the Smithsonian Institute Libraries. Chicago: American Library Association, 1992.

Schaaf, Larry J. Out of the Shadows: Herschel, Talbot, and the Invention of Photography. New Haven: Yale University Press, 1992.

Taylor, Roger and Larry J. Schaaf. Impressed by Light: British Photographs from Paper Negatives, 1840-1860. New York: Metropolitan Museum of Art, 2007. 
Taylor, Roger. Photographs Exhibited in Britain: 1839-1865. Ottawa, Canada: National Gallery of Canada, 2002.

Tallis, John and Jacob George Strutt, Tallis's History and Description of the Crystal Palace and the Exhibition of the World's Industry in 1851. London, New York: J. Tallis and Co., 1852.

Waggoner, Diane. The Pre-Raphaelite Lens: British Photography and Painting. Washington D.C.: National Gallery of Art, 2010.

Weaver, Mike, ed. The Art of Photography, 1839-1989. New Haven \& London: Yale University Press, 1989.

Weaver, Mike, ed. British Photography in the Nineteenth Century: The Fine Art Tradition. Cambridge, UK: Cambridge University Press, 1989.

Weaver, Mike. The Photographic Art: Pictorial Traditions in Britain and America. New York: Harper \& Row, 1986.

Wood, John. America and the Daguerreotype. lowa City: University of lowa Press, 1991.

Young, Paul. Globalization and the Great Exhibition: The Victorian New World Order. New York: Palgrave Macmillan, 2009. 